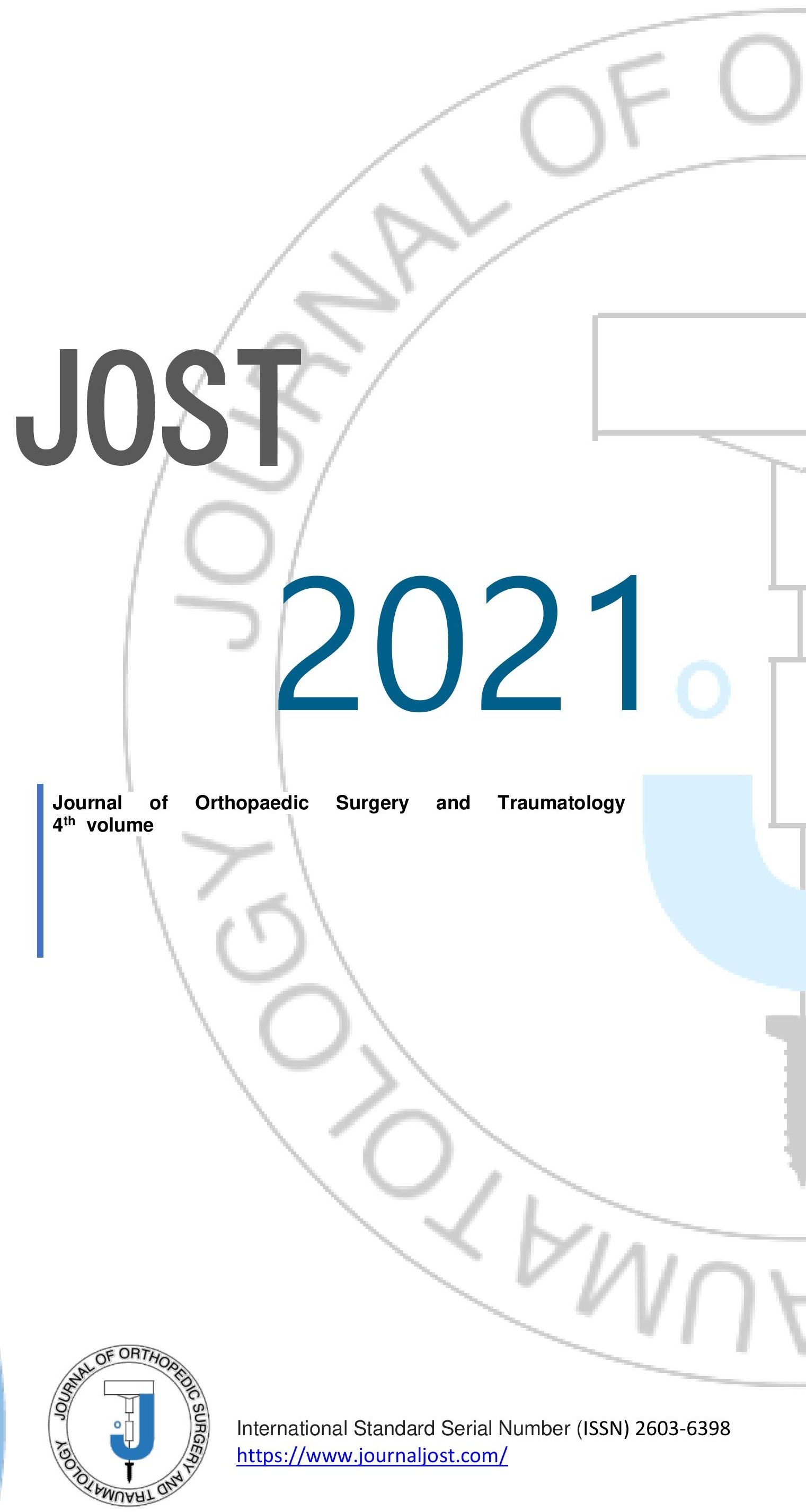




\section{Índice}

1-. Scheuermann Kyphosis for dummies (Alonso-Caravaca A.)...................................Page 1

2-. Fascitis necrotizante (Aguilar-González J.)............................................................Page 17

3-. Fracturas de cuello y diáfisis femoral ipsilateral (Ortega Yago A.)........................Page 25

4-. Cirugía de acortamiento por dismetría (Garrido-Rojo R.)......................................Page 35

5-. Parálisis del nervio espinal en paciente COVID-19 (Martín-Escartín C)............... Page 45

6-. Sección traumática de la rama profunda del nervio cubital (Poveda-Mira J.)......Page 51 


\title{
Scheuermann Kyphosis for dummies
}

\author{
Adrián Alonso Caravaca ${ }^{1, *}$ and Amparo Ortega Yago ${ }^{2}$ \\ 1 Degree in Medicine. University of Murcia. Orthopaedic Surgeon Registrar at Hospital Universitario y \\ Politécnico La Fe, Valencia, Spain. https://orcid.org/0000-0001-8398-2860 \\ 2 Degree in Medicine. Catholic University of Valencia. Orthopaedic Surgeon Registrar at Hospital Universi- \\ tario y Politécnico La Fe, Valencia, Spain. \\ * Correspondence: adrian-alonso-caravaca@gmail.com
}

Academic Editor: Firstname Last-

name

Received: date

Accepted: date

Published: date

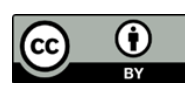

Copyright: (c) 2021 by the authors. Submitted for possible open access publication under the terms and conditions of the Creative Commons Attribution (CC BY) license (http://creativecommons.org/licenses /by/4.0/).

\begin{abstract}
Scheuermann kyphosis debuts in young adolescents and it is defined as a fixed hyperkyphosis $>40^{\circ} \mathrm{Cobb}$, with associated anterior wedging of vertebral endplates of $>5^{\circ}$ in three or more adjacent vertebrae. It is thought to be caused by mechanical stress on structurally deficitary vertebral endplates. For its diagnosis, clinical history and plain radiographs are used, but also MRI when there is neurological affection. Treatment depends on the severity of the curve: those $\angle 60^{\circ}$ can be treated orthopedically with Milwaukee bracing in combination with rehabilitation treatment (stretching or muscle strengthening) and postural hygiene. If $>70^{\circ}$, surgical treatment is indicated using a posterior-only approach, as it reduces de apparition of complications when compared with anterior and combined approach. Vertebral osteotomies will be made depending on the DAR. We will use pedicular screws and bars, and transverse hooks to end instrumentation, as we attach distally the SSV and proximally the first kyphotic vertebra, to avoid revision surgery. Among the complications (14\%) we find surgical site infection (up to 10\%), neurological injury (8\%), or pulmonary complications derived from anterior approach (20\%). Habrá que hacer, por tanto, un balance global del paciente y de su equilibrio sagital para garantizar un resultado óptimo.
\end{abstract}

Keywords: kyphosis; Scheuermann's disease; surgery

Resumen: La Cifosis de Scheuermann aparece en jóvenes adolescentes y se define como una hipercifosis rígida estructural $>40^{\circ} \mathrm{Cobb}$, con la presencia de acuñamiento anterior de los platillos vertebrales $>5^{\circ}$, en tres o más vértebras contiguas. Se piensa que está producida por estrés mecánico sobre una vértebra cuyo platillo está estructuralmente debilitado. Para el diagnóstico, además de la clínica, utilizamos radiografías simples y RMN cuando asocien clínica neurológica. Su tratamiento depende del grado de cifosis, siento aquellas $<60^{\circ}$ tratadas sólo si son sintomáticas o progresan, mediante ortesis de tipo Milwaukee en combinación con estiramientos/fortalecimiento muscular e higiene postural. Si es $>70^{\circ}$, estaría indicado tratamiento quirúrgico optándose por un abordaje únicamente posterior ya que reduce la aparición de complicaciones comparado con el abordaje anterior o combinado. Realizaremos osteotomías vertebrales en función de su DAR. Para la fijación de la columna, utilizaremos tornillos pediculares y barras, así como uñas en los extremos de la instrumentación. Fijaremos distalmente en función del SSV y proximalmente incluiremos la vértebra más craneal incluida en la cifosis lo que evitará cirugías de revisión. Entre las complicaciones (14\%), encontramos la infección de la herida quirúrgica (hasta 10\%), lesiones neurológicas (8\%), o complicaciones pulmonares en el abordaje anterior (20\%). An holistic approach must be made, focussing on sagittal balance, in order to obtain the best results for the patient.

Palabras clave: cifosis; Enfermedad de Scheuermann; cirugía 


\section{Introducción}

La Cifosis de Scheuermann es una patología que aparece predominantemente en pacientes jóvenes (12-17 años), pero casi nunca antes de los 10 años, con una prevalencia que vería del 1-8\% según series, sin discrimnacion por sexos, y que afecta principalmente a la columna torácica (pero no únicamente). [1] Es, además, una patología con un poder importante de comorbilidad si se deja sin tratamiento. Por todo ello, en los siguientes apartados, comenzaremos a entender esta enfermedad, y lo que deberíamos hacer si nos encontramos con un paciente en el que la sospechemos. Antes de comenzar, y con fines didácticos, hay que señalar que la enfermedad se caracteriza por lo siguiente [2]:

1. Hipercifosis torácica "rígida": se trata de una cifosis torácica con un ángulo de $\mathrm{Cobb}>40^{\circ}$ (que para la región dorsal está formado por una línea paralela al platillo vertebral superior de T4 y el inferior de T12). Será una cifosis rígida porque no corrige completamente cuando le pedimos al paciente que se ponga "recto", es decir, que esté lo más erguido posible.

2. Acuñamiento vertebral anterior $>5^{\circ}$ : este ángulo lo mediremos en la radiografía lateral (al igual que el anterior) trazando dos líneas paralelas a los platillos de la vértebra en cuestión.

3. Acuñamiento presente en al menos 3 o más vértebras contiguas.

\subsection{Historia}

A modo de curiosidad, esta enfermedad toma el nombre de la primera persona que la describió, Holger Werfel Scheuermann en 1920 [3] que pensaba que se trataba de una lesión vertebral osteocondral que causaba un acuñamiento. Sin embargo, fue más tarde, en 1964, cuando Sorensen [2] describió los hallazgos radiográficos diagnósticos del Scheuermann y que ya hemos descrito al principio de la introducción.

\subsection{Etiopatogenia y fisiopatología}

Existen muchas teorías al respecto, sin embargo, la que más aceptada está actualmente, es la del estrés traumático sobre una vértebra débil debido a la alteración de su platillo vertebral [4]. Pero antes de hablar sobre la enfermedad, ¿qué es el platillo vertebral y por qué es importante? Se trata de una zona compuesta por cartílago y hueso esponjoso que está en íntimo contacto con el disco intervertebral. Es una zona intrínsecamente débil que está expuesta a la transmisión de fuerzas axiales y rotacionales que inciden sobre la columna. (Figura 1) Es además una zona de paso de los vasos sanguíneos hacia el disco intervertebral (de naturaleza avascular), por lo que, si se interrumpe su crecimiento, o se altera su morfología, podremos decir que el disco también sufrirá las consecuencias de una degeneración más precoz. [5] (Figura 2)

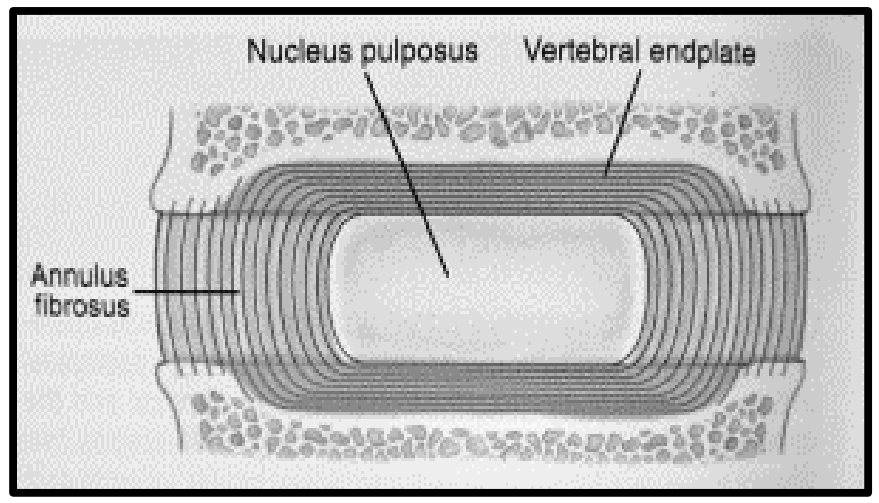

Figura 1. Esquema del platillo vertebral, como un componente osteocondral de la vértebra en intimo contacto con el disco. Imagen tomada del libro de Neumann 2009 (página 330). [6] 
Figura 2. Esquema que muestra la íntima relación nutritiva del "endplate" con el disco intervertebral. Imagen obtenida del trabajo de Ruiz Willis, C. [7]

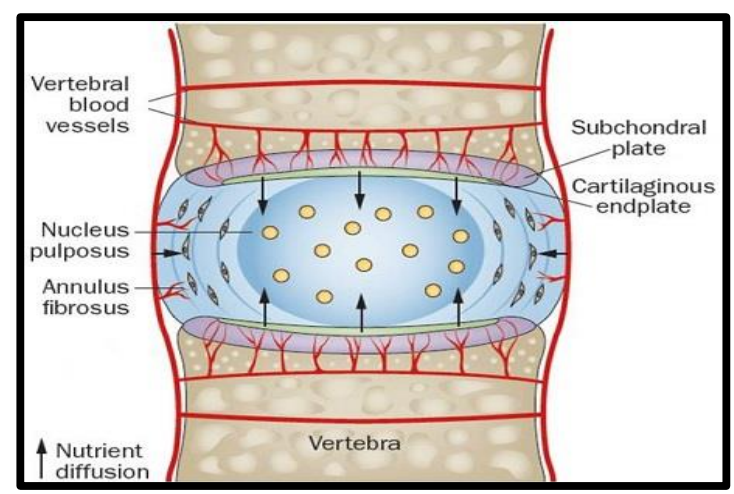

Se conoce que existe un componente genético, por la concordancia entre gemelos homocigóticos de incidencia de la enfermedad, sin embargo, solo se ha postulado, sin confirmar una teoría de herencia autosómica dominante, en la que estarían implicados los genes del colágeno $1 \mathrm{~A} 1$ y 1A2. [8] ¿Qué se ha encontrado en ese fin de platillo vertebral en la enfermedad de Scheuermann? [9]

- Mineralización irregular debido a una osificación endocondral desorganizada.

- Cartílago anormal con una ratio colágeno:proteoglicanos alterada. Está aumentada la cantidad de proteoglicanos en la biopsia de este cartílago de crecimiento.

Todo ello va a dar lugar a un crecimiento deficitario del cartílago de crecimiento vertebral durante la adolescencia y que acabará modificando la morfología vertebral hacia una acuñada ("wedge-shaped").

A modo de resumen, podría decirse que se produce una osteonecrosis del cartílago de crecimiento en la porción anterior de las vértebras de los pacientes afectados por esta enfermedad. Tenemos los factores que predisponen a tener una vértebra débil, pero ahora, ¿hay algo que pueda hacer que se altere su morfología? [10]

- Actividades deportivas extenuantes (halterofilia, gimnasia artística/rítmica, rugby...)

- Trabajadores manuales (posición de flexión de tronco).

- Obesidad y alto IMC. Esta teoría no se ha confirmado, pero sugieren que puede estar involucrado. [11]

\section{Materials and Methods}

El diagnóstico de esta patología es clínico y radiográfico, por lo que deberemos tener en cuenta ambos aspectos.

\subsection{Clínica y tipos (5,12)}

2.1.1. Forma clásica/tipo I: La descrita por Scheuermann en la que sólo existe afectación torácica y su ápex estará localizado en T7-9. Se suele diagnosticar a partir de la adolescencia, con el estirón y casi siempre por los familiares o en algún examen físico rutinario (como puede ser en las clases de educación física). Se deberá hacer un examen rutinario de estos pacientes que incluya: 
1. Exploración completa de columna, incluyendo el balance sagital/coronal para valorar escoliosis entre otros hallazgos que puedan estar presentes. (Figura 3) [13]

- Hipercifosis torácica estructural

- Hiperlordosis lumbar no estructural

- Anteversión pélvica

- Hombros caídos (abducción escapular)

- Escoliosis (15-20\%) que debe tener el mismo ápex que la cifosis [14]

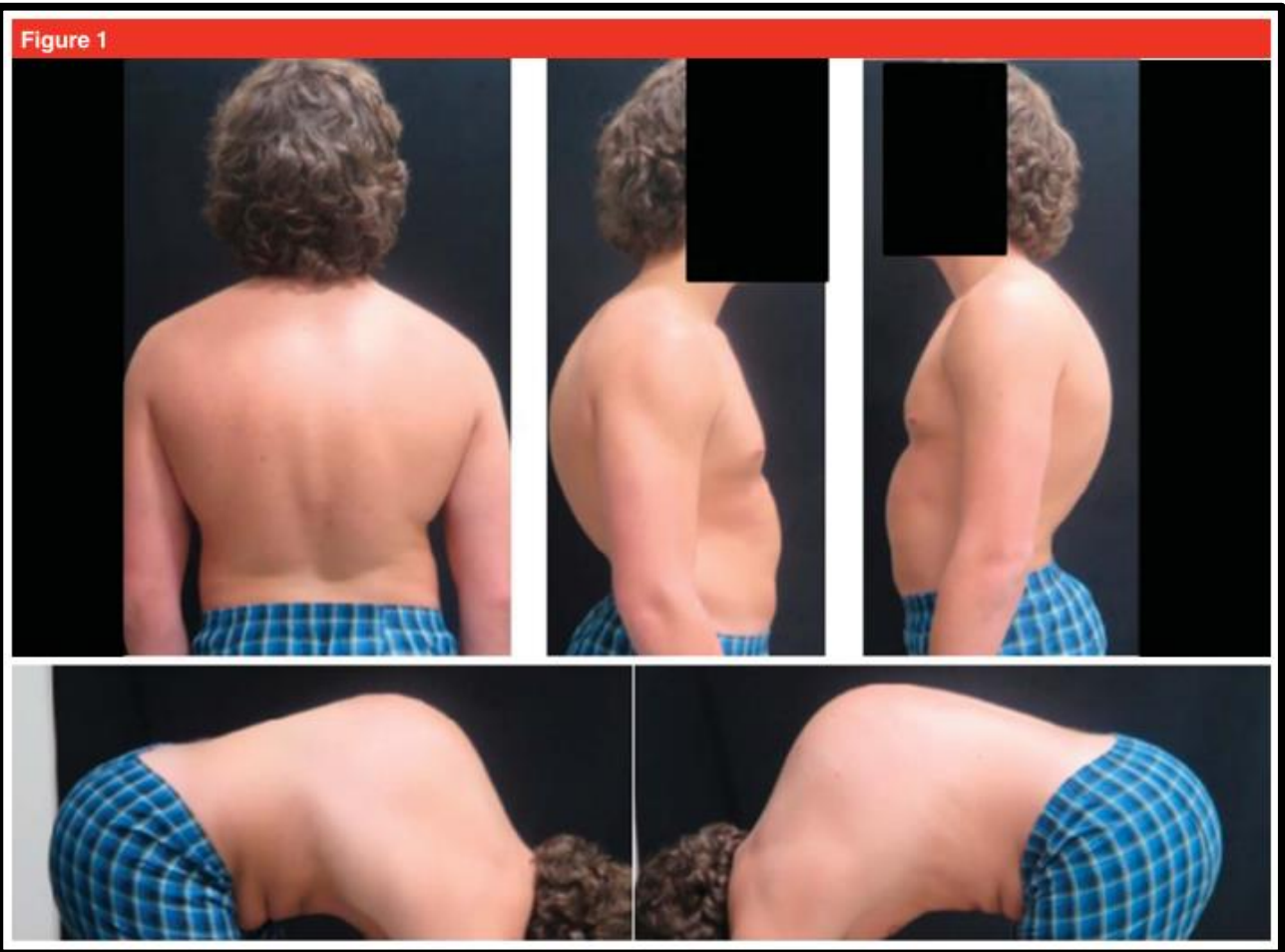

Figura 3. Inspección de columna en un paciente con Scheuermann. Obsérvese que la hipercifosis condiciona una joroba. Imagen tomada del trabajo de Sardar, ZM. 2019.

2. Rango completo de movilidad, que puede estar limitado en estos pacientes.

3. Exploración neurológica completa para detectar posibles alteraciones. Es raro que se presenten en estos pacientes a menos que se asocien a espondilolistesis, quistes durales, hernias discales o sea una cifosis muy angular (es decir, que tenga pocas vertebras causantes de la cifosis). Casi siempre aparecerá de forma postraumática.

4. Evaluar clínica pulmonar. En algunos casos, con curvas muy pronunciadas $\left(>100^{\circ}\right)$ que limitan su calidad de vida por la aparición de un patrón pulmonar restrictivo.

5. Radiografía simple. Debemos realizar radiografía de columna completas (reconstrucciones 30*90) para valorar la alineación vertebral en ambos planos (coronal/sagital). Para el diagnóstico del Scheuermann, la que más información nos da es la proyección lateral y podremos encontrar multitud de hallazgos. (Figuras 4 y 5)

Entre los hallazgos más comunes que se pueden ver en radiografía, hay que incluir otros que se valoran mejor con el uso de RMN. Incluyen platillos vertebrales irregulares, nódulos de Schmorl (16-35\%), afectación discal (50\%), espondilosis/espondilolistesis, edema óseo (que suele asociarse a dolor espalda) y/o escoliosis. (Figuras 5 y 8) 


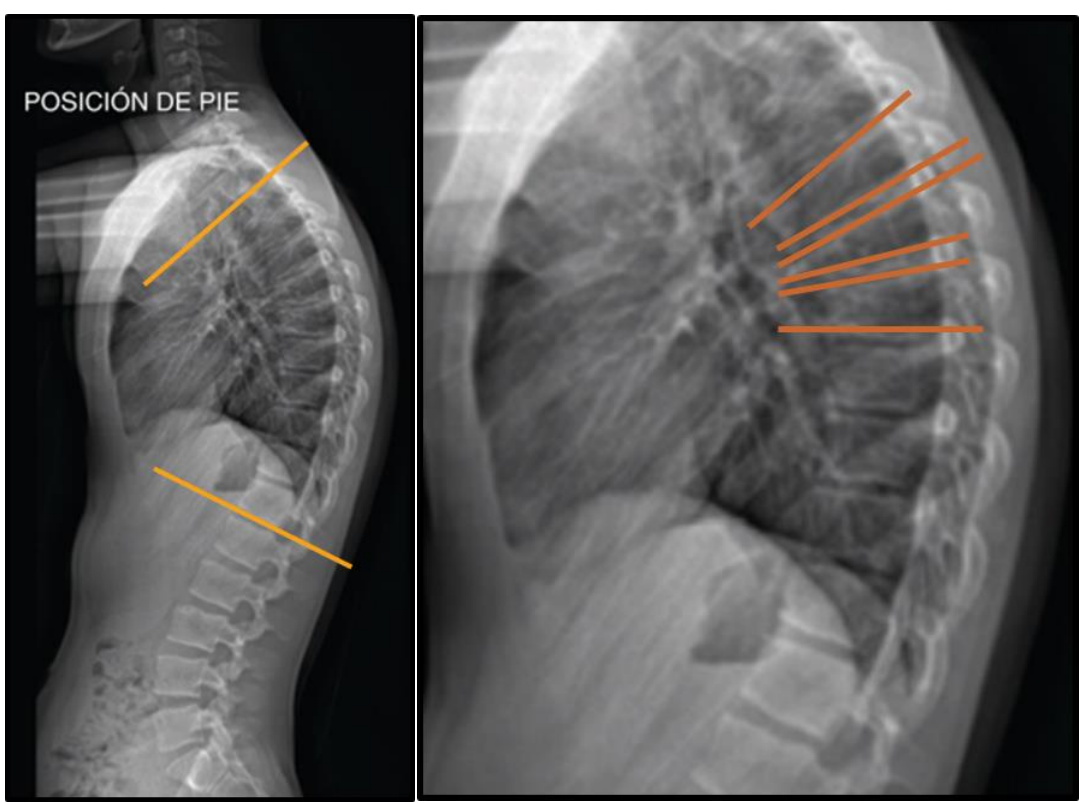

Figura 4. Radiografía 30*90 en proyección lateral donde se encuentra una hipercifosis de $55^{\circ}$ con ápex en $\mathrm{T} 5$ y el acuñamiento anterior de tres vértebras.
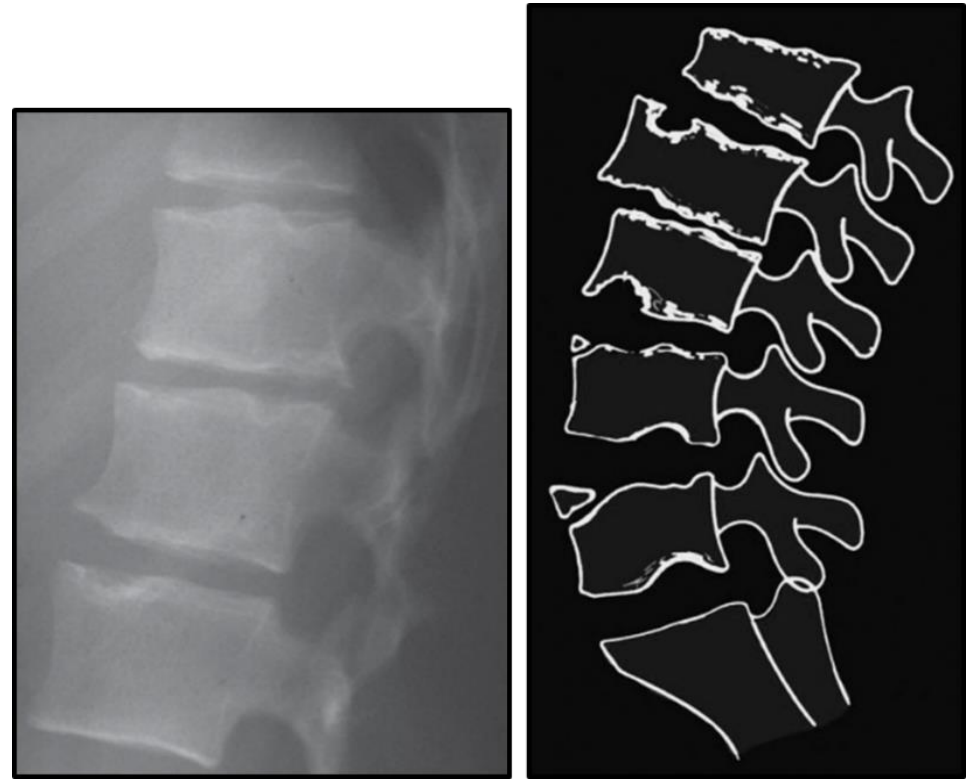

Figura 5. Ampliación de radiografía lateral con esquema de hallazgos radiográficos posibles en la Enfermedad de Scheuermann descritos en el texto. Imágenes tomadas del trabajo de Palazzo, C. 2014.

Otro aspecto muy importante que valorar, es el equilibrio sagital en la radiografía, y eso se hace mediante el cálculo de los parámetros pélvicos en vistas a la planificación preoperatoria (Figura 6). En concreto, la incidencia pélvica (PI) es el ángulo que forma una línea perpendicular al punto medio del promontorio con el punto medio de la línea que une las cabezas femorales. Este valor es importante no solo en la cifosis de Scheuermann sino para el balance sagital global y el tratamiento de muchas patologías de columna. [15]

Para mantener un buen equilibrio sagital, el balance PI - LL (lordosis lumbar) $<10^{\circ}$, se debe mantener. Sin embargo, se ha propuesto otra fórmula para los pacientes con Cifosis de Scheuermann que está validada, sin embargo, que estos pacientes tengan menor tasa de complicaciones postoperatorias está todavía por descubrir. [16] La fórmula es la siguiente: $\Delta$ (delta) $=($ cifosis torácica -45$)+($ cifosis toracolumbar -0$)+(P I-L L)= \pm 10^{\circ}$ 


\section{$\mathrm{PI}=\mathrm{PT}+\mathrm{SS}$}
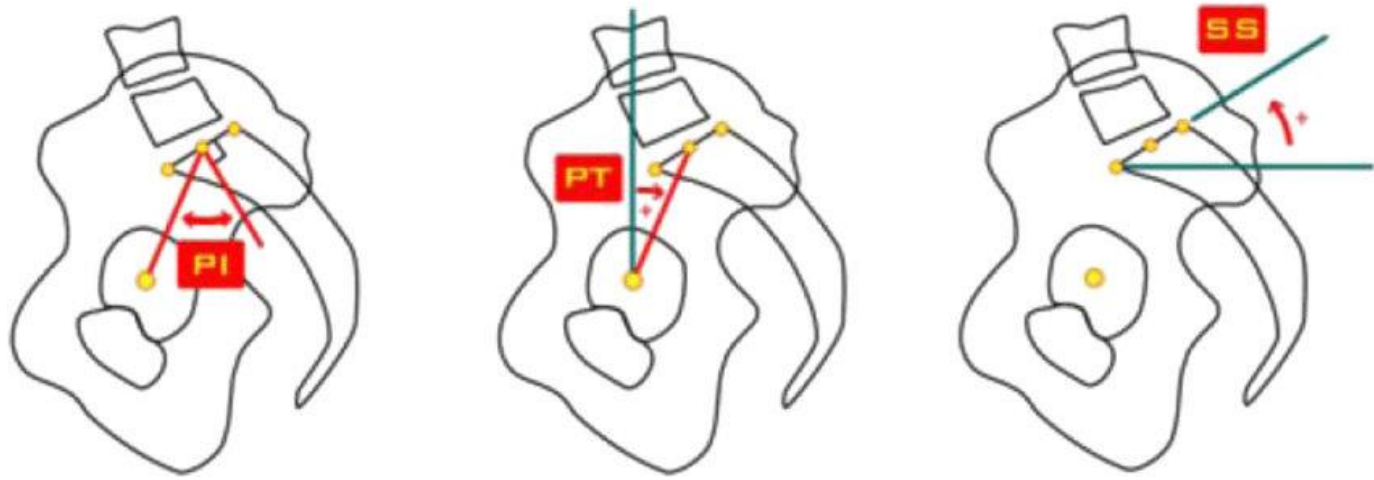

Figura 6. Medición de parámetros pélvicos. PI = pelvic incidence (incidencia pélvica), PT = pelvic tilt, SS = sacral slope. Imágenes tomadas del trabajo de Le Huec, JC. 2014.

Además, para la planificación prequirúrgica también necesitaremos tener radiografías de la mano no dominante (para valorar el estado del crecimiento) y de columna lateral en corrección con fulcro en la región del ápex de la curva, para valorar la flexibilidad de esta (corrección >50\%). (Figura 7)
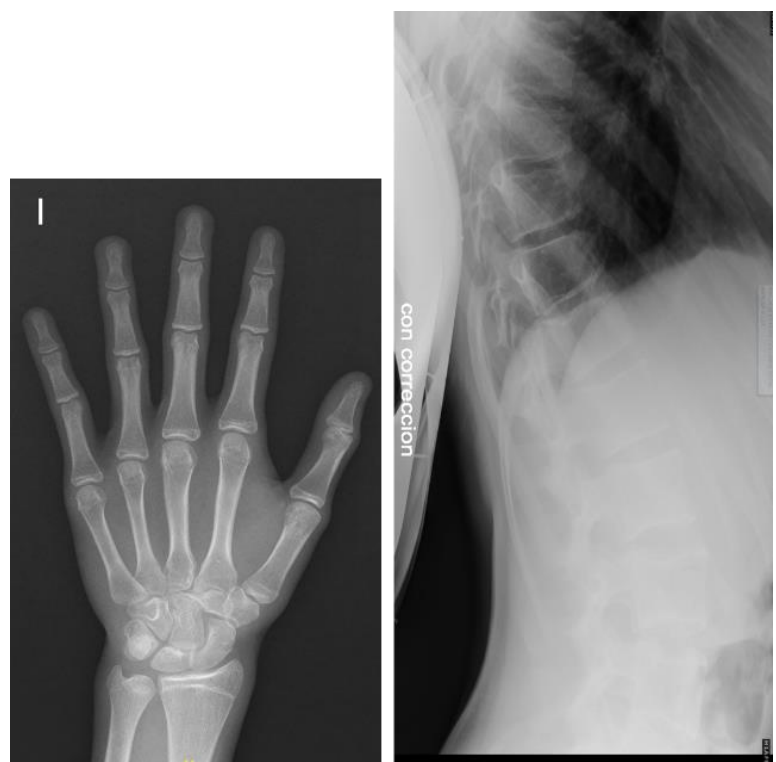

Figura 7. Pruebas necesarias para planificación preoperatoria (Rx mano no dominante y corrección curva).

2.1.2. Forma toracolumbar/tipo II: En este caso, existe afectación de la columna lumbar, con la consecuente pérdida de lordosis fisiológica. Generalmente estas formas cursan con mayor dolor, que casi siempre se localiza a nivel del ápex. En otros casos, se acompaña de dolor lumbar de tipo mecánico y por la tensión muscular. [17]

Lo hallazgos radiográficos en el tipo II son similares a los encontrados anteriormente. Además, conviene hablar de los nódulos de Schmorl [18] pueden ser centrales o intraósesos/intraesponjosos, pero también retromarginales anteriores o posterior y esto es debido a que durante el crecimiento y el proceso de osificación de las vértebras, las apófisis en anillo (un núcleo de osificación secundario que forma el platillo vertebral), está formada por cartílago todavía, y se puede fracturar con la consecuente herniación del disco hacia esas zonas. 
Quiero recalcar que no existe una enfermedad de Scheuermann cervical, o al menos no se ha documentado. Se hipotetiza que pudiera ser debido a la estabilidad de los uncus (una apófisis de los cuerpos vertebrales cervicales) que hace que apenas tengan movilidad y exista el estrés mecánico necesario. Finalmente hay que comentar que esta limitación o sintomatología no se relaciona con la magnitud de la curva y que muchas veces los pacientes cursan de forman asintomática.
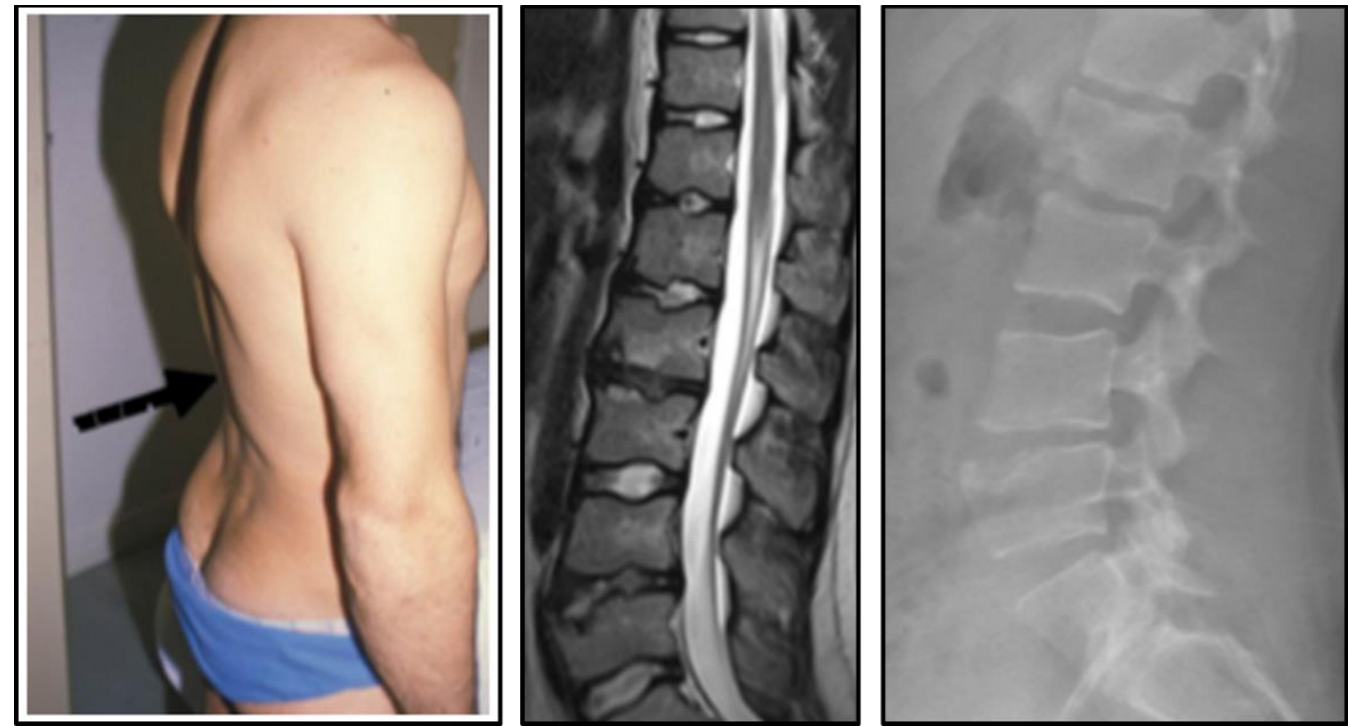

Figura 8. Imagen clínica, RMN y radiográfica de una enfermedad de Scheauermann atípica o tipo II. Imágenes tomadas del trabajo de Palazzo, C. 2014.

\section{Tratamiento}

Existe ligero desacuerdo en la literatura con respecto a los rangos límite a la hora de tratar la cifosis de manera conservadora, ortopédica o quirúgica, aunque generalmente existe una tendencia a ciertos valores de los que hablaremos seguidamente. Generalmente en las curvas de baja magnitud $\left(>60^{\circ}\right)$ no solemos realizar prácticamente tratamiento, será suficiente con la observación, consejo, y evitar la práctica deportiva que implique estrés mecánico excesivo sobre las vértebras (por supuesto, evitando deportes de los que hemos hablado antes).

\subsection{Conservador}

La gran mayoría de los pacientes entran en este grupo de pacientes en los que solamente es necesario observar si la curva progresa. En cuanto a curvas de mayor magnitud (50-80ํㅡㄹ $\mathrm{Cobb})$, que asocien o no síntomas, se recomienda lo siguiente:

- Higiene postural

- Estiramientos pectorales e isquiotibiales / fortalecimiento muscular de erectores del tronco. Junto con lo anterior, presentan evidencia demostrada de reducción del dolor. [19]

- Psicoterapia en caso de existir afectación psicológica por imagen (que no suele haber).

- Tratamiento ortopédico. El tratamiento conservador prínceps en nuestra especialidad.

- Terapia física / manual / osteopatía. Sin evidencia demostrada. 
3.1.1. Tratamiento con corsé (tipo Milwaukee, Boston o antri-gravitatorios): Se basa en la diminución de presión sobre estos platillos vertebrales en formación. Es el único tratamiento conservador que ha logrado enlentecer o parar la progresión de la enfermedad, así como reducir el dolor. Si bien existen una serie de requisitos para usar corsé estos corsés:

1. Estar en periodo de crecimiento. Pacientes esqueléticamente inmaduros porque presentan curvas flexibles.

2. Tiempo-dependiente. Serán necesarias de 16-23h/día para que tenga algo de efecto.

3. Deberá continuarse el tratamiento hasta 1-2 años tras terminado el crecimiento.

Según la forma de la enfermedad tendrán una serie de apoyos. Posteriores a nivel del ápex y sacro (éste únicamente en la forma clásica) y dos anteriores en la parte alta del tronco y baja para elevarlo, compensar los posterior, y evitar que la gravedad ejerza efecto deletéreo sobre la curva. [20] También conviene decir que, una vez retirado el corsé, existe la posibilidad de que se pierda la reducción que se conseguía con la curva, es decir, que aumente la gravedad de esta. [21]

\subsection{Quirúrgico [22]}

El tratamiento quirúrgico se basa en tres pilares: liberación de estructuras, corrección de la deformidad y artrodesis instrumentada. Generalmente se acepta una magnitud mayor de $70^{\circ}$ como indicación quirúrgica, aunque en realidad es el paciente el que suele demandar la cirugía debido a discomfort con los síntomas o la deformidad. Algunas de las indicaciones más aceptadas son:

- Deformidad progresiva

- Dolor lumbar crónico refractario

- Déficit neurológico progresivo

- Fracaso del tratamiento conservador

- Indicación "paciente-dependiente"

3.2.1. Historia: en un principio se abogó por el abordaje posterior con la instrumentación de Harrignton o el Cotrel-Dobusset, pero este tipo de fijación generaba demasiados fallos y complicaciones ante la falta de apoyo anterior terminaron por abandonarse de forma individual y comenzaron a ponerse de moda los dobles abordajes anterior-posterior, que, aunque no estaban exentos de complicaciones, conseguían mayores reducciones de las cifosis. [23] Se basaban en la liberación anterior de las estructuras vertebrales mediante toracotomía (discectomías + fusión intersomática), y posteriormente la fusión posterior. A veces, el halo-tracción nos puede ser útil para tratar de flexibilizar una curva, que en principio se asemeja rígida (Figura 9). Actualmente, el tratamiento que se considera de elección es el abordaje único posterior, mediante tornillos pediculares y asociando osteotomías, con muy buenos resultados, comparables a los del abordaje doble (que debe realizarse en dos tiempos para evitar mayores complicaciones).

\begin{tabular}{cc}
\hline Abordaje combinado (anterior-posterior) & Posterior-"only" \\
\hline "Menor pérdida de correción" & Menor pérdida sanguínea \\
"Mayor corrección" & Menor tiempo quirúrgico \\
& Menor riesgo de cifosis de unión \\
\hline
\end{tabular}

Tabla 1. Ventajas relativas a cada uno de los tipos de abordajes. La pérdida de corrección ha disminuido a lo largo de los años con la mejora de la técnica quirúrgica tanto en el abordaje anterior como el posterior. Siendo ahora similar al mismo en el "posterior-only" también en cuanto a resultados quirúrgicos. (24) 
El principal problema es que cuando analizamos los resultados, los estudios de abordaje combinado suelen ser de baja calidad, antiguos y se basan en pacientes con curvas más importantes y de mayor magnitud. Lo que puede hacer que estas supuestas ventajas de este tipo de abordaje estén sesgadas (Tabla 1).

¿Cuándo será necesario el abordaje anterior? Clásicamente se ha utilizado para el Scheuermann del adulto, en el tipo II (porque es necesario obtener más grados de corrección) o aquellas cifosis que son rígidas en general, debido a la limitación o debilidad de las estructuras nobles (vasculares y nerviosas) anteriores. En cualquier caso, nunca se harán ambas en el mismo acto quirúrgico, sino de forma secuencial porque se ha estudiado que disminuye las complicaciones.

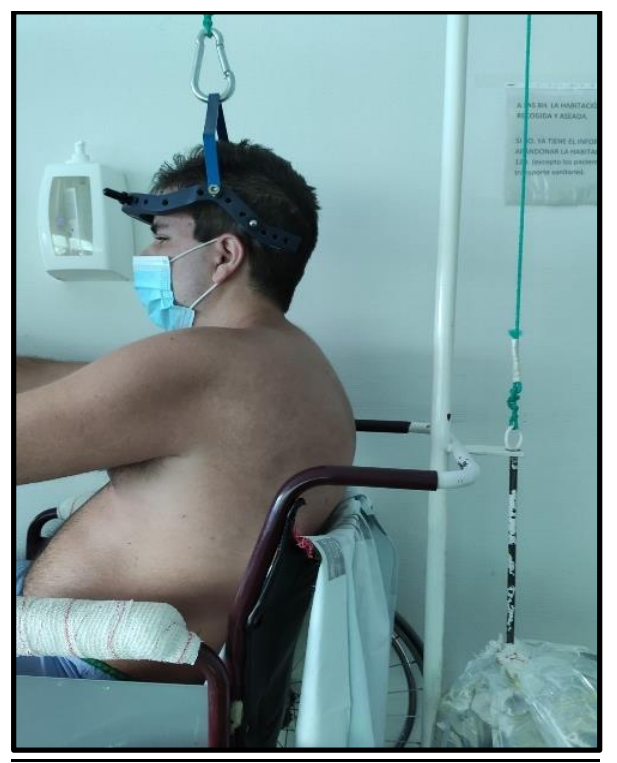

Figura 9. Ejemplo de paciente con Scheuermann, y tratamiento adyuvante con halotracción previo tratamiento quirúrgico.

3.2.2. Corrección de la deformidad: Mediante osteotomías Según la clasificación de Schwabb [25] podemos clasificar las osteotomías en 6 grupos: (Figura 10)

1. Facectomía agresiva y/o Smith-Peterson (OS-P). Se reseca parte la lámina y la espinosa.

2. Osteotomía de Ponte (OP; resección de ambas facetas). Además, con exéresis del ligamento interespinoso y del amarillo. En esta dos necesitaremos que el disco esté abierto por delante para poder corregir la deformidad (aproximadamente $5-10^{\circ}$ por vértebra).

3. Osteotomía de sustracción pedicular (OSP; en cuña anterior sobre el cuerpo vertebral), con una corrección de hasta $30^{\circ}$ por vértebra.

4. Osteotomía de sustracción pedicular + exéresis del disco suprayacente. Esta dos últimas no dependen de que haya o no, espacio anterior abierto, ya que por sí sola, actúa sobre la parte anterior de la columna.

5. Resección de columna vertebral (RCV) de un nivel con exéresis de los discos adyacentes.

6. Resección de columna vertebral multinivel.

A modo de resumen, se podría decir que 3 osteotomía de Smith-Peterson, equivaldrían en corrección a 1 osteotomía de sustracción pedicular. [26] 


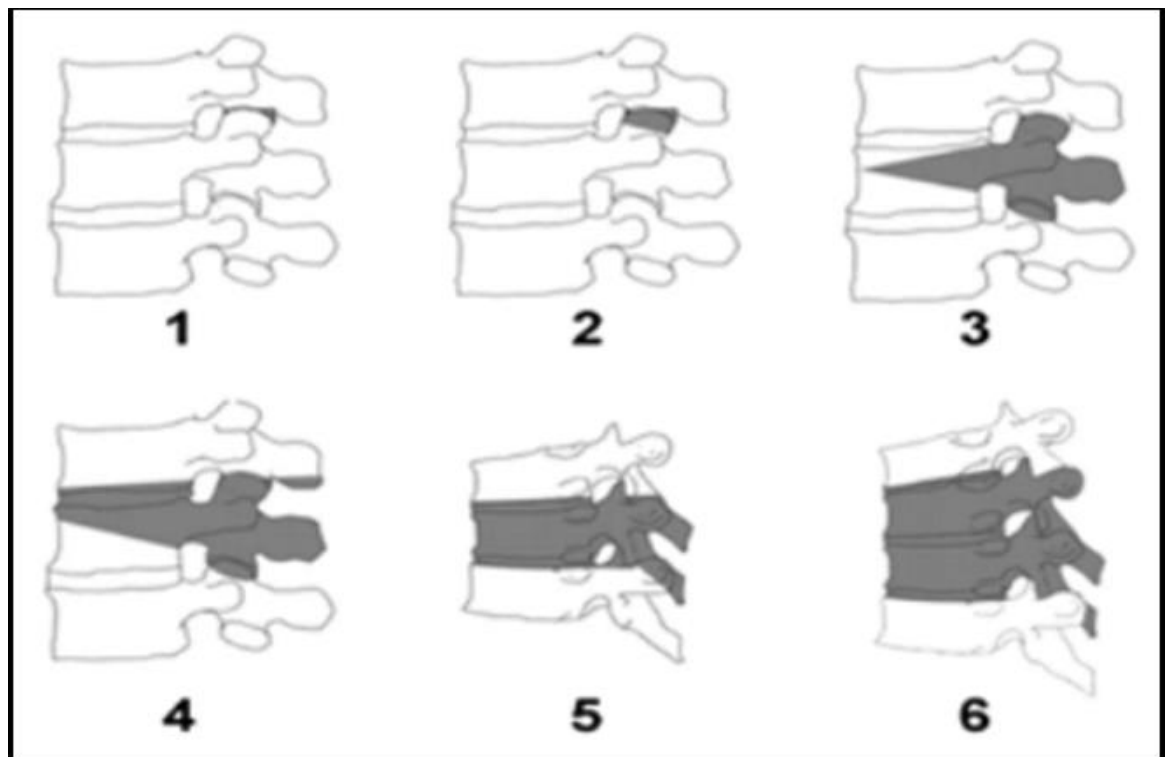

Figura 10. Osteotomías vertebrales. Imagen tomada del trabajo de Schwabb, F. et al.

¿Cuántas osteotomías necesitamos? Para ayudar a responder esta pregunta, podemos utilizar el valor del DAR (sagital Deformity Angular Ratio) = ángulo cifosis / número de vértebras de la cifosis. A menor número mejor, curvas más suaves y viceversa para curvas más angulares donde necesitaremos mayor número de osteotomías. Además, un DAR muy alto se ha asociado a mayor riesgo de alertas en la neuro-monitorización. [27] También podremos calcularlo en base al hilo de la plomada: si cae $>5 \mathrm{~cm}$ por delante del disco lumbosacro necesitaremos al menos una OSP.

3.2.3. Cifosis transicional o de la unión: Esta complicación, frecuente en el tratamiento quirúrgico antiguamente, según series, tiene una incidencia del 20-40\%. Se define como un ángulo de Cobb $>10 \%$ entre los segmentos fusionados y los no fusionados. [28] Constructos más rígidos aumentan el riesgo de cifosis de la unión, mientras que aquellos más flexibles, pueden provocar una pérdida de la reducción (debemos valorar el riesgo-beneficio de cada tipo de instrumentación). (Figura 11)

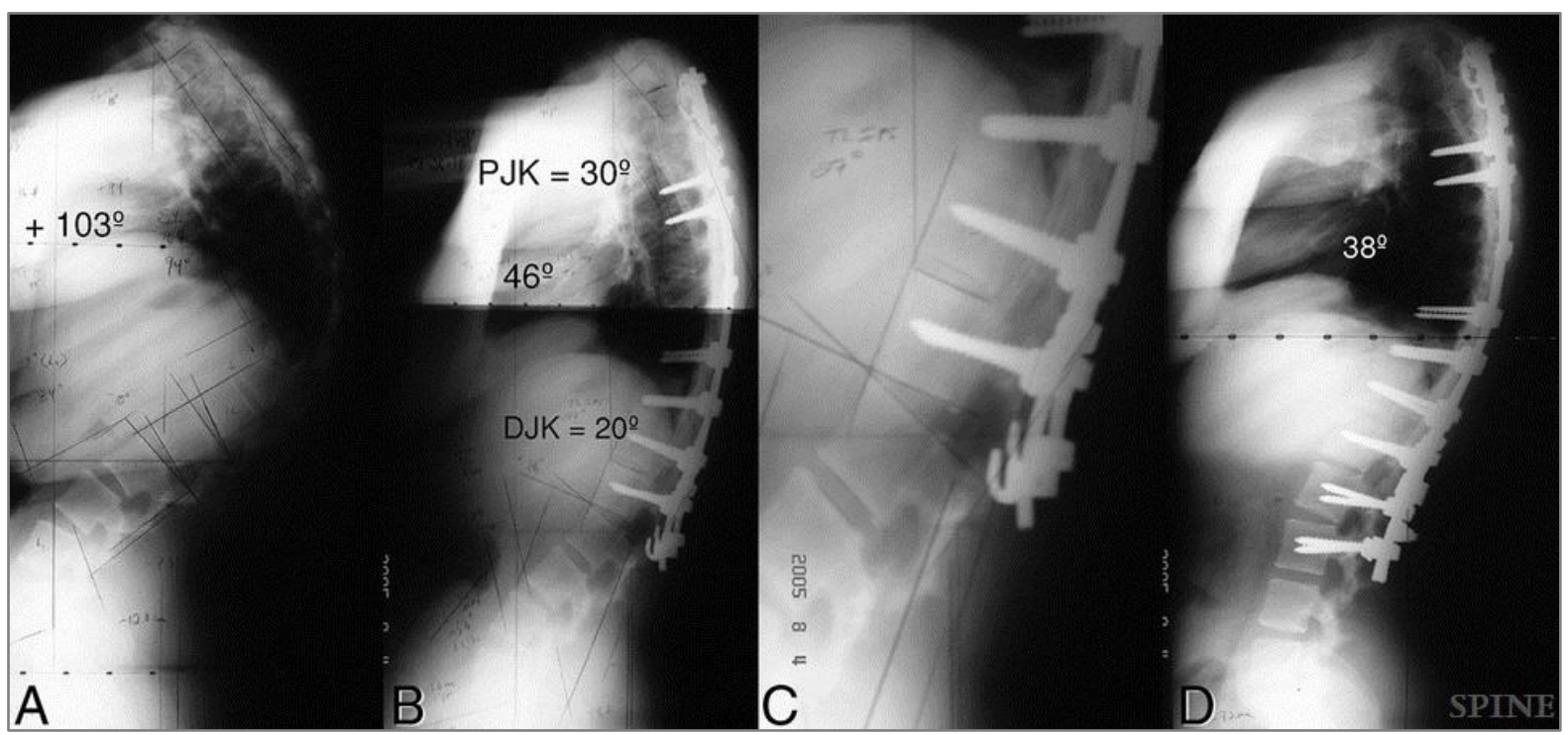

Figura 11. Niña de 16 años con una cifosis inicial de $103^{\circ}$ (A), que se trata quirúrgicamente y en el postoperatorio se desarolla una cifosis transicional proximal y distal ( $30^{\circ}$ y $20^{\circ}$ respectivamente; $\mathrm{B}$ y $\mathrm{C}$ ). Para su correccion se amplica la instrumentción (D). Imágenes tomadas del tabajo de Looner, BS., et al. 
Esta complicación se ha asociado a una mayor incidencia pélvica de los pacientes, una falta de fijación de niveles que deberían estar incluidos, así como a una sobrecorrección quirúrgica (empeoraremos el balance sagital al dejar una lordosis lumbar pequeña que no podrá compensar la cifosis). [29] Para evitar dicha complicación, se han valorado las siguientes opciones [30]:

- Fusional proximalmente a la vértebra de Cobb.

- Mantener los tejidos blandos en los niveles límite.

- "Soft-landing" o aterrizaje suave de la unión (con ganchos, agujas o barras de transición que cambia de diámetro) para una transición más gradual (ya probado en la escoliosis con buenos resultados).

3.2.4. Abordaje posterior. Selección del nivel de fusión [31] (Figura 12): previamente existía controversia en cuando a cuál debe ser el último nivel distal. Primeramente, se utilizaba la FLV (1st lordotic verterbra = primera vértebra lordótica) o FLD (disck) que es el más craneal que se abría en lordosis anterior $\geq 5^{\circ}$. Sin embargo, daba muchas complicaciones debido a que era de dificil valoración en pacientes con hiperlordosis y finalmente quedaban curvas con fusiones muy cortas. Por los motivos descritos, se desribió y se utiliza hoy en día el SSV (sagital stable vertebra), que es la última que toca (más proximal) una línea perpendicular a la horizontal trazada desde el vértice posterior del cuerpo de S1. [32] Este nuevo criterio, proporcionó gran mejoría de la indicidencia de cifosis de la unión distal, así como una mayor resistencia al "pull-out" de los tornillos, menor pérdida de reducción y menor desbalance sagital post-quirurgico. Como apreciación, si la última vértebra que tocaba, lo hacía por poco, convenía mirar el disco suprayacente, de forma que si éste estaba en lordosis de $\geq 5^{\circ}$, ese nivel de fusión se consideraría correcto para la fijación. A nivel proximal, se debe incluir la última vértebra del ángulo de Cobb (la más alta) y tener en cuenta que desde el ápex de la curva debe haber el mismo número de vértebras fijadas (o incluso una vértebra más en proximal).

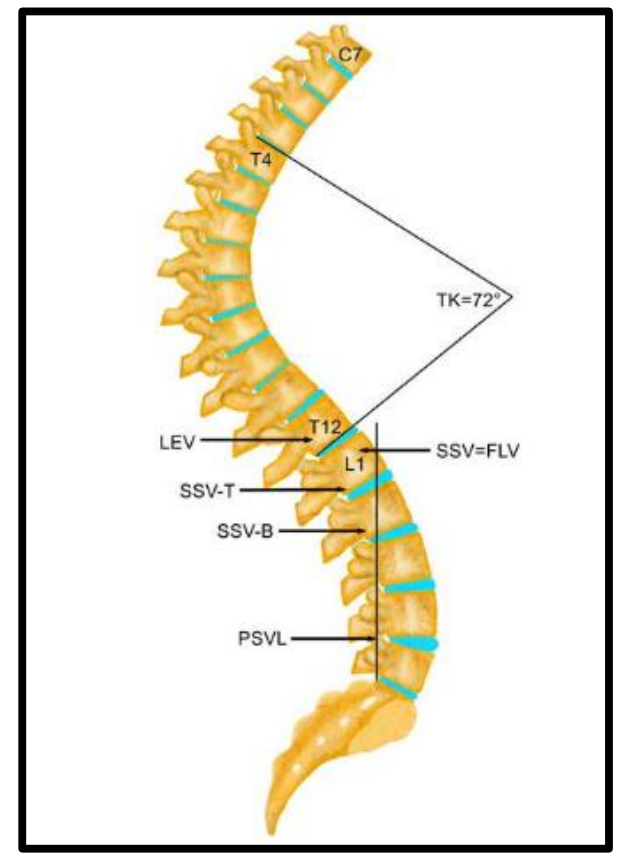

Figura 12. Esquema de parámetros de utilidad para seleccionar el nivel de fijación de la artrodesis posterior. PSVL = posterior sacral vertical line. Imagen tomada del trabajo de Gong, Y., et al.

3.2.5. Complicaciones quirúrgicas: A parte de la cifosis de la unión, existen otras complicaciones que hay que tener en cuenta, con una incidencia, según series del 14\%. [33] Por lo general, son más frecuente en adultos y se tratan de la infección herida quirúrgica (4$10 \%)$, lesión neurológica aguda (2-8\%), o cirugía de revisión (3-14\%). 
Sin embargo, hay otras mucho más frecuentes en el abordaje anterior como las complicaciones vasculares $(6 \%)$ o pulmonares $(20 \%$; embolia pulmonar, derrame pleural, hemotórax, atelectasias, insuficiencia respiratoria aguda...).

Entre las soluciones que se proponen, sobre todo a la hora de evitar la lesión neurológica, se propone mejorar la investigación en el campo de la monitorización multimodal neurofisiológica. Aunque hasta el momento no se entiende o no se utiliza tanto como poco la cirugía de la escoliosis, es necesario su desarrollo en esta patología para reducir al mínimo las complicaciones. [34]

Por último, hay que indicar que un novedoso estudio ha encontrado correlación entre las irregularidades del platillo vertebral y las fracturas por fragilidad vertebrales. Por lo tanto, se podría pensar que en la enfermedad de Scheuermann habría un mayor riesgo de fracturas por fragilidad, sin embargo, los estudios no muestran claros resultados. [35]

\section{Conclusiones}

Para terminar, y como conceptos que debemos tener claros con respecto a la Cifosis de Scheuermann, destacar los siguientes puntos:

- La etología de esta enfermedad está todavía por confirmar y presenta un resto actualmente.

- La clínica y la radiografía simple son suficiente para darnos el diagnóstico de esta patología. Se recomienda pedir RMN en caso de clínica neurológica, ya que podrá asociar otras patologías como hernias o espondilolistesis que habrá que tratar también.

- Cuánto antes se lleve a cabo el tratamiento de la enfermedad, siempre que esté indicado, mejor será el pronóstico del paciente (independientemente que se conservador con ortesis o quirúrgico mediante artrodesis).

- Actualmente el tratamiento quirúrgico opta más por un abordaje único posterior a fin de evitar las complicaciones. Sin embargo, si la curva es muy desafiante, es posible que cirujanos experimentados (a veces en conjunto con cirugía torácica) realicen abordajes dobles.

- Seleccionar los niveles correctos de la instrumentación es primordial para que el pronóstico de estos pacientes sea bueno, y evitar cirugías de revisión. Queremos recordar que son pacientes jóvenes y con tiempo para presentar complicaciones relacionadas con el implante.

- ¿Por qué tratamos la Cifosis de Scheuermann? No se trata de la indicación meramente quirúrgica, como ya hemos hablado anteriormente, sino que habrá que tener en cuenta clínica, edad, magnitud de la curva, complicaciones, calidad de vida del paciente, y estética. 


\section{Apéndice 1. Caso clínico (Figuras 13 y 14)}

Varón de 16 años con $85^{\circ}$ de cifosis y $70^{\circ}$ lordosis, ademas de un Sanders $>V$ que indica prácticamente madurez esquelética. En la Rx en corrección apenas corrige, por lo que finalmente se opta por tratamiento quirúrgico. Entre la planificación preoperatoria se encuentran los siguientes valores: ápex $=\mathrm{T} 9, \mathrm{PI}=35^{\circ}, \mathrm{SSV}=\mathrm{L} 3, \mathrm{FLL}=\mathrm{L} 3$. Tras la cirugía, encontramos los siguiente valores: cifosis torácica $=57^{\circ}$, lordosis lumbar $=50^{\circ}, \mathrm{PI}=44^{\circ}$; por lo que la fórmula quedaría de la siguiente manera $44-55=-7^{\circ}$, valor que se considera correcto para el balance sagital global. La ténica utilizada ha sido un abordaje posterior único con instrumentación desde T2 (uñas) y T3 hasta L3 con tornillos pediculares y una doble barra (simulando el sistema de Dobousset). Además, previa a la instrumentación se realizaron osteotomías de Ponte multinivel. La monitorización neurofisiológica multimodal no presentó alteraciones.
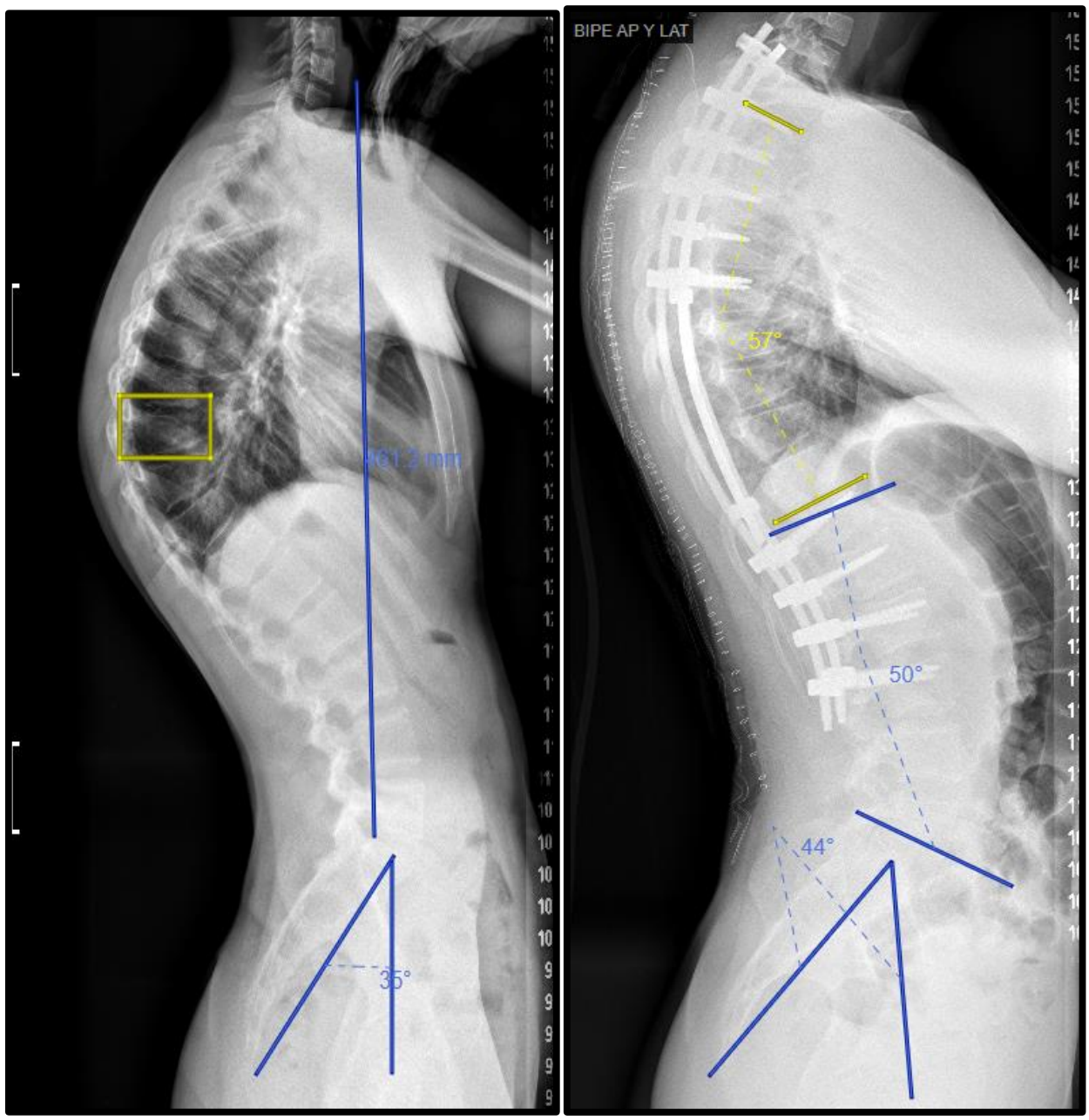

Figuras 13 y 14. Caso clínico descrito en el texto. 


\section{Apéndice 2. Algoritmo manejo cifosis del adolescente}

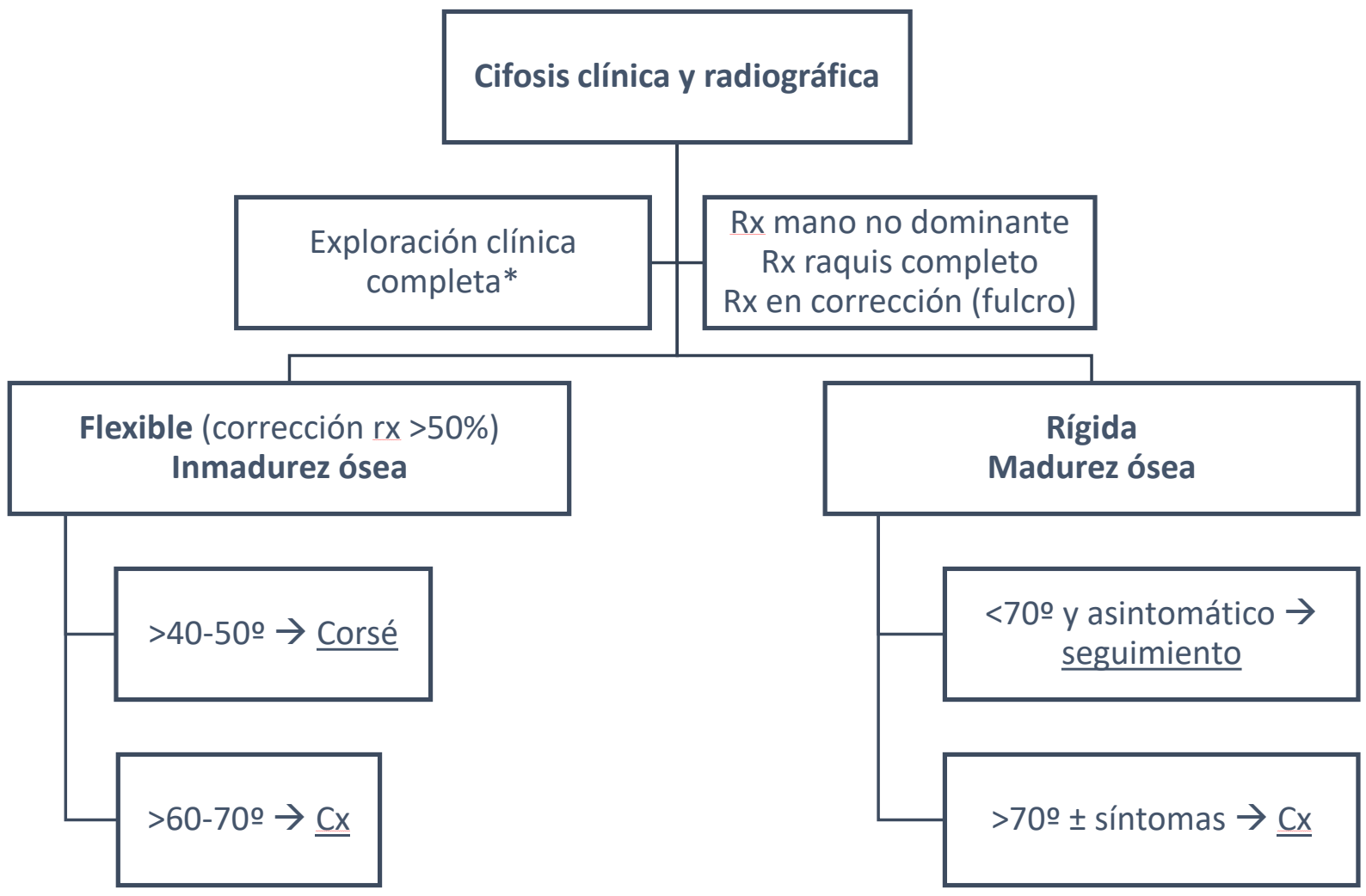

Figura 15. Algoritmo de manejo de la cifosis del adolescente. Tendremos que hacer *diagnóstico diferencial antes de diagnosticar de Cifosis de Scheuermann, con cifosis postural, hipercifosis atribuible a otra patología, cifosis post-quiúrgica, espondilitis anquilosante, y escoliosis.

Contribución de los autores: Todos los autores han participado de manera equitativa, así como han leído y aceptado esta versión para la publicación del manuscrito.

Fondos: Este artículo no ha recibido fondos de ningún tipo para su redacción o publicación.

Declaración sobre Consentimiento Informado: Se ha obtenido el consentimiento informado escrito de todos los sujetos incluidos en este estudio, así como para la publicación de datos e imágenes.

Agradecimientos: A la Unidad de Cirugía de Columna del Hospital Universitario y Politécnico La Fe por el aporte de información adicional para el artículo, así como los pacientes del caso clínico.

Conflicto de interés: Los autores declaran no tener conflicto de intereses.

\section{Referencias}

1. Makurthou AA, Oei L, Saddy S El, Breda SJ, Castaño-Betancourt MC, Hofman A, et al. Scheuermann disease; evaluation of radiological criteria and population prevalence. Spine (Phila Pa 1976) [Internet]. 2013 Sep 1 [cited 2020 Sep 18];38(19):16904. Available from: https://pubmed.ncbi.nlm.nih.gov/24509552/

2. Sørensen K. Scheuermann's juvenile kyphosis: clinical appearances, radiography, aetiology, and prognosis. 1964;

3. SCHEUERMANN, W. H. Kyphosis dorsalis juvenilis. Ugeskr Laeger [Internet]. 1920 [cited 2020 Oct 16];82:385. Available from: https://ci.nii.ac.jp/naid/10024568536 
4. Aufdermaur M, Spycher M. Pathogenesis of osteochondrosis juvenilis scheuermann. J Orthop Res. 1986;4(4):452-7.

5. Palazzo C, Sailhan F, Revel M. Scheuermann's disease: An update. Jt Bone Spine [Internet]. 2014;81(3):209-14. Available from: http://dx.doi.org/10.1016/j.jbspin.2013.11.012

6. Kinesiology of the Musculoskeletal System - 2nd Edition [Internet]. [cited 2020 Oct 16]. Available from: https://www.elsevier.com/books/kinesiology-of-the-musculoskeletal-system/neumann/978-0-323-03989-5

7. Wills CR, Foata B, González Ballester M, Karppinen J, Noailly J. Theoretical explorations generate new hypotheses about the role of the cartilage endplate in early intervertebral disk degeneration. Front Physiol. 2018 Sep 19;9(SEP).

8. McKenzie L, Sillence D. Familial Scheuermann disease: A genetic and linkage study. J Med Genet [Internet]. 1992 Jan 1 [cited 2020 Sep 18];29(1):41-5. Available from: http://jmg.bmj.com/

9. Zaidman AM, Zaidman MN, Strokova EL, Korel A V., Kalashnikova E V., Rusova T V., et al. The mode of inheritance of scheuermann's disease. Biomed Res Int. 2013;2013.

10. Swärd L, Hellström M, Jacobsson B, Nyman R, Peterson L. Disc degeneration and associated abnormalities of the spine in elite gymnasts: A magnetic resonance imaging study. Spine (Phila Pa 1976) [Internet]. 1991 [cited 2020 Oct 16];16(4):437-43. Available from: https://pubmed.ncbi.nlm.nih.gov/1828629/

11. Fotiadis E, Kenanidis E, Samoladas E, Christodoulou A, Akritopoulos P, Akritopoulou K. Scheuermann's disease: Focus on weight and height role. Eur Spine J [Internet]. 2008 May 27 [cited 2020 Oct 16];17(5):673-8. Available from: https://link.springer.com/article/10.1007/s00586-008-0641-x

12. Scheuermann Disease - StatPearls - NCBI Bookshelf [Internet]. [cited 2020 Sep 18]. Available from: https://www.ncbi.nlm.nih.gov/books/NBK499966/

13. Halal F, Gledhill RB, Fraser FC. Dominant Inheritance of Scheuermann's Juvenile Kyphosis. Am J Dis Child [Internet]. 1978 [cited 2020 Oct 16];132(11):1105-7. Available from: https://pubmed.ncbi.nlm.nih.gov/717319/

14. Ristolainen L, Kettunen JA, Heliövaara M, Kujala UM, Heinonen A, Schlenzka D. Untreated Scheuermann's disease: A 37year follow-up study. Eur Spine J [Internet]. 2012 May 22 [cited 2020 Sep 18];21(5):819-24. Available from: https://link.springer.com/article/10.1007/s00586-011-2075-0

15. Le Huec JC, Faundez A, Dominguez D, Hoffmeyer P, Aunoble S. Evidence showing the relationship between sagittal balance and clinical outcomes in surgical treatment of degenerative spinal diseases: a literature review. Vol. 39, International Orthopaedics. Springer Verlag; 2014. p. 87-95.

16. Samuel Bederman S, Farhan S, Hu X, Lieberman IH, Belanger TA, Musa A, et al. Sagittal spinal and pelvic parameters in patients with Scheuermann's disease: A preliminary study. Int J Spine Surg. 2019;13(6):536-43.

17. Liu N, Chen Z, Qi Q, Shi Z. The relationship of symptomatic thoracolumbar disc herniation and Scheuermann's disease. Eur Spine J [Internet]. 2014 [cited 2020 Oct 16];23(5):1059-66. Available from: https://pubmed.ncbi.nlm.nih.gov/24241014/

18. Greene TL, Hensinger RN, Hunter LY. Back pain and vertebral changes simulating scheuermann's disease. J Pediatr Orthop [Internet]. 1985 [cited 2020 Oct 16];5(1):1-7. Available from: https://pubmed.ncbi.nlm.nih.gov/3156876/

19. Bezalel T, Carmeli E, Levi D, Kalichman L. The effect of schroth therapy on thoracic kyphotic curve and quality of life in scheuermann's patients: A randomized controlled trial. Asian Spine J. 2019;13(3):490-9.

20. Zaina F, Atanasio S, Ferraro C, Fusco C, Negrini A, Romano M, et al. Review of rehabilitation and orthopedic conservative approach to sagittal plane diseases during growth: Hyperkyphosis, junctional kyphosis, and Scheuermann disease [Internet]. Vol. 45, European Journal of Physical and Rehabilitation Medicine. Edizioni Minerva Medica S.p.A.; 2009 [cited 2020 Oct 16]. p. 595-603. Available from: https://moh-it.pure.elsevier.com/en/publications/review-of-rehabilitation-and-orthopedic-conservative-approach-to-

21. Hefti F, Jani L. The treatment of Scheuermann's kyphosis with the Milwaukee brace. Z Orthop Ihre Grenzgeb. 1981;119(2):185-92. 
22. Huq S, Ehresman J, Cottrill E, Ahmed AK, Pennington Z, Westbroek EM, et al. Treatment approaches for Scheuermann kyphosis: A systematic review of historic and current management. J Neurosurg Spine. 2020;32(2):235-47.

23. Wenger DR, Frick SL. Scheuermann kyphosis [Internet]. Vol. 24, Spine. Spine (Phila Pa 1976); 1999 [cited 2020 Oct 19]. p. 2630-9. Available from: https://pubmed.ncbi.nlm.nih.gov/10635526/

24. Yun C, Shen CL. Anterior release for Scheuermann's disease: a systematic literature review and meta-analysis. Eur Spine J. 2017;26(3):921-7.

25. Schwab F, Blondel B, Chay E, Demakakos J, Lenke L, Tropiano P, et al. The comprehensive anatomical spinal osteotomy classification. Neurosurgery [Internet]. 2015 Mar 1 [cited 2020 Oct 19];76:S33-41. Available from: https://pubmed.ncbi.nlm.nih.gov/25692366/

26. Koller H, Lenke LG, Meier O, Zenner J, Umschlaeger M, Hempfing A, et al. Comparison of anteroposterior to posterior-only correction of Scheuermann's kyphosis: A matched-pair radiographic analysis of 92 patients. Spine Deform [Internet]. 2015 Mar 1 [cited 2020 Oct 19];3(2):192-8. Available from: https://pubmed.ncbi.nlm.nih.gov/27927312/

27. Lewis NDH, Keshen SGN, Lenke LG, Zywiel MG, Skaggs DL, Dear TE, et al. The deformity angular ratio: Does it correlate with high-risk cases for potential spinal cord monitoring alerts in pediatric 3-column thoracic spinal deformity corrective surgery? Spine (Phila Pa 1976) [Internet]. 2015 Aug 1 [cited 2020 Oct 19];40(15):E879-85. Available from: https://pubmed.ncbi.nlm.nih.gov/26222664/

28. Lonner BS, Newton P, Betz R, Scharf C, O’Brien M, Sponseller P, et al. Operative management of Scheuermann's kyphosis in 78 patients: Radiographic outcomes, complications, and technique. Spine (Phila Pa 1976) [Internet]. 2007 Nov [cited 2020 Oct 19];32(24):2644-52. Available from: https://pubmed.ncbi.nlm.nih.gov/18007239/

29. Denis F, Sun EC, Winter RB. Incidence and risk factors for proximal and distal junctional kyphosis following surgical treatment for Scheuermann kyphosis: Minimum five-year follow-up. Spine (Phila Pa 1976). 2009 Sep;34(20).

30. Lange T, Schmoelz W, Gosheger G, Eichinger M, Heinrichs CH, Boevingloh AS, et al. Is a gradual reduction of stiffness on top of posterior instrumentation possible with a suitable proximal implant? A biomechanical study. Spine J [Internet]. 2017 Aug 1 [cited 2020 Oct 19];17(8):1148-55. Available from: https://pubmed.ncbi.nlm.nih.gov/28373080/

31. Sardar ZM, Ames RJ, Lenke L. Scheuermann's Kyphosis: Diagnosis, Management, and Selecting Fusion Levels. J Am Acad Orthop Surg. 2019;27(10):e462-72.

32. Gong Y, Yuan L, He M, Yu M, Zeng Y, Liu X, et al. Comparison Between Stable Sagittal Vertebra and First Lordotic Vertebra Instrumentation for Prevention of Distal Junctional Kyphosis in Scheuermann Disease: Systematic Review and Meta-analysis. Clin Spine Surg. 2019;32(8):330-6.

33. Lonner BS, Toombs CS, Guss M, Braaksma B, Shah SA, Samdani A, et al. Complications in Operative Scheuermann Kyphosis: Do the Pitfalls Differ from Operative Adolescent Idiopathic Scoliosis? Spine (Phila Pa 1976) [Internet]. 2015 Mar 1 [cited 2020 Oct 20];40(5):305-11. Available from: https://pubmed.ncbi.nlm.nih.gov/25901978/

34. Samdani AF, Bennett JT, Ames RJ, Asghar JK, Orlando G, Pahys JM, et al. Reversible intraoperative neurophysiologic monitoring alerts in patients undergoing arthrodesis for adolescent idiopathic scoliosis: What Are the Outcomes of Surgery? [Internet]. Vol. 98, Journal of Bone and Joint Surgery - American Volume. Lippincott Williams and Wilkins; 2016 [cited 2020 Oct 20]. p. 1478-83. Available from: https://pubmed.ncbi.nlm.nih.gov/27605692/

35. Gaudé M, Chapurlat R, Pialat JB, Szulc P. Long term prognosis of Scheuermann's disease: The association with fragility fracture - The MINOS cohort. Bone [Internet]. 2018 Dec 1 [cited 2020 Oct 20];117:116-22. Available from: https://pubmed.ncbi.nlm.nih.gov/30244156/ 


\title{
FASCITIS NECROTIZANTE. EXPERIENCIA EN LOS ÚLTIMOS CINCO AÑOS EN UN SERVICIO DE CIRUGÍA ORTOPÉDICA Y TRAUMATOLOGÍA.
}

\author{
Autores: Aguilar JC 1, Cuñat BR 2, Angulo MA 1, Baeza J 1, Amaya V 1, Baixauli FF \\ ${ }^{1}$ Hospital Univeristari I Politècnic La Fe, Valencia, Spain \\ ${ }^{2}$ Hospital de Manises, Valencia, Spain.
}

\section{Resumen:}

La fascitis necrotizante es una infección rara, muy agresiva y potencialmente letal. Identificarla a tiempo supone un reto y es clave para poder realizar una intervención quirúrgica precoz y mejorar la supervivencia.

El objetivo del trabajo es analizar el manejo de esta patología en un servicio de Cirugía Ortopédica y Traumatología para optimizar resultados.

Estudio retrospectivo observacional que incluye ocho pacientes tratados de fascitis necrotizante entre los años 2013-2018. Revisión bibliográfica comparando datos de la evidencia actual con los obtenidos en la serie.

Se intervinieron 8 pacientes en 5 años. La mediana de edad fue de 60,5 años. El 75\% fueron varones. La localización más frecuente fue en miembros inferiores. El $88 \%$ de los casos presentaba factores de riesgo, destacando la historia de traumatismo o agresión cutáneo-mucosa reciente y diabetes. La prueba diagnóstica más utilizada fue la tomografía computerizada con una sensibilidad 100\%. La media del score "Laboratory Risk Index for Necrotizing Fasciitis" fue 7,71/13.

El 75\% de los pacientes fue operado en menos de 24 horas. Se re-intervinieron el 88\%, el $43 \%$ antes de 24 horas desde la primera cirugía.

Se utilizó terapia de presión negativa con buenos resultados en un $25 \%$ de los casos. La mortalidad intrahospitalaria fue del 25\% y la media de seguimiento 260,5 días.

Para mejorar la supervivencia en la fascitis necrotizante es clave el diagnóstico precoz, que sólo es posible si identificamos el prototipo de paciente de riesgo y conocemos las herramientas diagnósticas disponibles además de la clínica.

Palabras clave: Infecciones de partes blandas. Fascitis necrotizante. Infecciones necrotizantes de partes blandas. Necrotizing fasciitis. Soft-tissue infections. Necrotizing soft-tissue infections. 


\section{INTRODUCCIÓN}

La infección de partes blandas es muy frecuente, su tratamiento es conservador y en la gran mayoría de los casos no requiere de la valoración de un especialista en Cirugía Ortopédica y Traumatología. Sin embargo, existe un subgrupo mucho menos frecuente al que denominamos infección necrotizante de partes blandas (INPB). Este grupo ha recibido diferentes nombres a lo largo de la historia, siendo actualmente el término de fascitis necrotizante (FN) el que se tiende a utilizar de manera consensuada para evitar confusiones. La característica más importante de la FN es su agresividad. Se trata de una infección que progresa muy rápidamente causando necrosis tisular y una grave repercusión sistémica que condiciona su elevada mortalidad. El tratamiento debe ser de entrada quirúrgico, ya que la cirugía precoz ha demostrado mejorar la supervivencia (1). Cuando nos enfrentamos a un caso clínico concreto es muy difícil diferenciar en el momento inicial si realmente nos encontramos ante una infección necrotizante. Por lo tanto, aspectos esenciales como son el diagnóstico y tratamiento precoz se convierten en un gran reto.

¿Cómo puedo ser capaz de identificar una fascitis necrotizante a tiempo para mejorar la supervivencia? El objetivo del trabajo es analizar el manejo de la FN en un servicio de Cirugía Ortopédica y Traumatología (COT) con el fin de optimizar los resultados y aportar una visión práctica para el manejo de esta letal enfermedad.

Clásicamente se han diferenciado dos grupos: la tipo I, infección polimicrobiana en la que habitualmente están involucadros al menos un germen anaerobio y uno o más anerobios facultativos y/o enterobacterias; $y$ la tipo II, monomicrobiana, causada por estreptococos beta-hemolíticos del grupo A, siendo el más frecuente el Streptococcus Pyogenes, aunque también otros grupos de estreptococos o Staphylococcus Aureus. (3, 7).

\section{MATERIAL Y MÉTODOS}

$\mathrm{Se}$ realiza un estudio retrospectivo observacional monocéntrico en el que se incluyen los pacientes con diagnóstico de FN tratado quirúrgicamente por el servicio de COT entre los años 2013 y 2018. Se obtiene la serie de pacientes mediante búsqueda informática en la base de datos de informes quirúrgicos del hospital. Se acota la búsqueda a las hojas quirúrgicas de Cirugía Ortopédica y Traumatología exclusivamente, dentro de las fechas indicadas. Los términos de búsqueda utilizados son "fascitis necrotizante" y "fascitis necrosante". Para esta búsqueda se utiliza la herramienta de explotación de la información del software "Orion". Los criterios de exclusión establecidos fueron la ausencia de cultivos microbiológicos positivos que confirmaran el diagnóstico de FN.

De cada paciente se recogen múltiples variables: Datos epidemiológicos básicos como la edad y el sexo; la presencia de factores de riesgo para el desarrollo de FN entre los que incluimos: diabetes mellitus (DM), enfermedad vascular periférica, inmunodepresión, e historia de traumatismo y/o agresión cutáneo-mucosa reciente. Se define reciente el period inferior a 3 semanas, considerando que dicho tiempo coincide con el de cicatrización y restitución de las lesiones de partes blandas. Nos referimos a traumatismo como cualquier agresión ("blunt trauma") distinta de las agresiones cutáneo-mucosas. En el grupo de agresiones cutáneo-mucosas se incluyen cualquier solución de continuidad de dichas barreras, incluidos los procesos quirúrgicos. Otras variables recogidas son la localización de la infección; variables clínicas iniciales incluyendo temperatura, ausencia o presencia de fiebre, hipotensión y shock; variables analíticas iniciales incluyendo los parámetros para el cálculo del score: "Laboratory Risk Indicator for Necrotizing Fasciitis" (LRINEC) (2); y pruebas de imagen utilizadas ya sea ecografía, tomografía computerizada (TC) o resonancia magnética 
(RM). Se recogen asimismo los tiempos desde inicio de síntomas hasta primera cirugía, tiempo desde primera cirugía hasta re-intervención, el número de reintervenciones y el resultado de los cultivos $y$ tipo de FN.

IMÁGENES CLÍNICAS cultivos, requerimientos de procesos de tratamiento especiales y complicaciones incluyendo la mortalidad intrahospitalaria se expresan en porcentaje. Para el cálculo del score LRINEC se utiliza la puntuación propia de la escala (2) y se
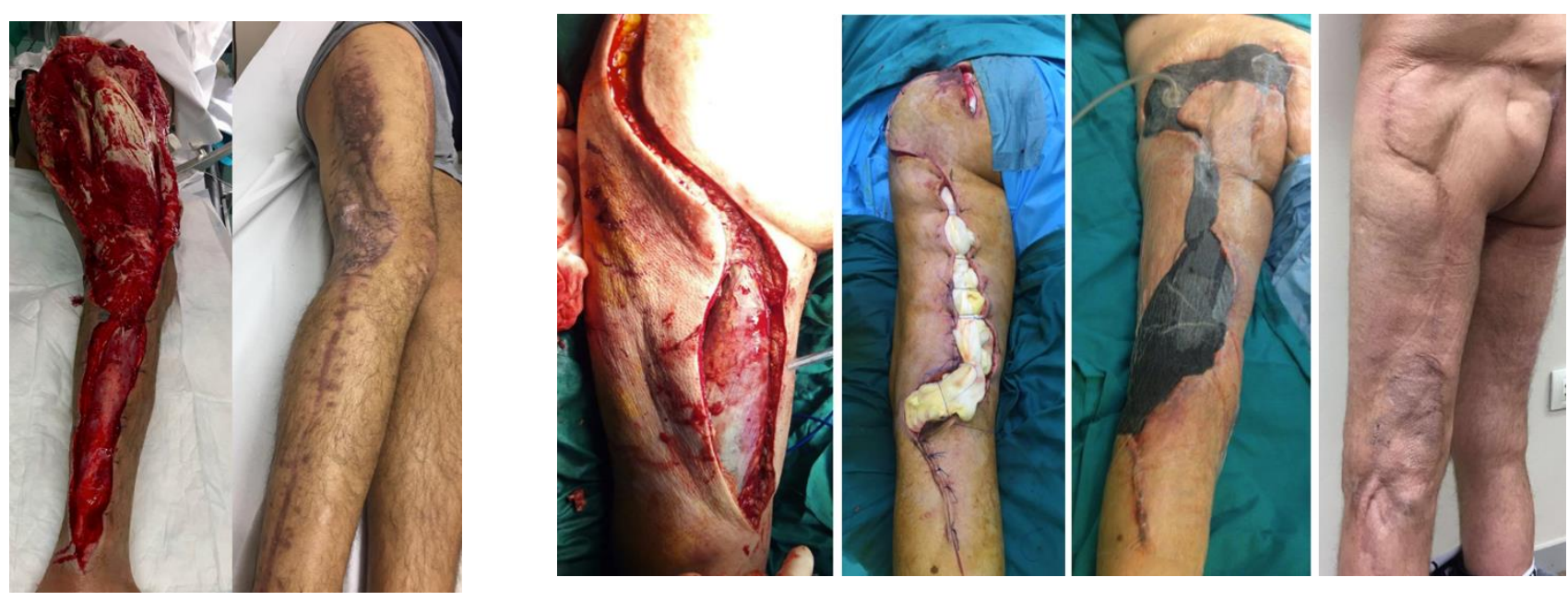

Por último, se recogen aspectos quirúrgicos incluyendo el requerimiento de amputación o cirugía de cobertura de partes blandas; utilización terapia de presión negativa; y finalmente el tiempo de seguimiento en días. Todos los datos son recogidos y tratados por un investigador diferente al cirujano implicado en el tratamiento de cada caso. Los pacientes fueron intervenidos por distintos cirujanos pertenecientes a diferentes unidades dentro de un mismo servicio y seguidos al alta hospitalaria en consultas externas.

Se realiza una revisión bibliográfica actualizada en la base de datos Pubmed utilizando para la búsqueda las palabras clave "fascitis necrotizante" y "necrotizing fasciitis" y descartando todo artículo no escrito en castellano o en inglés, para realizar una comparación de los datos con los obtenidos en nuestra serie.

Para los estadísticos descriptivos se utiliza la mediana para la edad y el sexo se expresa en porcentaje. Las demás variables incluyendo los factores de riesgo, localización de la infección, realización de pruebas de imagen, tipo de FN en base a resultados de los expresa como la media. En cuanto a los tiempos de intervención se establecen dos categorías según sea mayor o menor de 24 horas, siendo este el límite entre intervención precoz o diferida descrito por la bibliografía $(1,3,4)$. También se establecen dos categorías para expresar los signos clínicos que se miden en porcentaje según su presencia o ausencia.

\section{RESULTADOS}

Se realiza tratamiento quirúrgico de un total de 8 pacientes con diagnóstico de FN durante un periodo de 5 años, entre 2013 y 2018. El $75 \%$ de los pacientes fueron de sexo masculino. La mediana de edad fue de 60,5 años. La localización más frecuente de la infección fue en miembros inferiores, representando el $100 \%$ de los casos. (Tabla 1) La media de seguimiento de los pacientes fue de 260 días.

En cuanto a las comorbilidades y factores de riesgo para el desarrollo de $\mathrm{FN}$, todos los 
pacientes presentaban algún factor de riesgo clásico. En este sentido lo más frecuente fue la presencia de traumatismo previo o agresión cutáneo-mucosa reciente incluyendo cirugía, apareciendo en 7 del total de los 8 pacientes de la serie, lo que supone un porcentaje de un $88 \%$ (Tabla 1). De estos pacientes, un $43 \%$ tenía antecedente de intervención quirúrgica reciente, entre las que se incluyeron: tratamiento de una fractura abierta tipo IIIC mediante fijador externo y bypass vascular, extirpación de un neuroblastoma de pelvis e intervención de un sinus pilonidal (estas dos últimas intervenciones realizadas por las especialidades correspondientes). Otro $43 \%$ de los pacientes presentó otra agresión cutáneo-mucosa reciente distinta de cirugía, incluyendo complicación de hemorroides, brote de hidrosadenitis supurativa e inyección intramuscular. El restante 14\% tuvo historia de traumatismo previo reciente sin agresión cutáneo-mucosa ("blunt trauma"), que consistió en una fractura de ramas pélvicas (Figura 1).

TRAUMATISMO O AGRESIÓN CUTÁNEO MUCOSA INCLUYENDO CIRUGÍA $(\mathrm{N}=7)$

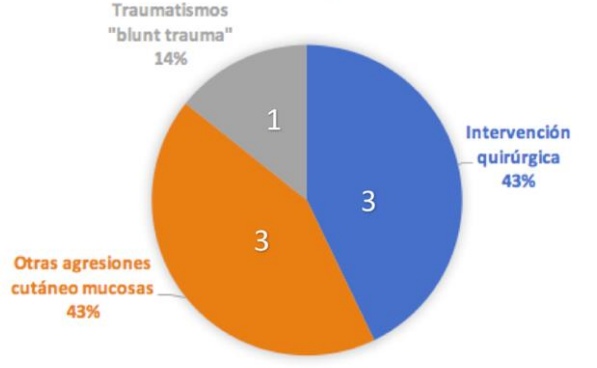

\section{FIGURA 1}

El otro factor de riesgo más frecuente fue la DM que estaba presente en el $62,5 \%$ de los pacientes. Todos los pacientes diabéticos presentaban diabetes tipo II no insulinodependiente. Otros factores de riesgo que aparecieron con menor frecuencia fueron la inmunodepresión, presente en un $38 \%$ de los pacientes. Entre las causas de inmunosupresión aparecen: SIDA, neuroblastoma con afectación de la médula ósea, y leucemia mieloide aguda con aplasia medular. El último factor de riesgo que aparece en nuestros pacientes es la enfermedad vascular periférica, presente en un $13 \%$ de los pacientes (Tabla 1). Es destacable que en la mayoría de los pacientes $(75 \%)$ coexistían dos o más factores de riesgo de los mencionados.

En cuanto a las variables clínicas registradas sólo un $25 \%$ de los pacientes presentaron fiebre, un $13 \%$ hipotensión y otro 13\% desarrollaron un shock séptico en las primeras 24 horas. La media del score LRINEC (2) fue de 7,71 sobre 13 puntos, aunque sólo fue realizado en 7 pacientes por falta de datos analíticos en el octavo paciente.

TABLA 1

\begin{tabular}{|c|c|c|c|c|c|c|c|c|}
\hline \multirow[t]{2}{*}{$\mathrm{N}$} & \multirow[t]{2}{*}{$\overline{\mathrm{EDA}} \mathrm{D}$} & \multirow[t]{2}{*}{ SEXO } & \multirow{2}{*}{$\begin{array}{l}\text { SEGUIMIENTOS } \\
\text { (días) }\end{array}$} & \multirow[t]{2}{*}{ LOCALIZACION } & \multicolumn{4}{|c|}{ FACTORES RIESGO FN } \\
\hline & & & & & TRAUMATISMO* & $\mathrm{DM}^{\mathrm{d}}$ & IDP $^{f}$ & $\mathrm{EVPh}^{\mathrm{h}}$ \\
\hline 1 & 24 & M & 266 & MII $^{\mathbf{a}}$ & $\begin{array}{c}\mathrm{SI}\left(\mathrm{cx}^{\mathrm{c}}\right. \\
\text { neuroblastoma) }\end{array}$ & NO & $\begin{array}{c}\text { SI } \\
\text { (neuroblastoma) }\end{array}$ & NO \\
\hline 2 & 30 & $\mathbf{M}$ & 686 & MID $^{\mathbf{b}}$ & $\begin{array}{c}\text { SI (fr. abierta + } \\
\text { bypass) }\end{array}$ & NO & NO & NO \\
\hline 3 & 42 & M & 26 & MII & SI (inyección droga) & NO & SI (SIDA) & NO \\
\hline 4 & 59 & $\mathbf{M}$ & $\begin{array}{c}<7 \\
\text { (EXITUS) }\end{array}$ & MID & SI (cx hemorroides) & DM2 $^{\mathrm{e}}$ & SI $\left(\mathbf{L M A}^{\mathrm{g}}\right)$ & NO \\
\hline 5 & 60 & $\mathbf{M}$ & 405 & MID & SI (cx sinus pilonidal) & DM2 $^{\mathrm{e}}$ & NO & SI \\
\hline 6 & 65 & $\mathbf{F}$ & 78 & MII & $\begin{array}{c}\text { SI (brote } \\
\text { hidrosadenitis) }\end{array}$ & DM2 $^{\mathrm{e}}$ & NO & NO \\
\hline 7 & 77 & $\mathbf{F}$ & 102 & MII & SI (fr. ramas pélvicas) & DM2 $^{\mathrm{e}}$ & NO & NO \\
\hline 8 & 79 & $\mathbf{M}$ & $\begin{array}{c}<7 \\
\text { (EXITUS) }\end{array}$ & MID & NO & DM2 $^{\mathrm{e}}$ & NO & NO \\
\hline
\end{tabular}


${ }^{a}$ MII: Miembro inferior izquierdo; ${ }^{b}$ MID: Miembro inferior derecho; ${ }^{c} \boldsymbol{C X}$ : Cirugía; ${ }^{d}$ DM: Diabetes mellitus; ${ }^{e}$ DM2: Diabetes mellitus tipo 2 (no insulinodependiente); ${ }^{f}$ IDP: Inmunodepresión; ${ }^{g}$ LMA: Leucemia mieloide aguda; ${ }^{h}$ EVP: Enfermedad vascular periférica

* Traumatismo o agresión cutáneo mucosa reciente incluyendo cirugía

En casi todos los pacientes (88\%) se realizó alguna prueba de imagen. Todo paciente en que se realizó prueba de imagen incluyó TC, cuya sensibilidad diagnóstica fue del $100 \%$. Otras pruebas menos utilizadas fueron la ecografía (25\%) y la RM (13\%).

Respecto a los tiempos de realización del tratamiento quirúrgico, en el $75 \%$ de los pacientes se realizó la intervención en las primeras 24 horas desde el inicio de los síntomas. Se realizó re-intervención en quirófano del $88 \%$ de los pacientes y el $43 \%$ de estos se re-intervinieron en 24 horas desde la cirugía inicial. En base a los resultados de los cultivos intraoperatorios, el $25 \%$ fueron FN tipo II y el $75 \%$ tipo I; siendo lo más frecuente en este último grupo la aparición de especies de Clostridium, representando un $38 \%$ del total.

En total, sólo 1 paciente fue amputado $(13 \%)$, un $38 \%$ requirió técnicas de reconstrucción de partes blandas basadas en colgajos y realizados por el servicio de Cirugía Plástica, y en un $25 \%$ de los casos se utilizó terapia de presión negativa.

La mortalidad intrahospitalaria fue del $25 \%$ y del resto de pacientes el seguimiento medio total fue de 304 días, siendo 78 días el menor tiempo de seguimiento.

\section{DISCUSIÓN}

La mortalidad de la FN es muy elevada tal y como han descrito algunos estudios $(1,5)$ y así sucede en nuestra serie. También los datos epidemiológicos son concordantes con lo publicado hasta la fecha ya que lo más frecuente es la afectación de varones en edad media y de localización en miembros inferiores (6) por lo que el patrón de afectación sigue la corriente habitual.

En cuanto al tipo de FN según microorganismo causante, clásicamente se han diferenciado dos grupos distintos. La FN tipo I es una infección polimicrobiana en la que habitualmente están involucadros al menos un germen anaerobio y uno o más anerobios facultativos $\mathrm{y} / \mathrm{o}$ enterobacterias. La FN tipo II es monomicrobiana y está causada por estreptococos beta-hemolíticos del grupo $A$, siendo el más frecuente el Streptococcus Pyogenes, aunque también puede estar causada por otros grupos de estreptococos o por Staphylococcus Aureus. $(3,7)$.

La incidencia de los tipos I y || suele ser similar (8) aunque varía en function de las series. En nuestra serie es más frecuente el tipo I, pero nos llama la atención sobre manera la importante representación por especies de Clostridium, hasta un 38\%, cuando es un microorganismo poco frecuente en lo publicado en la bilbiografía $(6,9)$. Este dato cobra importancia cuando tenemos en cuenta que, además del tratamiento quirúrgico, la instauración de tratamiento antibiótico es fundamental en el manejo.

Si atendemos a los datos clínicos de los pacientes, la aparición de dolor es una constante, siendo el síntoma principal, como es bien conocido. Sin embargo, los signos sistémicos sugestivos de sepsis como la hipotensión, el shock y la fiebre no siempre aparecen inicialmente y así lo hemos visto en nuestra serie. Estos signos han demostrado tener una baja sensibilidad que oscila entre el $10-40 \%$ según estudios (3). Estos datos subrayan la importancia de no infravalorar la gravedad de los pacientes en la fase temprana de la enfermedad por el hecho de no presentar alteración de constantes vitales. Al analizar los antecedentes de los pacientes de nuestra serie destaca la presencia de factores de riesgo para el desarrollo de $\mathrm{FN}$ en un elevado porcentaje de los casos (88\%), sobre todo la presencia de traumatismos o agresión cutáneomucosa reciente incluyendo cirugía, y la DM. La DM ha sido descrita en la literatura como un factor de riesgo importante para presentar FN, e incluso como un factor de mal pronóstico clínico que puede predecir la necesidad de amputación (10); sin embargo, 
en muchos trabajos no se especifica el tipo de DM. Todos los pacientes diabéticos en nuestra serie eran DM tipo II, lo cual coincide con aquellos estudios que especifican el tipo de DM (11-14).

En muchos de los casos, en un mismo sujeto existía acumulación de más de dos factores de riesgo simultáneos. Creemos que es importante conocer estos factores para estar alerta y pensar en el diagnóstico de $\mathrm{FN}$ al encontrarnos ante un caso con este tipo de antecedentes y un cuadro clínico sospechoso.

A la hora de apoyar el diagnóstico de sospecha de $\mathrm{FN}$ se utilizan comúnmente pruebas de imagen, y se han propuesto varias en esta patología, como la radiografía, ecografía, TC O RM. Quizá destaca de manera negativa la RM por tratarse de una prueba con poca disponibilidad de urgencia y que puede retrasar el diagnóstico. En cuanto a pruebas más rápidas y accesibles, la radiografía presenta una baja sensibilidad ya que es capaz de detectar gas, pero éste no siempre aparece en los tejidos ya que es dependiente del microorganismo causante. El TC es una prueba que presenta una alta sensibilidad, tal y como ha demostrado en nuestra serie, habiendo sido capaz de diagnosticar a la totalidad de los pacientes. En nuestro ámbito, la realización de TC no supone un retraso en el tratamiento debido a la rápida accesibilidad, pero no en todos los centros sucede así. Es necesario destacar que no siempre son necesarias pruebas de imagen para decidir intervenir a un paciente con un cuadro clínico sospechoso de FN, y nunca si va a suponer un retraso en el tratamiento.

¿Qué herramientas diagnósticas rápidas disponemos entonces para apoyar nuestro diagnóstico clínico y tomar la decisión de realizar una intervención quirúrgica? Se han propuesto valores analíticos que son capaces de diferenciar entre infecciones de partes blandas necrotizantes y no necrotizantes, destacando el score LRINEC (2) que reúne una serie de parámetros analíticos sanguíneos (nivel de Proteína $C$ Reactiva, leucocitos, hemoglobina, sodio, creatinina y glucosa) para crear una puntuación de 0 a 13 y estratificar a los pacientes en perfiles de bajo, intermedio o alto riesgo para la detección precoz de la patología. Desde que se propuso el score se ha utilizado en varios trabajos que han intentado validarlo. Una revisión reciente (8) que incluyó siete estudios que utilizaron el score LRINEC ha propuesto un punto de corte de 5,8/13. A partir de ese valor o mayor, el valor predictivo positivo para FN oscila entre $57 \%$ hasta $92 \%$ en tres estudios diferentes incluidos, y el valor predictivo negativo oscila entre $86 \%$ y $96 \%$ en otros dos estudios incluidos en la revisión.

Por lo tanto, si seguimos este punto de corte, ante un score menor, sería muy improbable la presencia de $\mathrm{FN}$ ya que es una prueba con un alto valor predictivo negativo, y por lo tanto la podríamos utilizar como screening. Si bien en nuestra serie la media de LRINEC de los 7 pacientes en los que se realizó fue de 7,71/13, nos impresiona que hasta en 2 pacientes el score estaba por debajo del punto de corte propuesto. Aunque hablamos de una serie pequeña, en nuestro caso no hubiera sido útil el score LRINEC como screening si se hubiera utilizado en el momento del diagnóstico, ya que hasta un $28 \%$ de los pacientes no se hubieran diagnosticado, con las consecuencias que ello conlleva.

Para profundizar en este tema, analizamos a los 2 pacientes con el score más bajo y pudimos comprobar que eran pacientes inmunodeprimidos con afectación de médula ósea y aplasia medular $y$, por lo tanto, un recuento bajo de leucocitos, que es uno de los parámetros que más puntúa en el test. Creemos por lo tanto que este score puede no ser útil en este tipo de pacientes, que a su vez son un grupo con mayor riesgo de presentar la patología.

En cuanto al tratamiento, y en vistas a los tiempos de intervención, se intentaron respetar los principios básicos para mejorar la supervivencia siempre que fue posible: hasta en un $75 \%$ de los casos se realizó intervención en las primeras 24 horas desde el inicio de los síntomas. En contraste, al analizar los tiempos a la hora de realizar una re-intervención quirúrgica, vimos que tan sólo un $43 \%$ de los casos se re-intervinieron en menos de 24 horas desde la primera 
cirugía (Figura 2). Se ha destacado la importancia de realizar una reevaluación quirúrgica a las 24 horas de la primera cirugía y después tantas veces como sea necesario hasta conseguir el control local de la infección $(3,4)$. Aunque nuestros resultados son buenos si atendemos a la mortalidad intrahospitalaria y requerimiento de amputación, hay que destacar que se pueden optimizar los tiempos de reintervención y para esto es importante tener en cuenta que cuando se presenta un paciente con $\mathrm{FN}$ requiere una planificación para disponer de quirófanos y recursos, personal, etc. A pesar de la importancia de los tiempos de intervención para el aumento de supervivencia, no se suelen reflejar datos concretos en este sentido en los trabajos publicados, y creemos necesario que aparezcan más estudios con este enfoque para destacar con cifras la importancia de intervenir y re-intervenir a los pacientes de forma precoz.

En los casos en los que se utilizó la terapia de presión negativa, siempre tras el control local de la infección, los resultados fueron satisfactorios, acorde a lo publicado en la literatura, aunque con series de casos pequeñas $(15,16)$.

\section{FIGURA 2}
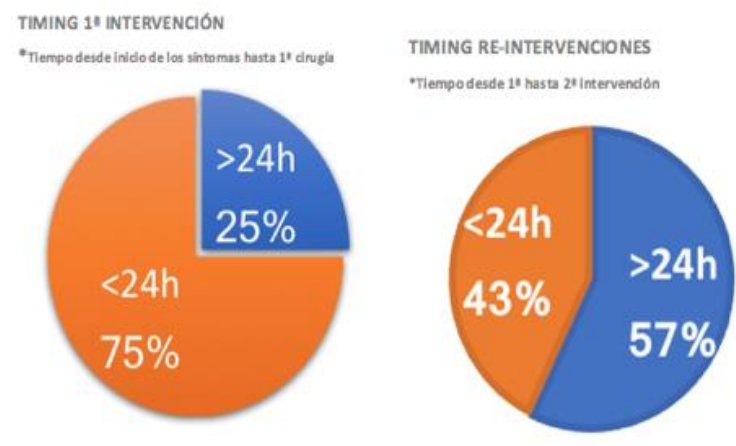

\section{BIBLIOGRAFÍA}

1. McHenry CR, Piotrowski JJ, Petrinic D, Malangoni MA. Determinants of mortality for necrotizing soft-tissue infections. Ann Surg 1995; 221(5):558-63.

2. Wong $\mathrm{CH}$, Khin LW, Heng KS et al. The LRINEC (laboratory risk indicator for necrotizing fasciitis) score: a tool for
El presente trabajo cuenta con todas las limitaciones inherentes a cualquier estudio retrospectivo que trata una serie de casos y, además, el tamaño de la muestra es limitado consistiendo en 8 pacientes. En este sentido es conveniente recalcar que el estudio no pretende arrojar datos de significación estadística. Sin embargo, dada la baja incidencia, consideramos que se trata de una serie valiosa a partir de la cual analizar el manejo de esta patología en nuestro medio.

Como conclusión, a la hora de optimizar los resultados en el manejo de la FN intentando mejorar la supervivencia, existen 2 puntos clave: El primero es el diagnóstico precoz, que sólo es posible si conocemos la clínica, siendo importante identificar el prototipo de paciente de riesgo para despertar la alarma. No existen muchas herramientas diagnósticas objetivas que apoyen el diagnóstico actualmente, salvo algunas pruebas de imagen como el TC, pero que nunca se deben realizar si van a suponer un retraso en el tratamiento de un paciente con un cuadro clínico compatible. El segundo punto clave es realizar una intervención temprana y programar las re-intervenciones de antemano para cumplir los tiempos propuestos.

distinguishing necrotizing fasciitis from other soft tissue infections. Crit Care Med 2004; 32: 1,535-1,541

3. Wong $\mathrm{CH}$, Chang $\mathrm{HC}$, Pasupathy $\mathrm{S}$, Khin LW, Tan JL, Low CO. Necrotizing fasciitis: clinical presentation, microbiology, and determinants of mortality. J Bone Joint Surg Am 2003; 85:1454-60.

4. Parra Caballero P., Perez Esteban S., Patiño Ruiz ME y cols. Revisión Actualización en 
fascitis necrotizante. Semin Fund Esp Reumatol 2012; 13:41-8.

5. May AK. Skin and soft tissue infections. Surg Clin North Am 2009; 89:403- 420

6. Angoules AG. Necrotising fasciitis of upper and lower limb: a systematic review. Injury. 2007 Dec;38 Suppl 5:S19-26. Epub 2007 Nov 28.

7. Bisno, A. L., \& Stevens, D. L. (1996). Streptococcal Infections of Skin and Soft Tissues. New England Journal of Medicine, 334(4), 240-246.

8. Stevens DL, Bryant AE. Necrotizing SoftTissue Infections. N Engl J Med 2017; 377:2253

9. Anaya DA, Dellinger EP. Necrotising softtissue infection: diagnosis and management. Clin Infect Dis 2007;44:705-10.

10. Tantraworasin, A., Khamnuan, P., Chongruksut, W., Jearwattanakanok, K., Patumanond, J.(2015). Necrotizing fasciitis: epidemiology and clinical predictors for amputation. International Journal of General Medicine Volume 8, 195-202.

11. Miller LG, Perdreau-Remington F, Rieg G et al. Necrotizing fasciitis caused by community-associated methicillin-resistant Staphylococcus aureus in Los Angeles. N Engl J Med 2005; 352: 1,445-1,453.

12. Tsitsilonis $\mathrm{S}$, Druschel $\mathrm{C}$, Wichlas $\mathrm{F}$ et al. Necrotizing fasciitis: is the bacterial spectrum changing? Langenbecks Arch Surg 2013; 398: 153-159

13. Bucca K, Spencer R, Orford N et al. Early diagnosis and treatment of necrotizing fasciitis can improve survival: an observational intensive care unit cohort study. ANZ J Surg 2013; 83: 365-370.

14. Glass, G., Sheil, F., Ruston, J., Butler, P.(2015). Necrotising soft tissue infection in a UK metropolitan population. The Annals of The Royal College of Surgeons of England 97(1), 46-51.
15. Baharestani MM. Negative pressure wound therapy in the adjunctive management of necrotizing fasciitis: examining clinical outcomes. Ostomy Wound Manage. 2008;54:44-50.

16. Lee JY, Jung $H$, Kwon $H$, Jung $S N$. Extended negative pressure wound therapyassisted dermatotraction for the closure of large open fasciotomy wounds in necrotizing fasciitis patients. World J Emerg Surg 2014;9:29. 
Artículo de revisión

\title{
Fracturas de cuello y diáfisis femoral ipsilateral: revisión de la literatura.
}

\author{
Ortega-Yago, A ${ }^{1 *}$, Balfagón-Ferrer, A ${ }^{2}$, Alonso-Caravaca, A $^{3}$, Castillo-Soriano, MA ${ }^{4,}$ De Pedro-Abascal, ${ }^{5}$ \\ 1 * Correspondence: ortegayago94@gmail.com \\ 1,2,3 Department of Orthopedic Surgery and Traumatology, The University and Polytechnic la Fe Hospital of \\ Valencia.
}

Academic Editor: Ortega-Yago, A. Received: 10 January 2021.

Accepted:

Published:

Copyright: (c) 2021 by the authors. Submitted for possible open access publication under the terms and conditions of the Creative Commons Attribution (CC BY) license (http://creativecommons.org/licenses /by/4.0/).

\begin{abstract}
: las fracturas de cuello y diáfisis femoral ipsilateral son fracturas poco frecuentes, que se asocian a pacientes jóvenes tras un mecanismo de alta energía. Este tipo de fracturas suponen un reto a la hora de su diagnóstico, dado que hasta un $20 \%$ de las fracturas de cuello femoral pueden pasar desapercibidas. La correcta planificación quirúrgica tras un diagnóstico preciso permite un tratamiento óptimo de las fracturas, al igual que una disminución de la tasa de complicaciones derivadas de las mismas. Actualmente con el avance de los implantes, existen múltiples opciones quirúrgicas para tratar estas fracturas, y que permite individualizar el tratamiento dependiendo del paciente y del tipo de fractura que tiene. Esta revisión tiene como objetivo sintetizar los conceptos acerca del diagnóstico y manejo quirúrgico de las fracturas ipsilaterales de cuello y diáfisis femorales.
\end{abstract}

Keywords: "fracturas diafisarias de femur", "fracturas de cuello femoral", "diagnóstico precoz"

\section{Introduction}

Las fracturas de cuello y diáfisis femoral ipsilateral son fracturas infrecuentes (2-6\%). La edad media es de 35 años aproximadamente, y más de la mitad de los casos se producen en hombres. Estas fracturas se producen por mecanismo de alta energía, en el cual existe un impacto de alta energía sobre la rodilla. Posteriormente, la energía entra por la rodilla creando una fuerza axial por la diáfisis hasta llegar al cuello femoral. [1,2]. Muchas veces se produce porque el miembro inferior está en abducción, a diferencia de cuando está en adducción, que tiende a producirse luxación posterior de cadera [3].

Las fracturas de cuello femoral que se asocian más frecuentemente a las fracturas ipsilaterales de diáfisis son las subcapitales (Figura 1) o las basicervicales no desplazadas, y las fracturas de cuello vertical (Pauwels tipo 3).

En muchas ocasiones existe conminación en la diáfisis femoral. Además, estas fracturas están asociadas a lesiones de rodilla ipsilaterales (20-40\%), entre las que se encuentran fracturas de meseta tibial, lesiones de complejos ligamentosos, fractura de rótula o luxación de rodilla. $[4,5]$ 

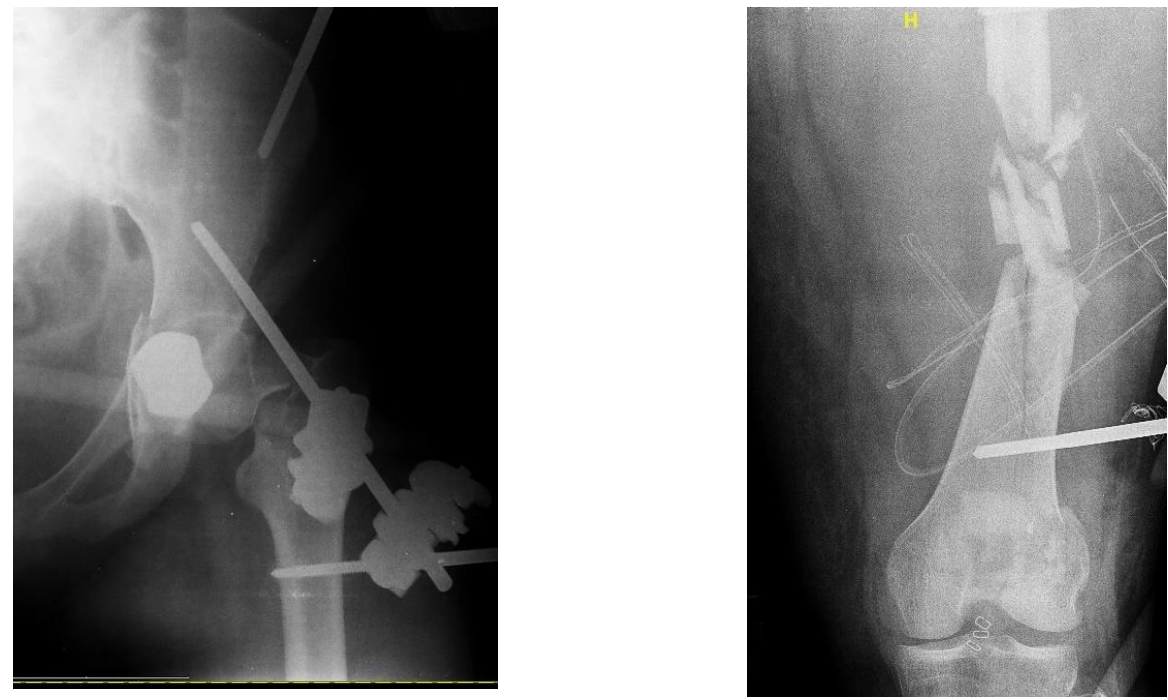

Figura 1: fractura subcapital y diafisaria de fémur izquierdo

\section{Diagnóstico}

El diagnóstico suele ser tardío y supone un reto para el traumatólogo, dado que puede pasar desapercibido en muchas ocasiones. Entre estos motivos, está el fémur, que tiende a la rotación externa. Otros factores añadidos son la falta de radiografías, la mala calidad de las mismas, el poco desplazamiento femoral del cuello, y la difícil exploración en pacientes inestables del paciente. Hasta el $20 \%$ de estas fracturas pueden pasar totalmente desapercibidas [3].

Para evitar que esto suceda, hemos de obtener una radiografía anteroposterior de pelvis, así como axial de cadera y lateral de diáfisis femoral. Con respecto, al uso del TC, prueba cada vez más utilizada en nuestro medio para planificación quirúrgica y diagnóstico de fracturas, se ha observado que es de gran utilidad para refinar el diagnóstico y descubrir fracturas ocultas.

Yang et al observaron que el $76 \%$ de las fracturas que no eran detectadas por las radiografías, sí fueron diagnosticadas gracias al TC. [6]. Conforme el uso del TC se fue extendiendo y los cortes fueron disminuyendo de grosor de milímetros, el diagnóstico ha conseguido precisarse más, llegando hasta el 82\% de la precisión diagnóstica [7].

Existen actualmente algunos protocolos de diagnóstico de imagen, entre los que se encuentran radiografías en rotación interna, la realización de un TC, controles fluoroscópicos prequirúrgicamente, previo a la fijación de diáfisis y tras la fijación de la misma, así como la realización de radiografía postintervención. Con ese protocolo, se reduce un $90 \%$ la probabilidad de que pase desapercibida una fractura oculta 


\section{3. ¿Cuándo intervenir al paciente?}

Existen recomendaciones para decidir cuándo es el momento idóneo para intervenir al paciente. Normalmente se aconseja que sea de forma urgente, nada más el paciente esté estable, dado que permite recuperar la vascularización femoral lo antes posible. Aun así, no existe un consenso sobre cuándo realizar la cirugía, dado que estas fracturas son raras, los patrones de fracturas son diferentes dependiendo de los pacientes, hay gran variabilidad de tratamientos, y las cohortes son pequeñas [3]

\section{Tratameinto quirúrgico}

En el tratamiento quirúrgico hay dos objetivos principales de realizar la cirugía: la reducción anatómica de la cabeza femoral, y la reducción de la diáfisis para corregir longitud, alineamiento y rotación.

Muchos autores coinciden en que la cabeza femoral tiene preferencia sobre el tratamiento de la diáfisis. Primero, porque las complicaciones de la cabeza femoral son mayores que la diáfisis (necrosis avascular, ausencia de consolidación), y segundo, porque si se reduce la diáfisis femoral primero, la reducción de la cabeza femoral es más complicada que si se realiza a la inversa [4,5]. Si no se pueda realizar una reducción cerrada de la cabeza femoral, está indicada la reducción abierta para realizar una reducción lo más anatómica posible.

En cuanto a las opciones de la osteosíntesis disponible para estas fracturas, tenemos el implante único y la combinación de dos implantes.

Con respecto a un implante, la reducción tiende a ser más compleja. Es preferible el uso de implante único si el cuello está mínimamente desplazado (Figura 2).

En cuanto a la combinación de dos implantes, la reducción del cuello tiende a ser algo más sencilla, y se prefiere cuando el cuello femoral está desplazado.

Entre las opciones de implante único tenemos el clavo cefalomedular (clavo de reconstrucción) y el DHS largo. La LCP no está preparada para fijar el cuello femoral por la incapacidad que tiene de realizar compresión. En algunos estudios se ha observado que el enclavado medular tiene mayor tasa de ausencia de consolidación con respecto a la combinación de dos implantes [9]. 


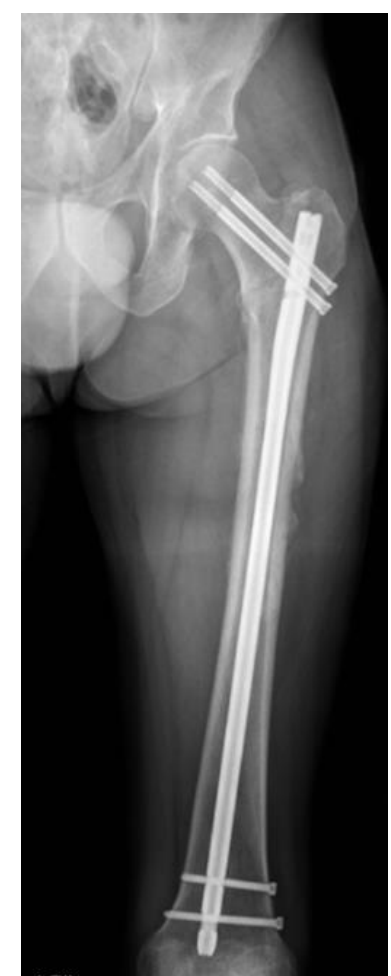

Figura 2: Clavo de reconstrucción, un implante.

Con respecto al uso de dos implantes, existen tres opciones:

- Clavo anterógrado + canulados: existe menos espacio para trabajar la reducción de la cabeza (Figura 3 y 4 ).

- Clavo retrógrado + DHS/ canulados: más trabajo para la reducción del cuello femoral (Figura 5)

- $\quad$ Placa de compresión / MIPO + DHS/ canulados 


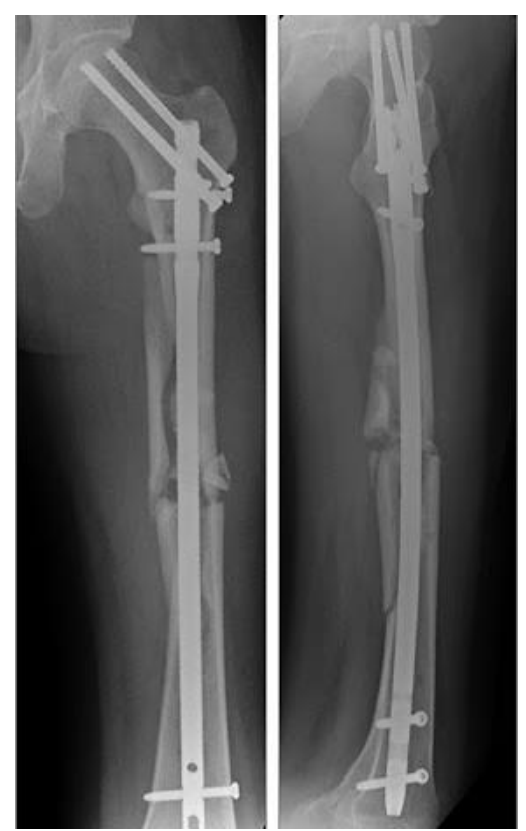

Figura 3 y 4: clavo anterógrado junto con tornillos canulados.

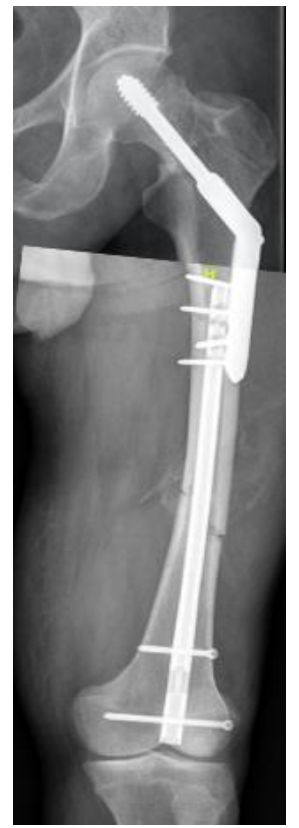

Figura 5: clavo retrógrado junto con DHS

Para el cuello femoral combinado con clavo anterógrado o retrógrado, se pueden utilizar diferentes opciones: $[9,10,11]$

- Femoral Nail system: es una opción cuando existen fracturas subcapitales. Contraindicado su uso en intertrocantéricas o pertrocantéricas.

- $\quad$ Tornillos canulados: para fracturas subcapitales

- DHS: para fracturas pertrocantéreas, intertrocantéreas o basicervicales. 
- DHS + canulados: En el caso de las Pauwels tipo 3, se puede utilizar combinados tanto el DHS como los canulados por el patrón vertical que presentan, y porque el DHS de forma aislada tiene dificultades para aguantar las fuerzas rotacionales en este patrón de fracturas. [12]
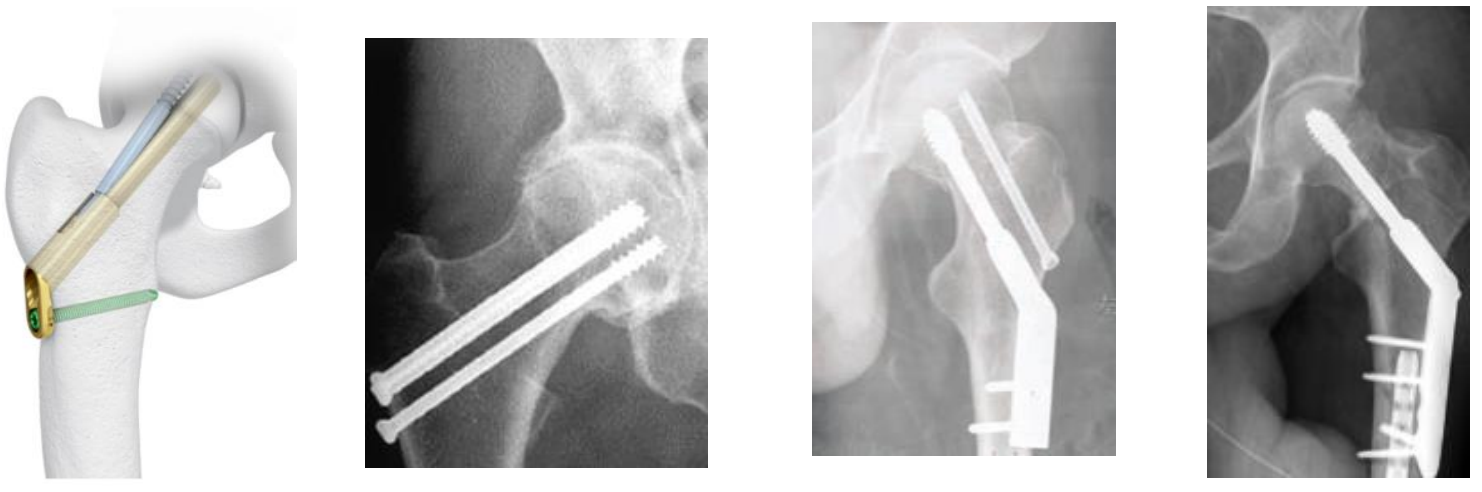

Figura 4: distintas opciones para fijar el cuello femoral: femoral nail system (A), tornillos canulados (B), DHS (C) y DHS junto con canulado (D).

No existen diferencias significativas entre el DHS y los tornillos canulados en cuanto a aumento de probabilidad de ausencia de consolidación, ni en la funcionalidad posterior del paciente. [10]

Las actuales recomendaciones aconsejan que se frese previo a introducir el clavo, dado que se ha visto que fresar disminuye la probabilidad de ausencia de consolidación, especialmente en la diáfisis. [5,10]. Esto se produce porque al no haber fresado, el clavo no se adapta dado que el componente del eje del clavo suele ser de tamaño inferior en comparación con los diámetros del canal medular.

El tratamiento definitivo de estas fracturas, dependerá del si el diagnóstico se hace antes, mientras o después de la fijación, o si la fractura de cuello femoral está desplazada.

Si la cabeza está mínimamente desplazada o sin desplazar, se tiende a intentar utilizar un implante. Para ello, se fija primero la cabeza de forma temporal, se coloca posteriormente el clavo en la diáfisis, y finalmente se fija de forma definitiva la cabeza.

Si la cabeza está desplazada, se tiende a utilizar dos implantes. Primero se fija la cabeza femoral con reducción cerrada o bien abierta, y posteriormente se reduce la diáfisis. De esa forma consigues manipular la diáfisis con el cuello femoral fijo.

Entre las técnicas que pueden utilizarse para fijar el cuello femoral está la "miss a nail". Esta técnica permite reducir la fractura de cuello femoral antes de fijar la diáfisis femoral. Permite estabilizar de forma temporal, bien con agujas (de forma anterior) o bien reducción abierta si es preciso el cuello femoral bajo control de escopia. Posteriormente se introduce 
un clavo de manipulación, se coloca un adaptador (miss a nail) y luego se introduce una guía. Luego se coloca una aguja para mantener la posición y estabilizar la fractura.

Se coloca bajo escopia las agujas guía para posteriormente insertar los tornillos perpendiculares a la fractura. Posteriormente se retira el clavo de manipulación y se determina la longitud de los tornillos, para luego introducirlos.

Si el hallazgo de la fractura es intraoperatorio tras la inserción del clavo endomedular, se pueden añadir tornillos canulados anteriores al clavo ( 2 implantes), o bien cambiar el clavo que se está utilizando a un clavo de reconstrucción. En el caso de que el hallazgo sea postoperatorio, dependiendo del tipo de fractura y del implante previo habremos de utilizar otro implante o bien modificar el implante previo (Figura 5).
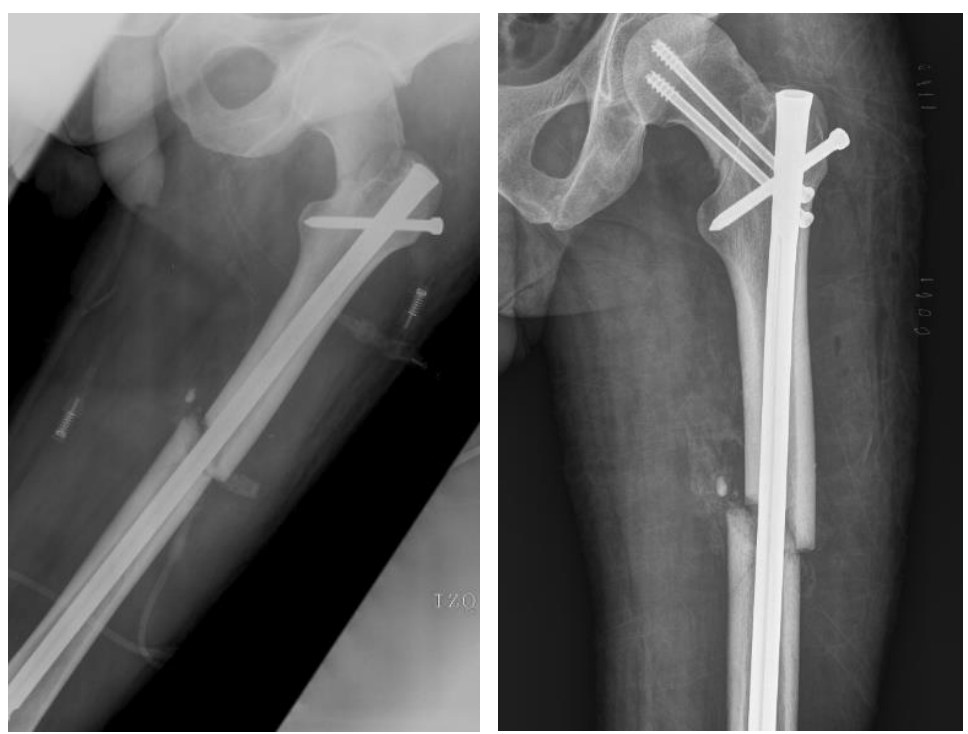

Figura 5: Clavo gross kempf. Se observa como hallazgo postoperatorio la aparición de fractura subcapital izquierda no diagnosticado en el momento previo a la fijación. En este caso, se optó por tornillos canulados en una segunda intervención.

En algunos casos, la reducción cerrada es fallida, por lo que es preciso utilizar la reducción abierta para estabilizar la cabeza previo a la fijación definitiva. Cuando se realiza la reducción abierta, entonces se utiliza la cabeza femoral como un joystic tras abrir la cápsula, y así se permite la correcta reducción [3]. En líneas generales, se tiende a utilizar la vía anterior directa (Smith Peterson) o bien la lateral (Hardinge), aunque esta es menos utilizada.

\section{Factores pronósticos y complicaciones}

Los factores asociados a buen pronóstico de la fijación son la cirugía precoz, la calidad de la reducción y la fijación estable. Los factores asociados a mal pronóstico son el desplazamiento y la conminución posterior [13]. 
Con respecto a las complicaciones, la ausencia de consolidación es más frecuente en la diáfisis femoral que en el cuello. El riesgo de ausencia de consolidación y osteonecrosis del cuello femoral depende de:

- Retraso en el diagnóstico

- Desplazamiento inicial

- Malreducción [13].

La incidencia de NAV y ausencia de consolidación es desconocida, pero se postula que aproximadamente el 5\% de las fracturas acabarán con necrosis avascular, y el 20\% con ausencia de consolidación, siendo este riesgo mayor si es una fractura abierta.

Se ha visto que la incidencia de NAV es menor que en el caso de fracturas de cuello femoral dado que se sospecha que la alta energía pueda disiparse por la diáfisis femoral, además de que muchas de las fracturas son no desplazadas, a diferencia de las fracturas aisladas de cuello femoral $[3,14]$.

Las tasas de mal unión se asociaban especialmente a un retraso de la fijación y a una mala reducción, así como conminución abundante. El posponer más de 48 horas antes de la cirugía no influía en la probabilidad de NAV cuando se comparaba con $>48$ horas tras cirugía. $[15,16,17]$

Sin embargo, la diáfisis tiene mayor tasa de complicaciones que si es aislada, dado que normalmente es más conminuta. El motivo por el cual la ausencia de consolidación pueda ser mayor que en las fracturas aisladas puede ser explicado porque son fracturas que han sufrido un mecanismo de alta energía, y además tienen una mayor tasa de fracturas abiertas comparado con las diafisarias aisladas. La afectación de partes blandas es la principal causa de esta complicación (Figura 6). [4,12]

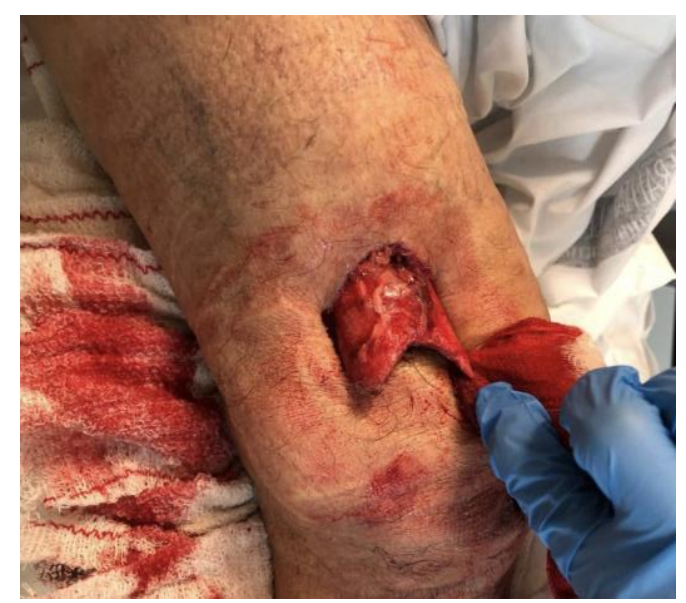

Figura 6: La afectación de partes blandas y las fracturas abiertas son el principal riesgo de ausencia de consolidación en la diáfisis. 
Se ha visto recientemente que las probabilidades de complicaciones en las fracturas ipsilaterales de cuello y diáfisis femorales son menores con clavo intramedular comparado con placa y tornillo [18].

Funding: Esta revisión no recibió financiación externa.

Conflicts of Interest: Los autores declaran que no existen conflictos de interés.

\section{References}

1. Alho A: Concurrent ipsilateral fractures of the hip and femoral shaft: A meta-analysis of 659 cases. Acta Orthop Scand 1996;67: 19-28.

2. Hak DJ, Mauffrey C, Hake M, Hammerberg M, Stahel PF: Ipsilateral femoral neck and shaft fractures: Current diagnostic and treatment strategies. Orthopedics 2015;38:247-251.

3. Jones CB, Walker JB. Diagnosis and Management of Ipsilateral Femoral Neck and Shaft Fractures. J Am Acad Orthop Surg. 2018 Nov 1;26(21):e448-e454

4. Singh R, Rohilla R, Magu NK, Siwach R, Kadian V, Sangwan SS. Ipsilateral femoral neck and shaft fractures: a retrospective analysis of two treatment methods. J Orthop Traumatol. 2008 Sep;9(3):141-7

5. Boulton CL, Pollak AN. Special topic: Ipsilateral femoral neck and shaft fractures--does evidence give us the answer? Injury. 2015 Mar;46(3):478-83

6. Yang KH, Han DY, Park HW, Kang HJ, Park JH. Fracture of the ipsilateral neck of the femur in shaft nailing. The role of CT in diagnosis. J Bone Joint Surg Br. 1998 Jul;80(4):673-8

7. Cannada LK, Viehe T, Cates CA, Norris RJ, Zura RD, Dedmond B, Obremskey W, Bosse MJ; Southeastern Fracture Consortium. A retrospective review of high-energy femoral neck-shaft fractures. J Orthop Trauma. 2009 Apr;23(4):25460.

8. Tornetta P 3rd, Kain MS, Creevy WR. Diagnosis of femoral neck fractures in patients with a femoral shaft fracture. Improvement with a standard protocol. J Bone Joint Surg Am. 2007 Jan;89(1):39-43.

9. Bedi A, Karunakar MA, Caron T, Sanders RW, Haidukewych GJ: Accuracy of reduction of ipsilateral femoral neck and shaft fractures: An analysis of various internal fixation strategies. J Orthop Trauma 2009;23:249-253.

10. Ostrum RF, Tornetta P 3rd, Watson JT, Christiano A, Vafek E. Ipsilateral proximal femur and shaft fractures treated with hip screws and a reamed retrograde intramedullary nail. Clin Orthop Relat Res. 2014 Sep;472(9):2751-8

11. Oh CW, Oh JK, Park BC, et al: Retrograde nailing with subsequent screw fixation for ipsilateral femoral shaft and neck fractures. Arch Orthop Trauma Surg 2006;126:448-453.

12. Cha YH, Yoo JI, Hwang SY, Kim KJ, Kim HY, Choy WS, Hwang SC. Biomechanical Evaluation of Internal Fixation of Pauwels Type III Femoral Neck Fractures: A Systematic Review of Various Fixation Methods. Clin Orthop Surg. 2019 Mar;11(1):1-14. doi: 10.4055/cios.2019.11.1.1. Epub 2019 Feb 18

13. Watson JT, Moed BR. Ipsilateral femoral neck and shaft fractures: complications and their treatment. Clin Orthop Relat Res. 2002 Jun;(399):78-86.

14. Upadhyay A, Jain P, Mishra P, Maini L, Gautum VK, Dhaon BK. Delayed internal fixation of fractures of the neck of the femur in young adults. A prospective, randomised study comparing closed and open reduction. J Bone Joint Surg Br. 2004 Sep;86(7):1035-40.

15. Araujo TP, Guimaraes TM, Andrade-Silva FB, Kojima KE, Silva Jdos S. Influence of time to surgery on the incidence of complications in femoral neck fracture treated with cannulated screws. Injury. 2014 Nov;45 Suppl 5:S36-9 
16. Wang T, Sun JY, Zha GC, Jiang T, You ZJ, Yuan DJ. Analysis of risk factors for femoral head necrosis after internal fixation in femoral neck fractures. Orthopedics. 2014 Dec;37(12):e1117-23. doi: 10.3928/01477447-20141124-60

17. Papakostidis C, Panagiotopoulos A, Piccioli A, Giannoudis PV. Timing of internal fixation of femoral neck fractures. A systematic review and meta-analysis of the final outcome. Injury. 2015 Mar;46(3):459-66.

18. Lu Y, Wang Y, Song Z, Wang Q, Sun L, Ren C, Xue H, Li Z, Zhang K, Hao D, Zhao Y, Ma T. Treatment comparison of femoral shaft with femoral neck fracture: a meta-analysis. J Orthop Surg Res. 2020 Jan 20;15(1):19. doi: 10.1186/s13018019-1496-z 


\title{
Cirugía de acortamiento por dismetría tras artroplastia total de cadera.
}

\author{
Garrido Rojo, R ${ }^{1}$, Aracil Silvestre, J ${ }^{2}$, Simón Pérez V ${ }^{3}$, Deserio Cuesta $\mathbf{J}^{4}$, García Chamorro $\mathbf{M}^{5}$. \\ 1 Autor de referencia 1; raquelgr3293@gmail.com
}

Resumen: Introducción; Doctor, ¿por qué tengo la pierna más larga? Durante una ATC es frecuente que ocurra un alargamiento del miembro para compensar la tendencia que existe a la inestabilidad posterior, mediante el uso de componentes de cuello más largos y con más offset. Es importante planificar un buen balance, ya que en general una dismetría de más de 7-10 mm es mal tolerada y es la causa más frecuente de litigios post PTC en EEUU. Material y métodos; Realizamos una revisión de tres pacientes que presentaban una dismetría mayor de $1 \mathrm{~cm}$ tras ATC y se sometieron a cirugía de corrección en nuestro hospital. Se valoró la sintomatología mediante la escala HHS y se midió la dismetría mediante el método de Woolson en la radiografía de pelvis. Resultados; En el primer paciente se realizó un recambio de cabeza más corta y un mallado de fascia lata; en el segundo se realizó un recambio a un cotilo de doble movilidad; en el tercero se decidió el recambio del vástago asociado a una osteotomía y descenso del trocánter mayor. En todos los casos los resultados fueron satisfactorios. Conclusión; En un paciente que presenta una dismetría no aceptable debemos valorar el riesgo/beneficio a la hora de planificar una corrección quirúrgica, ya que el acortamiento de un miembro va a conllevar un aumento de la inestabilidad de la prótesis. Existen diversas opciones terapéuticas pero escasa bibliografía sobre los resultados, y así mismo bastante contradictorios. Hoy día el mejor tratamiento es la prevención, mediante el uso de marcadores pre y perioperatorios, la navegación y/o la escopia intraoperatoria.

Palabras clave: “dismetría”, "PTC", “artroplastia total”, “cadera”, “acortamiento", “abordaje anterior".

\section{Introducción}

La intervención de prótesis de cadera o artroplastia total de cadera (ATC) es un procedimiento cada vez más habitual, sobretodo en vista de la mayor prevalencia de la enfermedad degenerativa de cadera en todo el mundo. Además de ser una de las intervenciones más realizadas es una de las más exitosas.

¿Qué podemos hacer actualmente para disminuir el porcentaje de luxaciones tras colocar una prótesis de cadera, mejorar la recuperación funcional del paciente para que sea lo más rápida posible y mejorar su dolor? En este sentido está tomando mucha importancia el abordaje anterior de cadera.

\subsection{Abordaje anterior de cadera}

El abordaje anterior de cadera se realiza en un plano internervioso e intermuscular, con respeto muscular y tendinoso, y por lo tanto es inherentemente estable. Sus tres 
principales ventajas son el menor dolor postoperatorio, la movilización precoz y la rápida recuperación.

En un metaanálisis reciente sobre complicaciones precoces ${ }^{(10)}$ se compara el abordaje anterior con el posterior y se ve que existen menores tasas estadísticamente significativas de infección, luxación y reintervención con el AAD. No se observaron diferencias estadísticamente significativas en osificación heterotópica, complicaciones de la herida, fracturas o sucesos tromboembólicos. Sin embargo, sí que se vio un mayor porcentaje de lesión nerviosa, pero esta es puramente sensitiva por lesión de las ramas terminales del nervio femorocutáneo, sin tener repercusión clínica ni en la satisfacción global del paciente.

Diversos estudios demuestran que es superior en cuanto a la satisfacción precoz por parte del paciente. En el metaanálisis que hace Miller en $2018^{\left({ }^{(10}\right)}$ se ve que el AAD presenta un mejor postoperatorio inmediato en comparación con el abordaje posterolateral: en los primeros 90 días el paciente presenta menos dolor, menor necesidad de fármacos narcóticos y mejor funcionalidad de la cadera. Por otro lado, el Registro holandés de Peters en 2018 (11) demuestra que la satisfacción a medio plazo (a partir de 3-12 meses) del paciente es mayor para los abordajes anterior y posterolateral (igualándose entre ellos) que para el lateral y anterolateral.

\subsubsection{Experiencia con el AAD en nuestro hospital}

En nuestro hospital se sigue la técnica de Berend y Lomardi. El paciente se coloca en decúbito supino, lo que nos da acceso a las dos piernas y por tanto a la posibilidad de realizar una buena evaluación perioperatoria de las dismetrías en todo momento.

Además, se utiliza un gancho elevador de fémur, para proteger la musculatura abductora durante todo el acto quirúrgico, sobretodo el tensor de la fascia lata. Después se realiza una liberación femoral rigurosa para evitar complicaciones perioperatorias, sobre todo fracturas y malposición de los implantes.

Gracias a esta posición del paciente en decúbito supino es sencilla la utilización de la escopia intraoperatoria, lo que permite poder realizar una buena planificación en todo momento, sobre todo en casos complejos.

En total en nuestro hospital contamos con alrededor de 1100 casos de PTC colocadas por vía anterior, con los siguientes resultados:

- No hemos encontrado ningún caso de dismetrías superiores a $1 \mathrm{~cm}$.

- Tampoco ningún caso de malas alineaciones del vástago ni hundimientos del mismo.

- Complicaciones menores: 1 caso de fractura incompleta intraoperatoria (que se solucionó con un cerclaje).

- Complicaciones mayores: 1 caso de luxación en PTC tras fractura de cadera (de 53 casos, es decir, el 1,28\%) y 2 luxaciones en PTC colocadas por coxartrosis (de 879 casos, es decir, el 0,22\%).

- Nuestros pacientes tienen una excelente movilidad, sin ninguna restricción. Se les permite la carga el primer día postoperatorio, en ocasiones sin ayudas ortésicas. 


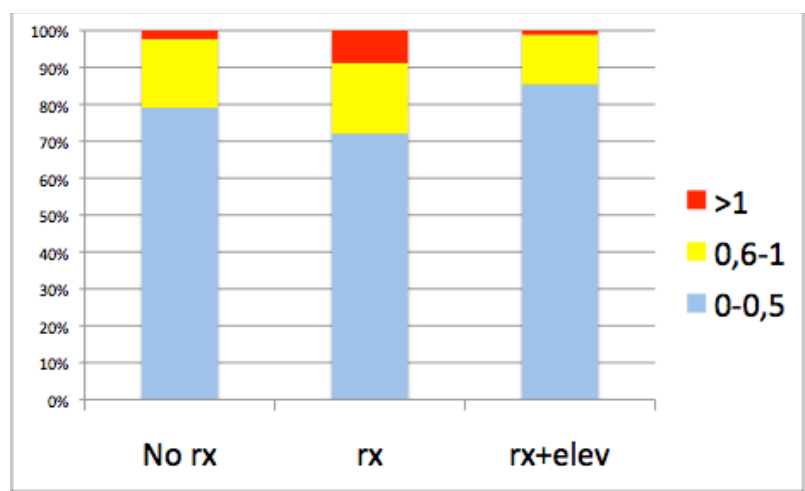

Imagen 1. Gráfico resumen del porcentaje de dismetrías

\subsection{Dismetrías de miembros inferiores}

Dentro de los objetivos más habituales cuando realizamos una artroplastia total de cadera tenemos la restauración de la biomecánica normal y la preservación de la igualdad de la longitud del miembro sin comprometer la estabilidad de la prótesis (2).

La desigualdad de longitud es un motivo común de insatisfacción y litigio para el paciente (2):(3);(4). De hecho, se trata de la causa más frecuente de litigios post PTC en USA. Según un estudio de Röder et al. (BMC Musculoskeletal Disorders 2012, 13:95), donde revisan 10415 casos de pacientes sin dismetría previa de 4 hospitales diferentes, la incidencia en Europa es de alrededor de un $7 \%$ : un 4,7\% de pacientes sufrieron un alargamiento de $>1 \mathrm{~cm}$ y un $2,7 \%$ sufrieron un acortamiento $>1 \mathrm{~cm}$. ${ }^{(3)}$

En general todos los resultados hablan de que en la mayoría de intervenciones se producen alargamientos de la extremidad intervenida, en los cuales lo más común es que no sean mayores a 1 centímetro de longitud. Estas dismetrías causadas por la intervención en la mayoría de los casos no son relevantes como para poder causar problemas en la biomecánica de la marcha ni en el desarrollo de una vida cotidiana normal para el paciente intervenido ${ }^{(1)}$. Edeen et al y Ranawat et al. escribieron que la diferencia de longitud de las piernas debe ser de $10 \mathrm{~mm}$ o menos para que un paciente tenga una buena calidad de vida (4), siendo peor tolerado el alargamiento de la misma. Una de las formas más aceptadas de medir la satisfacción de un paciente tras una PTC es la HHS (Harris Hip Score).

Existen tres causas de dismetrías después de una PTC:

- Suprapelvica: debida a factores relacionados con el raquis lumbar, como patologías degenerativas con escoliosis que causen una oblicuidad de la pelvis. Suele pasar desapercibida preoperatoriamente.

- Funcional o aparente: lo más frecuente es que se produzcan contracturas de la musculatura abductora, que se pueden tratar mediante ejercicios de fisioterapia con estiramiento de TFL o GM. Si no se solucionara se podría realizar también un mallado de la cintilla iliotibial.

Estas contracturas pueden ser:

- Primarias

- Secundarias a un aumento del offset

- Secundarias a un alargamiento

- Estructural o real (osteoarticular). Es la que está causada por el aumento de la distancia cabeza-cuello de la prótesis o el mal posicionamiento de la misma.

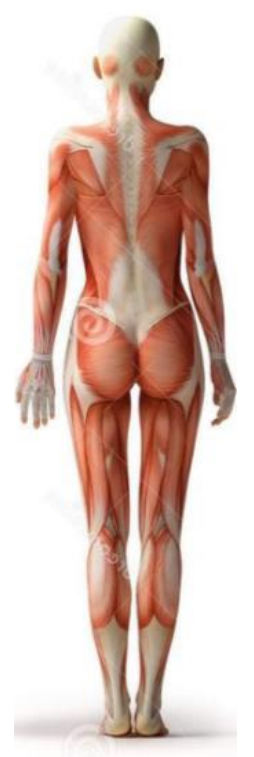




\subsubsection{Dismetría estructural}

Existen una serie de factores que influyen en la posibilidad de que se produzca una dismetría después del implante de una PTC:

- Posición del paciente en decúbito lateral.

- Tipo anestesia (más frecuente con la raquídea).

- Poco uso medidores intraoperatorios.

- Incomodidad de la radioscopia o navegación.

- Cirugías previas.

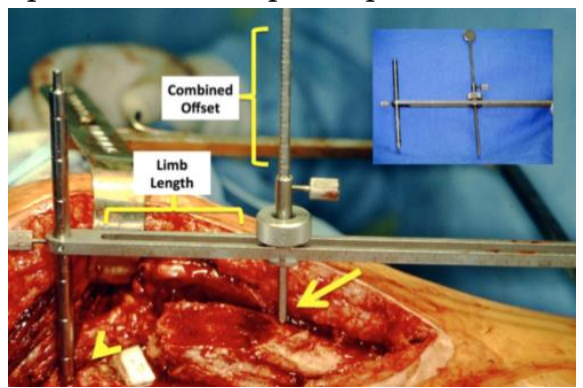

En algunas ocasiones la dismetría es un resultado indirecto del posicionamiento de los componentes, como por ejemplo el alargamiento del cuello de la prótesis para compensar la inestabilidad_de la misma. La complicación más temible tras una PTC es la posible luxación de la misma. Para mejorar esto se ha visto que, además de un cotilo horizontalizado y en anteversión, una de las formas de conseguirlo es utilizar componentes de cuello más largos y con más offset. Con ello sin embargo vamos a causar una dismetría, por lo que es importante planificar bien un balance de ambas consecuencias. En este sentido ha sido fundamental la introducción del uso de la escopia intraoperatoria que nos permite el abordaje anterior directo.

Se utilizan distintas técnicas para evaluar la discrepancia de longitud en las extremidades inferiores como mediciones clínicas, la radiografía pélvica, la telemetría, la tomografía computerizada o la medición intraoperatoria.

Hay varios métodos para medir radiográficamente la longitud del miembro. El primer método, descrito por Williamson y Reckling, consiste en trazar una línea horizontal por los dos puntos inferiores de las tuberosidades isquiáticas. También podemos trazar una línea horizontal entre las superficies inferiores de las lágrimas del acetábulo, que pueden ser puntos más fiables que las referencias isquiáticas (método de Woolson et al) (9). En cualquier caso se mide la distancia entre estos puntos y el centro del trocánter menor. Alternativamente (según Meermans et al) ${ }^{(12)}$ se puede trazar una línea vertical, perpendicular al centro estimado de la cabeza en cada fémur, y la diferencia de longitud entre las dos líneas verticales representa la diferencia de longitud del miembro.
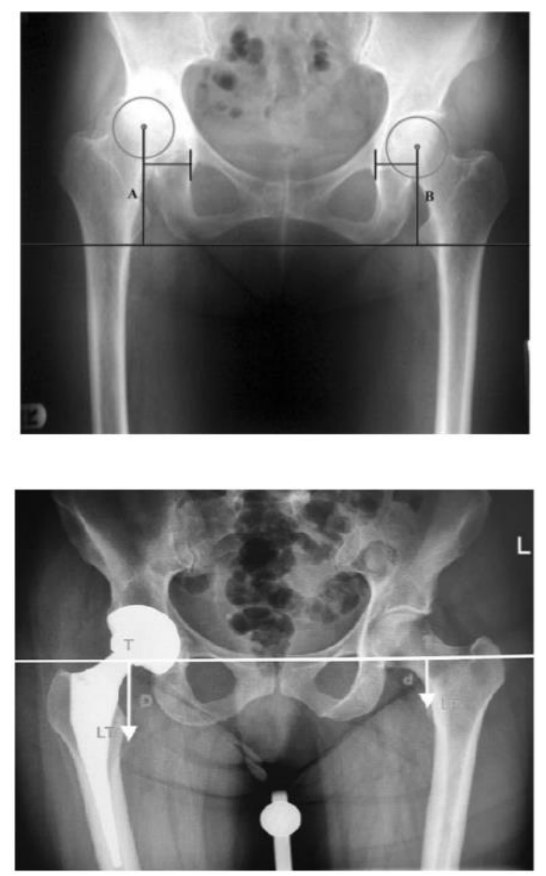

Imagen 2. Valoración radiográfica de la diferencia de longitud de los miembros según el método de Meermans ${ }^{(12)}$

Imagen 3. Valoración radiográfica de la diferencia de longitud de los miembros según el método de Woolson ${ }^{(9)}$ 
Una de las preguntas más importantes que el médico debe hacer el paciente es cómo aprecia la longitud del miembro (si la hubiera). Se ha visto que la percepción del paciente y la presencia de una dismetría de miembros real no están bien correlacionadas: existe una discrepancia entre la HHS y la dismetría medida radiológicamente en la mayoría de los pacientes.

La severidad de los síntomas aumenta con el aumento de la longitud del miembro: entre ellos destacan una discapacidad como resultado del dolor, cojera, fatiga, parálisis nerviosa y alteración funcional de la cadera. La lesión nerviosa es la complicación más grave asociada con la dismetría: en una revisión de 23 ATC complicadas con una parálisis del nervio peroneo y ciático, Edwards et al (13) encontraron un rango de alargamiento de $2,7 \mathrm{~cm}$ para el peroneo y de $4,4 \mathrm{~cm}$ para el ciático.

Aunque el problema del LLD (leg lenght discrepancy) no pueda ser eliminado, sí puede ser minimizado teniendo en cuenta factores como una buena planificación preoperatoria, identificación de los factores de riesgo, las mediciones intraoperatorias y varios métodos de corrección. Entre ellos destaca una buena planificación preoperatoria para definir el correcto corte del cuello, la correcta longitud del cuello del componente femoral y la profundidad de inserción del mismo, así como el uso de un punto de referencia estándar en pelvis y en fémur y la medición de la distancia entre ellos intraperatoriamente. Esto es posible actualmente gracias al uso de la escopia que nos permite el abordaje anterior directo. Además, gracias a la posición en decúbito supino somos capaces de comparar la distancia entre ambos maléolos internos (leg-to-leg comparison), aunque este método sea más inexacto.

\subsection{Tratamiento de las dismetrías: la cirugía de corrección}

Para las dismetrías estructurales la aplicación de un alza suele ser suficiente, aunque a veces el paciente podría seguir teniendo sintomatología y necesitar un tratamiento de fisioterapia intensiva. En el peor de los casos se puede llegar a realizar una cirugía de acortamiento.

En el estudio retrospectivo de McWilliams et al (1) fueron revisados 21 pacientes que se sometieron a una cirugía de corrección de dismetría después de una artroplastia primaria de cadera. La dismetría fue medida en la radiografía de pelvis según el método de Woolson ${ }^{(9)}$, que como hemos dicho toma como referencia el centro rotacional de la cabeza femoral, la lágrima del acetábulo y el centro del trocánter menor. En el seguimiento postoperatorio, siguiendo el método modificado de D’Aubigne y Postel, se investigó el dolor, la funcionalidad y la satisfacción postquirúrgica de los pacientes.

El resultado fue que, de todos ellos, ninguno llegó a la puntuación máxima en la escala de satisfacción (0-6), y que solo tres de ellos quedaron exentos de síntomas y complicaciones. Sin embargo concluyen que, a pesar de que la cirugía de revisión no está exenta de riesgos y puede no aliviar completamente el dolor del paciente, por la mejoría que produce se considera un tratamiento útil y exitoso para aquellos pacientes que no responden al tratamiento conservador.

En resumen, las opciones de tratamiento que existen hasta el momento actual son las siguientes:

- Alza para compensar la dismetría (mayor comodidad para el paciente).

- Estiramientos de la cintilla en extensión de rodilla y cadera.

- Alargamiento del lado sano.

- Acortamiento del miembro intervenido: conlleva un gran riesgo de luxaciones si se realiza por las vías convencionales.

- Cotilos de doble movilidad o restrictivos

- Recambio de cabeza con cuello más corto

- Osteotomía de trocánter mayor y descenso del mismo. 


\section{Materiales y métodos}

En el siguiente artículo revisaremos y discutiremos tres casos de pacientes de nuestro hospital que presentaron síntomas refractarios ante una dismetría de miembros después de la colocación de una prótesis total de cadera, y que por tanto necesitaron una corrección quirúrgica en nuestro hospital, utilizándose en cada uno de ellos una técnica diferente.

En nuestro caso utilizamos la puntuación del HHS en lugar del D'Aubigne and Postel score y el método de Woolson ${ }^{(9)}$ para medir las discrepancias en la radiografía AP de pelvis.

Los objetivos marcados son los siguientes:

- Valorar las dismetrías provocadas por la intervención y síntomas causantes.

- Analizar los tratamientos quirúrgicos para compensar las dismetrías según el grado de deformidad y características del paciente.

Las palabras clave que se utilizaron fueron "prótesis cadera", "dismetrías extremidades inferiores", "tratamientos dismetrías", "hip arthroplasty", "asymmetry lower limb extremity", "leg", "hip arthroplasty AND asymmetry lower limbs", "limb - length discrepancy after hip arthroplasty", "x-ray measurement lower limb", "lower limb inequality".

\section{Resultados}

En el primer paciente se realizó un recambio de cabeza más corta y un mallado de la fascia lata. En el segundo se realizó un recambio a un cotilo de doble movilidad, y en el tercero se decidió realizar el recambio del vástago asociado a una osteotomía y descenso del trocánter mayor.

En los tres casos los pacientes presentaban una dismetría de tipo mixto, es decir, tanto estructural como funcional. Los resultados fueron satisfactorios en todos los casos.

\subsection{Caso clínico 1}

Paciente mujer de 64 años, intervenida de PTC derecha por fractura de cuello de fémur, en otro hospital, en agosto de 2014. Se le coloca un cotilo con cabeza de $32 \mathrm{~mm}$ standard talla 50 y vástago bloqueante 12/14, por vía posterolateral.

Acude en julio de 2016 a consultas externas de nuestro hospital con dolor al iniciar la marcha y claudicación. Camina sin bastones pero refiere que cuando lleva un tiempo andando necesita caminar en abducción. El dolor es referido sobre todo en cara posterior cadera y cara anterior de muslo. Utiliza siempre un alza de $2 \mathrm{~cm}$ en pierna contralateral. El HHS fue de 80.

En la radiografía se evidencia un cotilo vertical y dismetría positiva de cadera derecha:

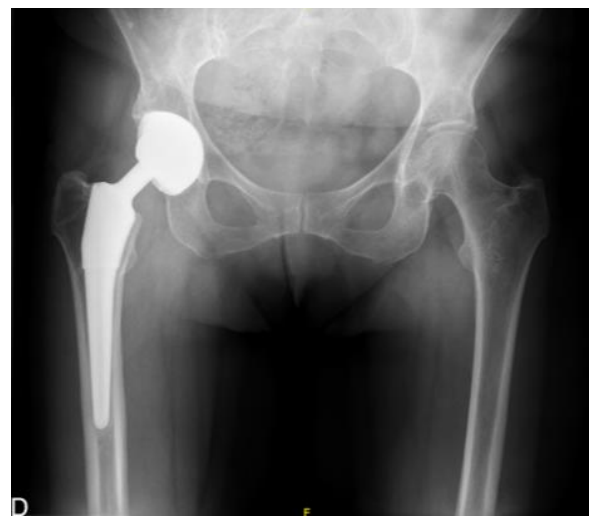

Imagen 4. Radiografía AP pelvis. Se observa un cotilo vertical $70^{\circ}$, una dismetría de $+5 \mathrm{~mm}$ derecha y un Offset de $+9 \mathrm{~mm}$. 
Se interviene quirúrgicamente para acortamiento en noviembre de 2016, realizándose un recambio de cabeza modular por abordaje anterior directo, sin excesiva liberación para evitar posible inestabilidad posterior. Se coloca una cabeza con cuello más corto, de cerámica, de $32 \mathrm{~mm}+1$ (es decir $-4 \mathrm{~mm}$, por lo que $4 \times 0,7=2,8 \mathrm{~mm}$ menos de altura y de offset). Se hace además un alargamiento de la cintilla iliotibial (mallado de la fascia lata proximal y distal al trocánter mayor). Se le ofrece también un recambio de cotilo para mejorar la posición, pero la paciente rechaza porque quiere recibir la menor agresión quirúrgica posible.
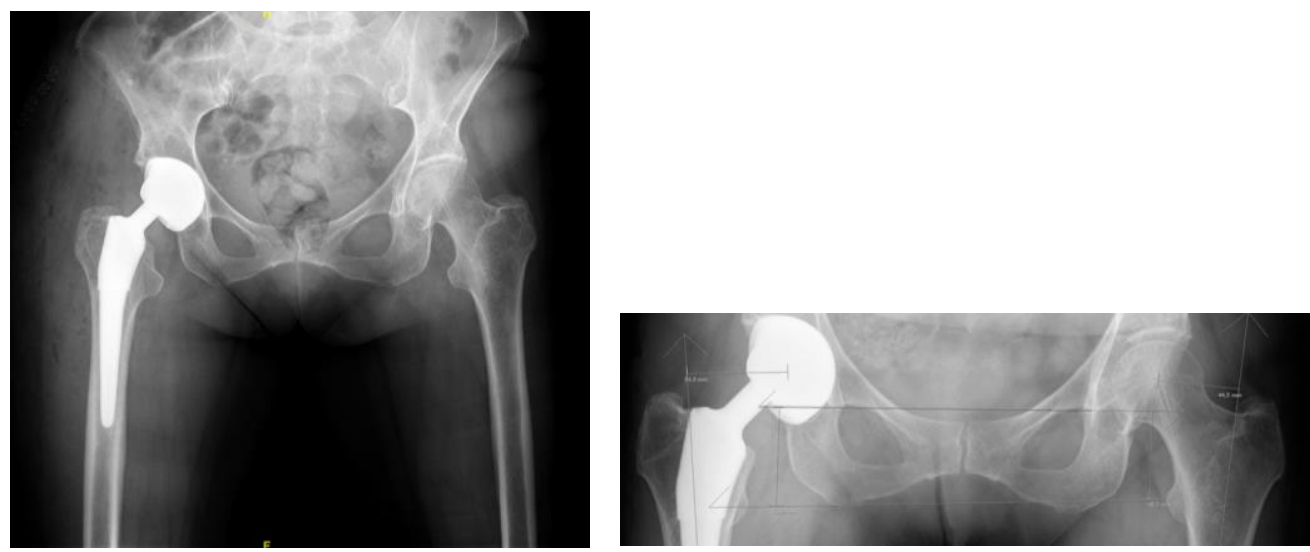

Imagen 5. Radiografía AP de pelvis de la misma paciente postoperatoria. Observamos una dismetría de $+2 m m$ y un Offset de +6 .

A los 2 meses de la intervención la paciente ya no toma analgésicos para el dolor. Usa $1 \mathrm{~cm}$ de alza y camina por casa sin bastones ni claudicación. Al año refiere realizar una actividad normal. Camina sin bastones, con alguna molestia ocasional que no requiere analgésicos. Clínicamente, HHS de 98 y control radiográfico sin cambios. Estabilidad y buena funcionalidad a la exploración: FE 120/10, RIRE 20/20, ABAD 30/30.

\subsection{Caso clínico 2}

Paciente mujer de 66 años, a la que hace 2 años se le implanta una prótesis total no cementada de cadera derecha por vía posterolateral por coxartrosis protusiva. En el postoperatorio presenta una parálisis del Nervio Ciático Poplíteo Externo y dolor neuropático.

Desde entonces utiliza un alza de $25 \mathrm{~mm}$ contralateral sin la cual casi no puede andar. Obtiene un HHS de 76. Camina con un bastón para la calle.
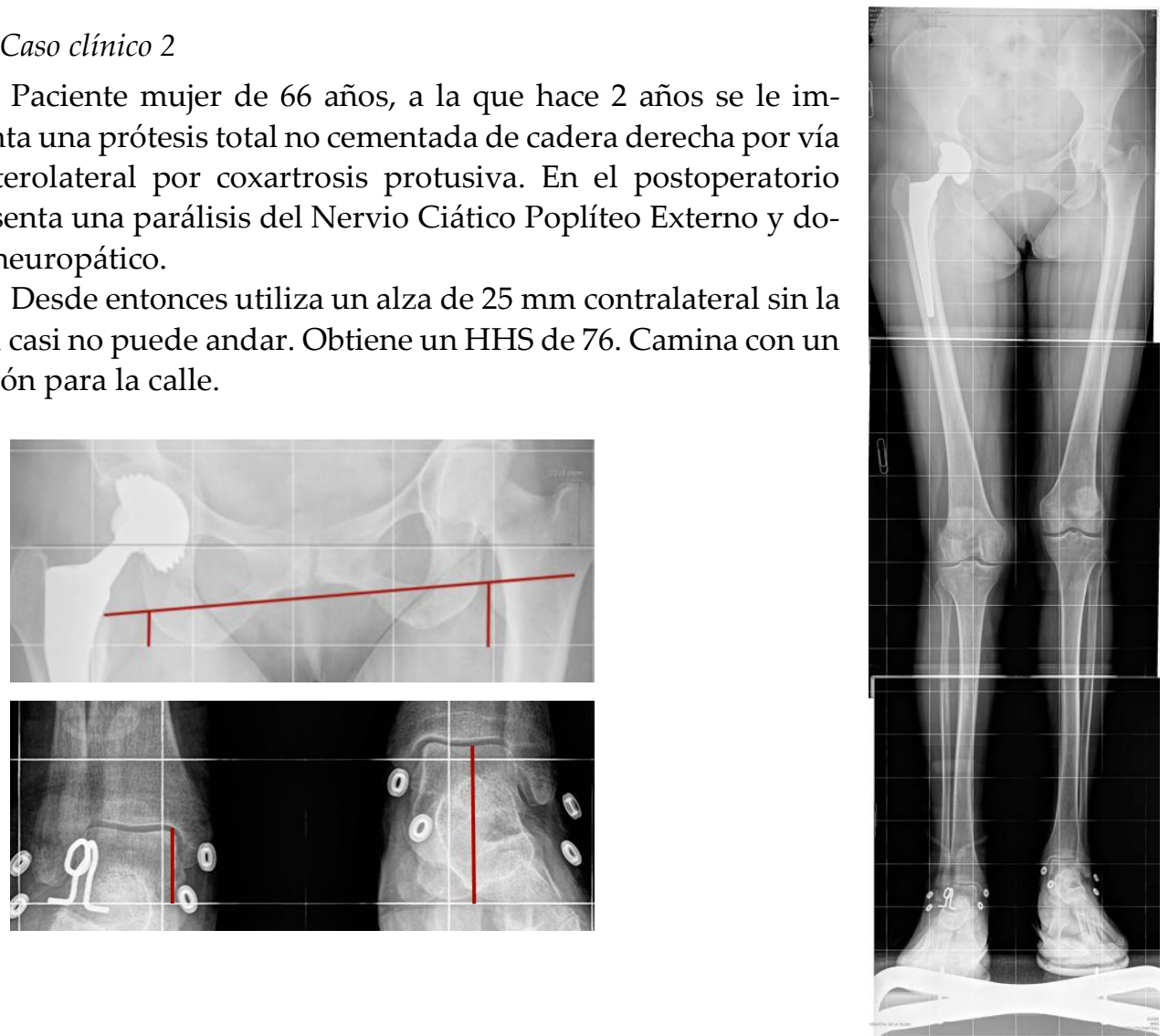
Imagen 6. Telemetría de MMII y radiografía AP pelvis: encontramos un alargamiento estructural de $14 \mathrm{~mm}$ con un aumento de Offset de $8 \mathrm{~mm}$ y un cotilo vertical a $70^{\circ}$.

El tratamiento de elección en este caso fue el cotilo de doble movilidad ${ }^{(6)}$. Se trata de un dispositivo que consta de una cabeza protésica móvil dentro de un polietileno retentivo, el cual, a su vez, se mueve libremente dentro de la copa acetabular metálica. Las dos articulaciones tienen como objetivo disminuir el desgaste y las fuerzas de aflojamiento, y aumentar la amplitud articular sin compromiso de la estabilidad intraprotésica. Sus ventajas son una mayor amplitud de movimiento sin limitaciones debido a su gran estabilidad, con buena transmisión de fuerzas y baja tasa de usura del polietileno.
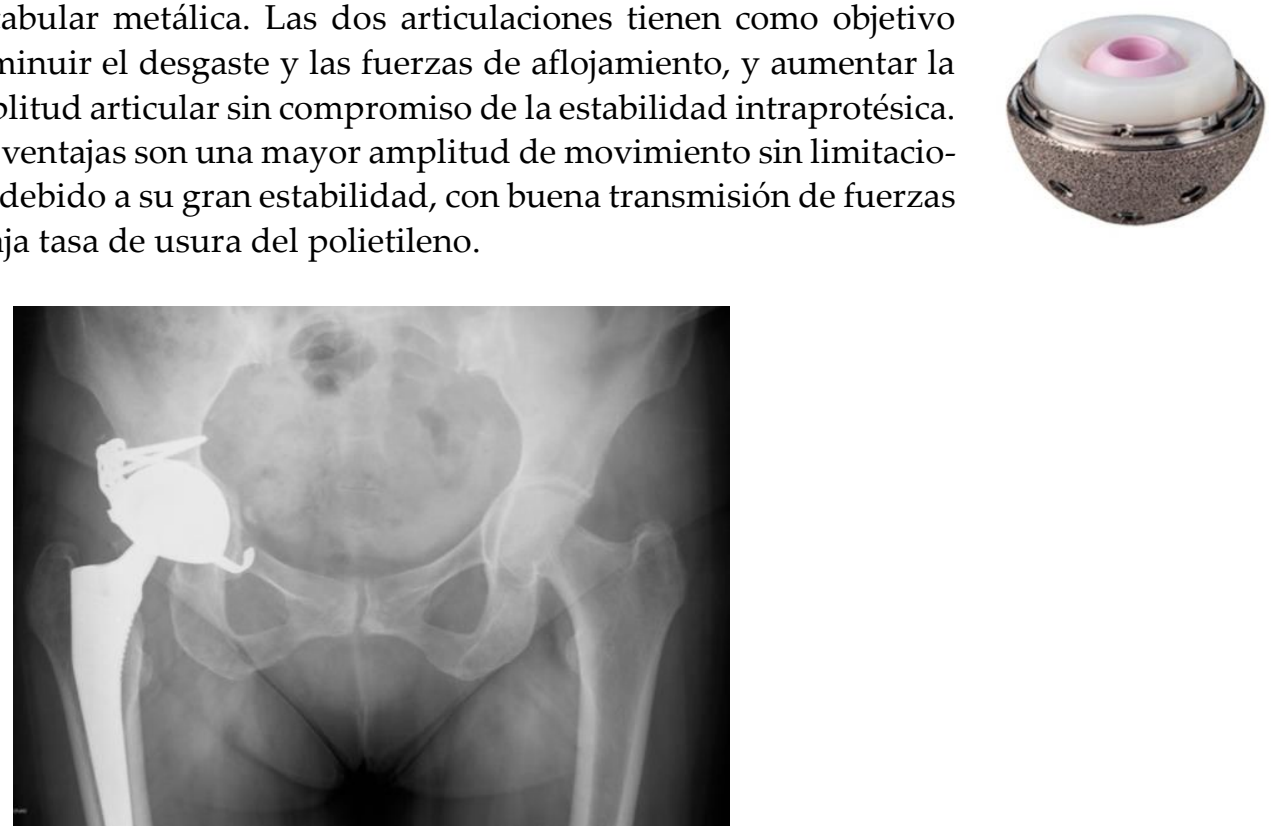

Imagen 7. Radiografía AP pelvis postoperatoria de la misma paciente, en bipedestación. Se observa una dismetría residual de $+10 m m$ y un Offset simétrico.

Un año postcirugía, la paciente usa un alza de $7-8 \mathrm{~mm}$ (previamente de $25 \mathrm{~mm}$ ) y camina perfectamente sin ayudas. Obtiene un HHS de 88 y ha mejorado del dolor neuropático. A la exploración, fuerza de peroneos y dorsiflexores a 4/5 (falta eversión y flexión dorsal activa por encima de $\operatorname{los} 0^{\circ}$ ).

\subsection{Caso clínico 3}

Se trata de una paciente mujer de 55 años intervenida en múltiples ocasiones por displasia de caderas con colocación de prótesis total bilateral. Se coloca PTC izquierda en 1994 (cotilo de 50 con dos tornillos y cabeza de cerámica con cuello corto y vástago 10).

Acude a consultas externas de nuestro servicio en marzo de 2016 porque desde hacía un mes notaba en diversas ocasiones sensación de resalte anterior en cadera derecha, así como un bulto palpable inguinal anterior que desaparecía posteriormente. Presentaba además una inseguridad para la marcha, con sensación de dismetría positiva en dicha cadera. Marcha con un bastón en mano derecha y un alza de $35 \mathrm{~mm}$ en zapato izquierdo.

A la exploración destaca una mayor molestia en rotación externa. Al forzar la rotación externa con flexión menor de $20^{\circ}$, es decir, en extensión, se nota un salto y se palpa lo que parece ser la cabeza femoral, que se reduce en rotación interna.

En RX y TAC no se aprecia movilización de componentes protésicos. 


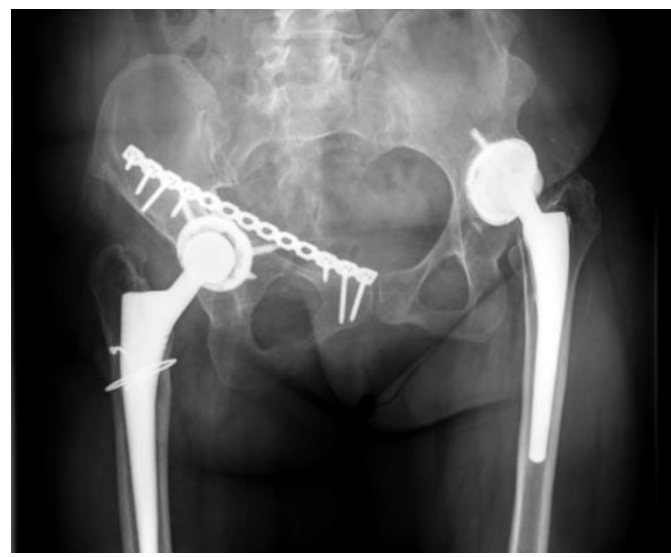

Imagen 8. Radiografía AP pelvis preoperatoria.

Ante la posibilidad de tratarse de subluxaciones autorreducidas de la cabeza femoral protésica a anterior, se dan una serie de pautas de rehabilitación (evitar la rotación externa y usar una prótesis pelvimuslera) y se decide reintervenir quirúrgicamente.

En junio de 2016 se realiza la extracción del componente femoral mediante osteotomía transfemoral, implantación de vástago largo de revisión y reinserción del fragmento trocantéreo descendido unos $2 \mathrm{~cm}$, para mejorar la dismetría sin afectar demasiado la estabilidad. Se cierra la osteotomía con garra aplanada de 4 orificios para mantener descendido el fragmento y se colocan dos cerclajes. Se decide no recambiar el cotilo dada la ausencia completa de pared anterior.

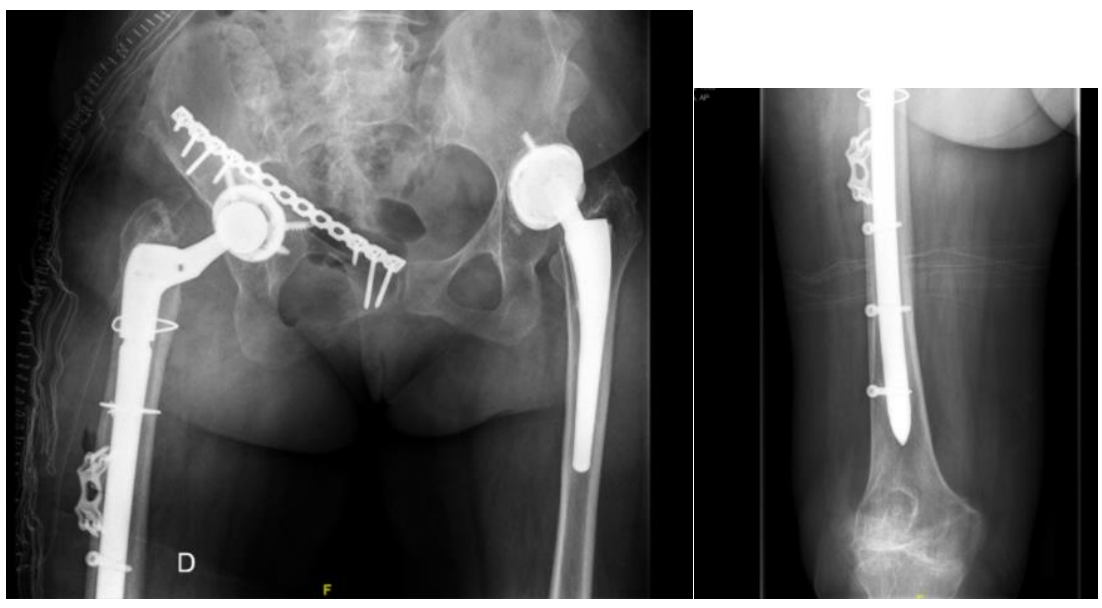

Imagen 8. Radiografía AP pelvis y AP fémur derecho postoperatoria.

En la revisión a los dos meses, acude con clínica de dolor en muslo superior y pérdida de fuerza en cuádriceps sugestiva de paresia del nervio femoral, que mejora a los 4 meses.

Última revisión en abril de 2018 con control radiológico inmodificado. La paciente camina sin bastones por casa y con uno en el lado derecho por la calle, debido a su afectación multiarticular (PTC contralateral y gonartrosis bilateral). A la exploración, FE 60/0 RIRE 10/20 ABAD 20/20 GM 3-4.

\section{Discusión}

Doctor, ¿por qué tengo la pierna más larga? Después de una artroplastia total de cadera es común que se produzca un alargamiento peroperatorio del miembro como una forma de compensar la tendencia a la inestabilidad posterior de la prótesis. La magnitud de la misma es variable, pero en general una dismetría de más de 7-10 mm es normalmente mal tolerada. 
Si un paciente presenta una dismetría no aceptable, deberemos valorar el riesgo/beneficio a la hora de planificar una corrección quirúrgica, ya que el acortamiento de un miembro va a conllevar un aumento de la inestabilidad. Debemos tener en cuenta también el aumento del offset, que puede producir una contractura lumbopélvica que conlleve un falso alargamiento de la extremidad.

Es importante además recalcar la escasa bibliografía que existe acerca de la cirugía de acortamiento tras PTC. Las opciones de tratamiento son amplias pero sus resultados no están claros. Por lo tanto, hoy en día el mejor tratamiento de una dismetría es su prevención, mediante el uso de marcadores pre y postoperatorios, técnicas de navegación y el uso de la escopia intraoperatoria, posible actualmente con el abordaje anterior directo.

Financiación: Esta revisión no recibió financiación externa.

Conflictos de interés: Los autores declaran que no existen conflictos de interés.

\section{Bibliografía}

1. McWilliams, Anthony B., et al. Revision Surgery for Leg Length Inequality after Primary Hip Replacement. HIP International, vol. 28, no. 5, Sept. 2018, pp. 554-558.

2. Parvizi, Javad \& Sharkey, Peter \& A Bissett, Gina \& H Rothman, Richard \& Hozack, Bill. Surgical Treatment of Limb-Length Discrepancy Following Total Hip Arthroplasty. The Journal of bone and joint surgery. American volume. 2004;85-A. 2310-7.

3. Flecher X, Ollivier M, Argenson JN. Lower limb length and offset in total hip arthroplasty. Orthop Traumatol Surg Res [Internet]. 2016;102(1):S9-20.

4. Röder C, Vogel R, Burri L, Dietrich D, Staub LP. Total hip arthroplasty: leg length inequality impairs functional outcomes and patient satisfaction. BMC Musculoskelet Disord [Internet]. 2012;13(1):95.

5. Ogawa K, Kabata T, Maeda T, Kajino Y, Tsuchiya H. Accurate leg length measurement in total hip arthroplasty: A comparison of computer navigation and a simple manual measurement device. Clin Orthop Surg. 2014;6(2):153-8.

6. Valdez, Sebastián, and Bertrand Bouxin. Cotilos con doble movilidad: principios, ventajas y resultados. Revista de la Asociación Argentina de Ortopedia y Traumatología 74.1 (2009): 102-110.

7. Brun, Ole-Christian L., et al. The Direct Anterior Minimal Invasive Approach in Total Hip Replacement: A Prospective Departmental Study on the Learning Curve. HIP International, vol. 28, no. 2, Mar. 2018, pp. 156-160.

8. García-Juárez, J. D., et al. Incidencia y efecto de la discrepancia en la longitud de la pierna después de la artroplastía total de cadera. Acta Ortopédica Mexicana 27.1 (2013): 43-46.

9. Woolson, Steven T., James M. Hartford, and Aenor Sawyer. Results of a method of leg-length equalization for patients undergoing primary total hip replacement. The Journal of arthroplasty 14.2 (1999): 159-164.

10. Larry E Miller, Joseph S Gondusky, Atul F Kamath, Friedrich Boettner, John Wright \& Samir Bhattacharyya. Influence of surgical approach on complication risk in primary total hip arthroplasty, Acta Orthopaedica. 2018; 89:3, 289-294, DOI: 10.1080/17453674.2018.1438694

11. Rinne M. Peters, et al. Similar Superior Patient-Reported Outcome Measures for Anterior and Posterolateral Approaches After Total Hip Arthroplasty: Postoperative Patient-Reported Outcome Measure Improvement After 3 months in 12,774 Primary Total Hip Arthroplasties Using the Anterior, Anterolateral, Straight Lateral, or Posterolateral Approach. J Arthroplasty, vol. 33, no 6, June 2018, p1786-1793.

12. Meermans G., et al. Preoperative Radiographic Assessment of Limb-length Discrepancy in Total Hip Arthroplasty. Clin Orthop Relat Res. 2011 Jun; 469(6): 1677-1682.

13. Edwards BN, Tulles HS, Noble PC. Contributory factors and etiology of sciatic nerve palsy in total hip arthroplasty. Clin Orthop. 1987;218:136-141. 


\title{
Journal of Orthopaedic Surgery and
} Traumatology

\section{Clinical case}

\section{PARÁLISIS DEL NERVIO ESPINAL EN PACIENTE COVID-19: A PROPÓSITO DE UN CASO \\ Martín Escartín $\mathrm{C}^{1}$, Sánchez-Ponce $\mathrm{G}^{1}$, Gil Marques $\mathbf{M}^{\mathrm{a}} \mathbf{M}^{2}$..}

\author{
${ }^{1}$ Servicio de Medicina Física y Rehabilitación, ${ }^{2}$ Servicio de Neurofisiología, Arnau Vilanova Hospital, Valencia,. \\ *Correspondencia: carlotame93@gmail.com
}

Copyright: ๑ 2021 by the authors. Submitted for possible open access publication under the terms and conditions of the Creative Commons Attribution (CC BY) license (http://creativecommons.org/licenses /by/4.0/).

\begin{abstract}
El nervio espinal accesorio (SAN) es el par craneal más susceptible de lesionarse. Principalmente cuando atraviesa el triángulo cervical posterior por su localización superficial. La causa más común de parálisis es la iatrógena tras cirugías a dicho nivel, aunque debemos sospecharla en otras situaciones donde el nervio pueda lesionarse por compresión o estiramiento. La parálisis del SAN puede provocar dolor e inestabilidad de la cintura escapular. Se requiere una exhaustiva exploración clínica para sospecharla y la ecografía de alta resolución puede ayudarnos en el diagnóstico como complemento del estudio neurofisiológico.
\end{abstract}

Keywords: Spinal accessory nerve palsy, trapezius muscle, winged scapula, critical illness.

\section{Introducción}

El nervio espinal accesorio (SAN) es el XI par craneal, está formado principalmente por fibras motoras que inervan el músculo trapecio y el esternocleidomastoideo, por ello desempeña un papel principal en la estabilidad de la cintura escapular.

El SAN está formado principalmente por fibras motoras. Está constituido por dos porciones: La espinal que nace de los 5 primeros segmentos cervicales C1-C5, inerva los músculos trapecio y esternocleidomastoideo. La craneal que nace a nivel bulbar y junto al nervio vago inerva los músculos laríngeos, faríngeos y el paladar. (1)

El nervio espinal accesorio es el par craneal más susceptible de lesionarse, con mayor frecuencia ocurre cuando atraviesa el triángulo cervical posterior, donde se localiza a nivel más superficial, solo cubierto por fascias y piel. $(2,3)$

La causa más común de parálisis del SAN es la lesión iatrógena durante la cirugía en las disecciones de cuello o intervenciones menores en esa zona, así como ejercicio intenso, estiramientos o movimientos repetitivos. $(3,4)$

La parálisis del nervio espinal causa debilidad y atrofia del trapecio, que condicionan una inestabilidad de la cintura escapular, acompañada de hombro caído y escápula alada con desplazamiento lateral de la misma (figura 1). Además de alteraciones en la movilidad del hombro, como la pérdida de la abducción por encima de la horizontal y dolor en ocasiones irradiado hacia el brazo. $(2,5)$ 
Es importante realizar una valoración adecuada del paciente para diagnosticar una lesión del SAN de forma temprana y determinar el manejo óptimo para prevenir complicaciones a largo plazo. (6)

El uso de ecografía de alta resolución puede ayudarnos en el diagnóstico, junto al estudio electromiográfico (EMG). Sobre todo en el caso de lesiones iatrógenas, ya que nos permite un diagnóstico más temprano al visualizar ecográficamente la transección del SAN y así poder planificar la necesidad de intervención quirúrgica para conseguir un mejor resultado clínico. $(6,7)$.

\section{Caso clínico}

Paciente varón de 43 años sin antecedentes médicos ni quirúrgicos de interés, que ingresa por fiebre alta, tos seca, artralgias, ageusia y astenia. Desarrolla un síndrome de distrés respiratorio agudo debido a neumonía por Covid-19, precisando ingreso en la Unidad de Cuidados Intensivos (UCI) durante 19 días con intubación endotraqueal, ventilación mecánica y ventilación en decúbito prono. Resaltar la necesidad de la administración de altas dosis de sedantes por la presencia de cuadros de agitación. La duración total del ingreso fue de 30 días.

En la primera valoración en la consulta en el Servicio de Rehabilitación, a las 3 semanas del alta hospitalaria, además del cansancio el paciente refiere dolor en zona escapular derecha de características neuropáticas, debilidad distal y sensación de adormecimiento en ambos pies. La exploración física muestra: hipoestesia en calcetín acompañada de debilidad distal en miembros inferiores; con balance motor (BM) según el Medical Research Council en la extensión del tobillo y del hallux de pie derecho $1 / 5 \mathrm{y}$ en pie izquierdo 4/5. También presenta marcha en steppage de predominio derecho.

Cabe destacar una atrofia en la fosa supraespinosa (figura 1) con marcada debilidad de trapecio (BM 1/5), discreta escápula alada (figura 1) y dificultad para elevar el brazo. Fuerza del esternocleidomastoideo conservada. Presencia de hiperestesia y alodinia en cintura escapular. 


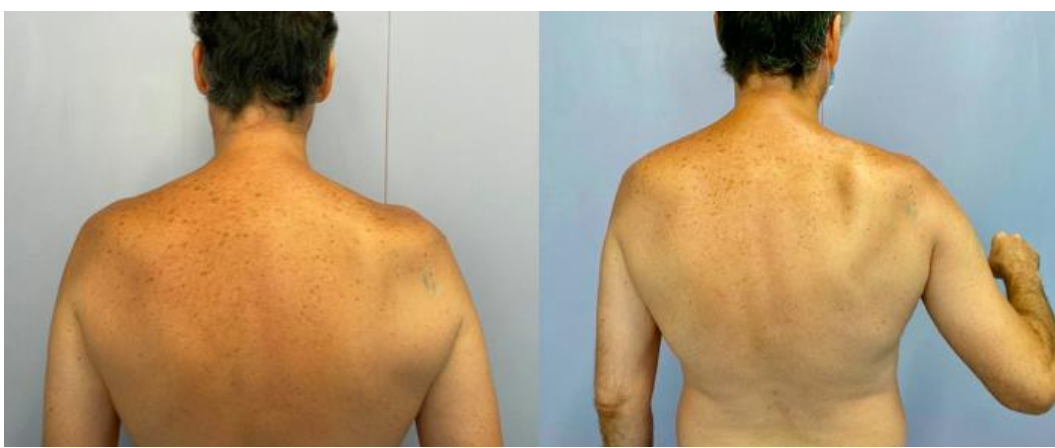

Figura 1: Hipotrofia de la fosa supraespinosa (izquierda) y escápula derecha alada (derecha).

Se realiza una ecografía en consulta con sonda lineal 8-12 Mhz (figura 2), observándose una diferencia en el grosor de ambos trapecios, con una marcada hipotrofia del trapecio superior derecho.
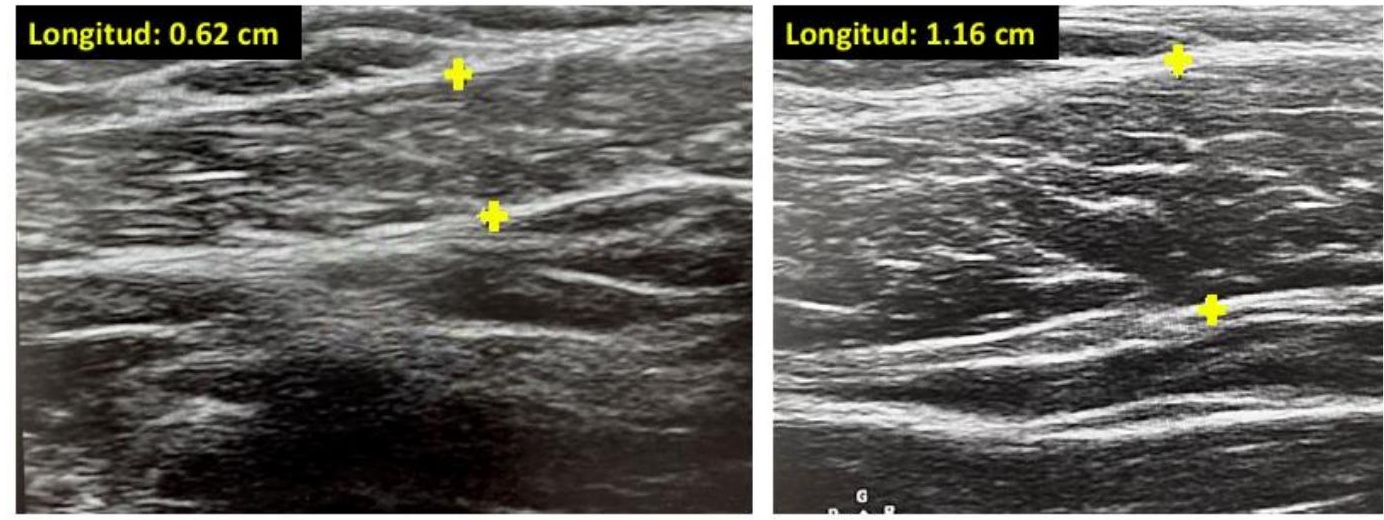

Figura 2: Corte transversal ecográfico de trapecio superior derecho 0,62 cm, e izquierdo $1,16 \mathrm{~cm}$.

Se solicita un EMG de miembros superiores e inferiores y una resonancia magnética (RM) cervical y de plexo braquial.

En la RM se aprecia una asimetría en el tamaño del músculo trapecio derecho con discreta hiperintensidad de señal en STIR (figura 3), probablemente por denervación. 

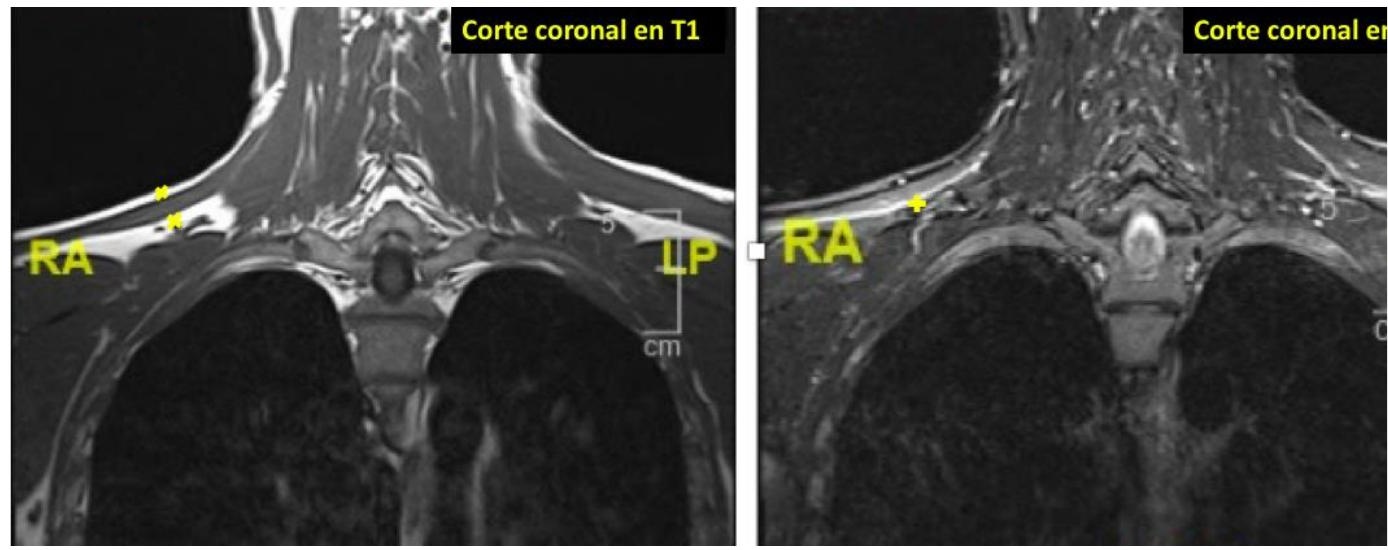

Figura 3: Corte coronal de RM en secuencia T1 y coronal en STIR.

El EMG muestra hallazgos compatibles con lesión del SAN derecho en fase subaguda, con actividad espontánea en el músculo trapecio, trazado al máximo esfuerzo pobre y potenciales de unidad motora (PUM) aislados con incremento de polifasia, así como alteración en la conducción motora del SAN a músculo trapecio derecho por disminución de su amplitud, comparado con contralateral normal (figura 4). También se evidencia lesión del nervio peroneal bilateral, asimétrica, de predominio derecho.
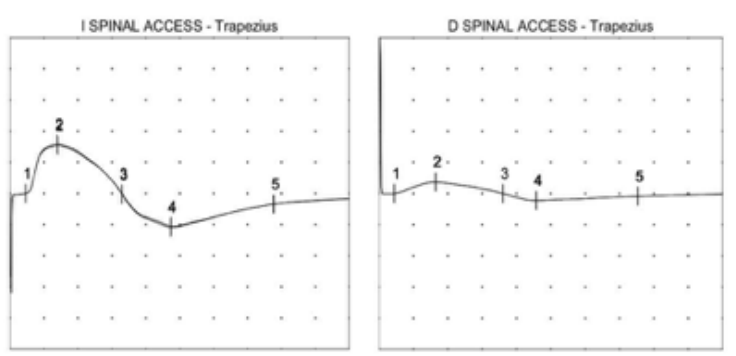

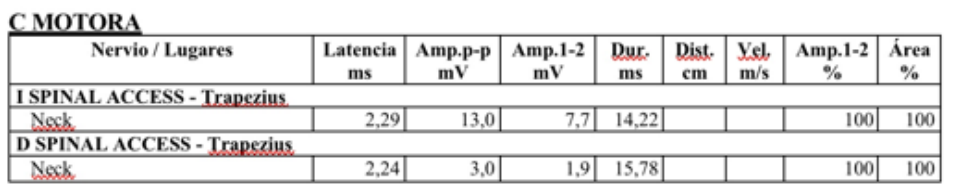

Figura 4: Conducción motora de nervio espinal accesorio bilateral

Tras las sospecha diagnóstica se planifica el tratamiento rehabilitador, que incluye manejo del dolor con medidas farmacológicas, estimulación eléctrica transcutánea, ejercicios de movilidad más fortalecimiento y reeducación de la marcha.

En la valoración a los 5 meses se objetiva evolución muy favorable con desaparición del dolor, mejoría a nivel de movilidad del hombro con BM del músculo trapecio derecho de 5-/5. A nivel de miembros inferiores: persiste hipoestesia en cara lateral de la pantorrilla y dorso del pie derecho con discreta debilidad en dorsiflexores de tobillo de $4 / 5$, extensor de dedos $3 / 5$ y extensor del hallux $1 / 5$. 


\section{Discusión}

La lesión del SAN de causa no iatrógena es infrecuente, aunque sí existe algún caso descrito en la literatura que plantean que el ejercicio muy intenso sobre los músculos de la cintura escapular es la principal causa de lesión espontánea, por movimientos repetitivos, estiramientos o debido a la hipertrofia muscular por trabajos o entrenamientos deportivos extremos. $(3,4)$

Nuestro paciente como único antecedente presentaba las movilizaciones y posturas en pronación que precisó durante su estancia en la UCI.

Destacar la importancia de realizar una exploración física exhaustiva en los pacientes tras una enfermedad crítica, sobretodo si han requerido posturas que favorezcan la compresión del SAN o después de movilizaciones que puedan provocar su estiramiento.

El diagnóstico diferencial de las posibles causas de escápula alada incluye: la parálisis del serrato anterior por la lesión del nervio torácico largo, la parálisis del trapecio por lesión del nervio espinal, la parálisis del romboides y patología glenohumeral o subacromial, entre otras causas. $(8,9,10)$

Aunque el EMG es el procedimiento más sensible para valorar la alteración en la conducción nerviosa en la lesión del SAN, este únicamente da información funcional y no puede dar información estructural del estado del nervio. $(11,12)$ En ocasiones, en pacientes con una transección completa se puede observar la presencia de respuesta motora de baja amplitud y algún PUM, que puede ser debido a diferentes causas, entre las que se incluye la inervación parcial del músculo trapecio directamente por ramas del plexo cervical. (13)

Por todo ello, la ecografía de alta resolución nos puede servir como complemento al estudio electromiográfico en la lesión del SAN ya que puede darnos información estructural que el estudio por EMG no puede valorar. Es rápida, permite evaluación a tiempo real, visualiza la localización de la lesión y ayuda en la planificación preoperatoria. Además, nos permite visualizar las ramas nerviosas más pequeñas que no son valorables con otras técnicas como la RM. $(12,14)$

Contribución autores: Todos los autores han leído y aceptado la publicación de este manuscrito.

Fondos: Esta investigación no ha recibido fondos externos.

Declaración de consentimiento informado: El consentimiento informado fue aceptado por todos los pacientes que aparecen en el estudio.

Conflicto de interés: Los autores no declaran conflicto de interés. 


\section{Referencias}

1. Johal J, Iwanaga J, Tubbs K, Loukas M, Oskouian RJ, Tubbs RS. The Accessory Nerve: A Comprehensive Review of its Anatomy, Development, Variations, Landmarks and Clinical Considerations. Anat Rec (Hoboken). 2019 Apr;302(4):620-629. Available from: http://doi:10.1002/ar.23823.

2. Wiater JM, Bigliani LU. Spinal accessory nerve injury. (1999). Clin Orthop Relat Res (368): 5-16.

3. Mariani PP, Santoriello P, Maresca G. Spontaneous accessory nerve palsy. J Shoulder Elbow Surg. 1998 Sep-Oct;7(5):545-6. Available from: http://doi:10.1016/s1058-2746(98)90211-7.

4. Ozdemir O, Kurne A, Temuçin C, Varli K. Spontaneous unilateral accessory nerve palsy: a case report and review of the literature. Clin Rheumatol. 2007 Sep;26(9):1581-3. Available from: http://doi:10.1007/s10067-006-0469-x.

5. Kibler WB, McMullen J. Scapular dyskinesis and its relation to shoulder pain. J Am Acad Orthop Surg. 2003 Mar-Apr;11(2):142-51. Available from: http://doi:10.5435/00124635-200303000-00008.

6. Didesch JT, Tang P. Anatomy, Etiology, and Management of Scapular Winging. J Hand Surg Am. 2019 Apr;44(4):321-330. Available from: http://doi:10.1016/j.jhsa.2018.08.008.

7. Cesmebasi A, Smith J, Spinner RJ. Role of Sonography in Surgical Decision Making for Iatrogenic Spinal Accessory Nerve Injuries: A Paradigm Shift. J Ultrasound Med. 2015 Dec;34(12):2305-12. Available from: https://doi.org/10.7863/ultra.15.01049.

8. Seror P, Lenglet T, Nguyen C, Ouaknine M, Lefevre-Colau MM. Unilateral winged scapula: Clinical and electrodiagnostic experience with 128 cases, with special attention to long thoracic nerve palsy. Muscle Nerve. 2018 Jun;57(6):913-920. Available from: https://doi.org/10.1002/mus.26059.

9. Seror P, Stojkovic T, Lefevre-Colau MM, Lenglet T. Diagnosis of unilateral trapezius muscle palsy: 54 Cases. Muscle Nerve. 2017 Aug;56(2):215-223. Available from: https://doi.org/10.1002/mus.25481.

10. Meininger AK, Figuerres BF, Goldberg BA. Scapular winging: an update. J Am Acad Orthop Surg. 2011 Aug;19(8):453-62. DOI:10.5435/00124635-201108000-00001.

11. Laughlin RS, Spinner RJ, Daube JR. Electrophysiological testing of spinal accessory nerve in suspected cases of nerve transection. Muscle Nerve. 2011 Nov;44(5):715-9. Available from: https://doi.org/10.1002/mus.22135.

12. Shen J, Chen W, Ye X, Qiu Y, Xu J, Zhu Y, Shen Y, Xu W. Ultrasound in the management of iatrogenic spinal accessory nerve palsy at the posterior cervical triangle area. Muscle Nerve. 2019 Jan;59(1):64-69. Available from: https://doi.org/10.1002/mus.26342.

13. Tubbs RS, Shoja MM, Loukas M, Lancaster J, Mortazavi MM, Hattab EM, Cohen-Gadol AA. Study of the cervical plexus innervation of the trapezius muscle. J Neurosurg Spine. 2011 May;14(5):626-9. Available from: https://doi.org/10.3171/2011.1.SPINE10717.

14. Krzesniak-Swinarska M, Caress JB, Cartwright MS. Neuromuscular ultrasound for evaluation of scapular winging. Muscle Nerve. 2017 Jul;56(1):7-14. Available from: https://doi.org/10.1002/mus.26342. 


\title{
Clinical case
}

\section{Sección traumática de la rama profunda del nervio cubital: caso clínico.}

\author{
Jose Poveda Mira ${ }^{*}$, Fernando Bonilla Enseñat ${ }^{1}$, César Poveda Cerrillo ${ }^{1}$, Carmen García Espert ${ }^{1}$, Emilio Baixauli Pe- \\ relló'.
}

Copyright: () 2021 by the authors. Submitted for possible open access publication under the terms and conditions of the Creative Commons Attribution (CC BY) license (http://creativecommons.org/licenses /by/4.0/).

\author{
${ }^{1}$ Hospital Universitari i Politécnic La Fe Valencia. Avenida Fernando Abril Martorell 106, Valencia, España. 46026. \\ ${ }^{*}$ Correspondencia: poveda_josmir@gva.es.
}

\begin{abstract}
Las lesiones traumáticas del nervio cubital son muy raras y pueden pasar desapercibidas, siendo necesario realizar una exploración completa de la mano para su diagnóstico. Presentamos el caso de un hombre de 23 años que acude por herida de 10 $\mathrm{mm}$ en el borde cubital de la mano sobre el canal de Guyon con imposibilidad para la abducción y adución de los dedos, signos de Watemberg y Froment positivos. Se realiza una exploración quirúrgica donde se aprecia sección de la rama profunda motora del nervio cubital. El diagnóstico de la lesión de la rama profunda del nervio cubital es fundamentalmente clínico y quirúrgico. La reparición se realiza mediante la sutura primaria terminoterminal epineural sin tensión. El pronóstico dependerá de factores del paciente, de la calidad de la cirugía y de la magnitud de la lesión.
\end{abstract}

Keywords: nervio cubital, sección nerviosa, signo Froment, canal Guyon, signo Watemberg.

\section{Introducción}

Las lesiones del nervio cubital en la mano suelen producirse por compresión a nivel del canal de Guyon. Sin embargo, la lesión traumática del nervio cubital es rara, y más aun la afectación exclusiva de la rama profunda motora del mismo. Estas lesiones suelen producirse en el contexto de grandes heridas y manos catastróficas [1]. Una exploración reglada de la mano nos va a permitir sospechar la existencia de la lesión y la zona en la que se ha producido para su posterior reparación en el caso de ser necesario.

\section{Caso clínico}

Presentamos el caso de un varón de 23 años que acude a urgencias hospitalarias derivado del centro de atención primaria por impotencia funcional en cuarto y quinto dedo de la mano derecha tras herida punzante con un cristal en el borde cubital proximal de la mano.

El paciente presenta una herida de $10 \mathrm{~mm}$ a nivel de eminencia hipotenar en región entre el hueso pisiforme y el gancho del ganchoso. Su mano se encuentra en flexión de 90 grados de la articulación interfalángica proximal de cuarto y quinto dedo con posición de 
semiflexión de la articulación interfalángica distal de los mismos. A la inspección física no se aprecia atrofia muscular ni cambios tróficos [Imagen 1].

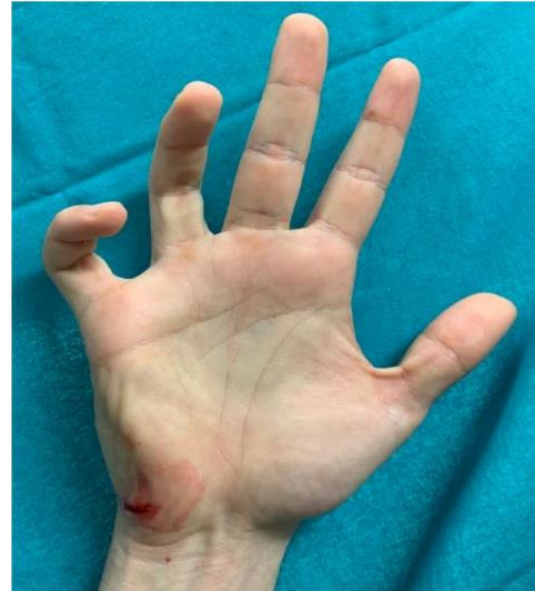

(a)

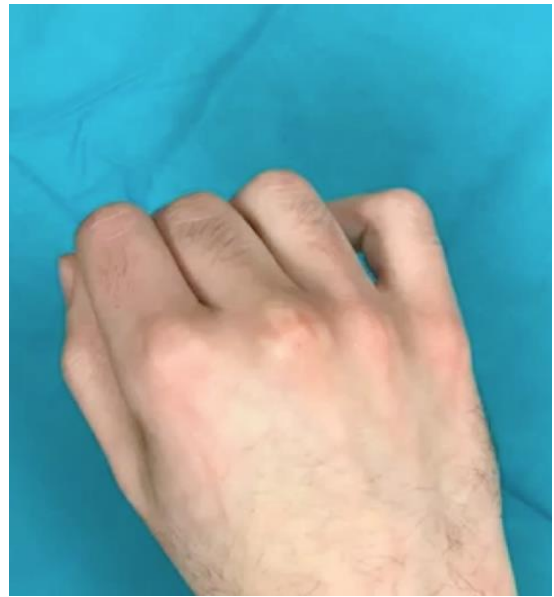

(b)

Imagen 1. (a) Se observa herida de $1 \mathrm{~cm}$ en cara palmar de la mano sobre la zona del pisiforme. (b) Posición de garra cubital de la mano y signo de Watemberg positivo.

Nuestro paciente presenta dolor en el quinto dedo con sensación de calambres en el borde cubital de la mano a la movilización pasiva. A la exploración de la movilidad activa se aprecia: imposibilidad para la aducción y abducción de los dedos segundo a quinto; imposibilidad para la aducción del pulgar (signo de Froment positivo); debilidad para la flexión metacarpofalángica de los dedos y para la extensión interfalángica con flexión de los dedos; y posición del quinto dedo en abducción (signo de Watemberg positivo) [Imagen 1 y 2]. La extensión de la articulación interfalángica del pulgar y de las metacarpofalángicas e interfalángicas de los dedos menores permanece conservada. No se aprecia afectación de la movilidad de la muñeca, así como tampoco, alteraciones de la sensibilidad táctil ni termoalgésica en ninguna parte de la mano ni muñeca. La exploración vascular es correcta en el momento de la exploración.

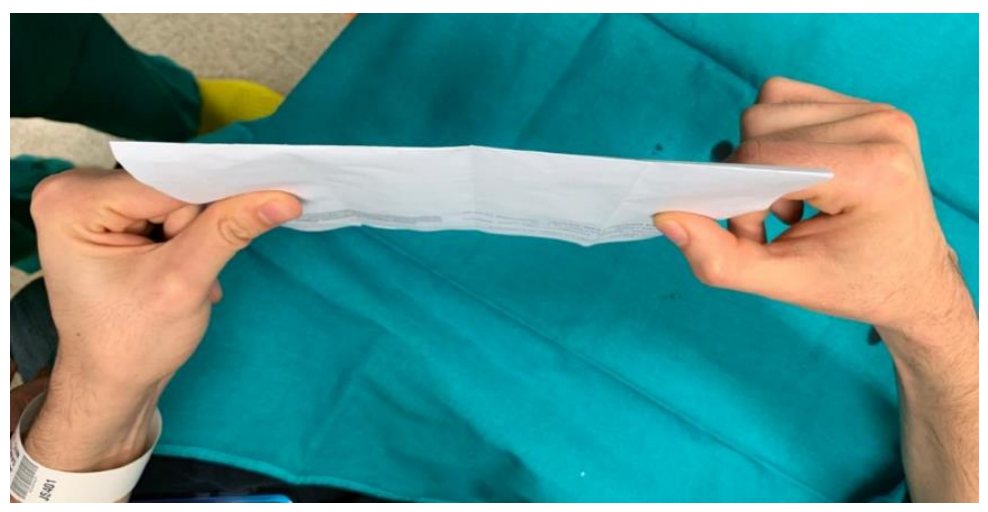

Imagen 2. Signo de Froment positivo por incapacidad de aducir el pulgar 
Se realizan radiografías en proyecciones anteroposterior y oblicua de la mano donde no se aprecian hallazgos de interés y una analítica sanguínea con parámetros bioquímicos, hemograma y hemostasia dentro de la normalidad.

Mediante la exploración física se estable el diagnóstico probable de herida con sección de la rama profunda del nervio cubital a nivel de la zona II del canal de Guyon, por lo que se realiza una primera asistencia en urgencias con lavado de la herida con suero abundante, limpieza de la mano con esponja con clorhexidina y administración de antibioterapia profiláctica con amoxicilina 1g/ácido clavulánico $125 \mathrm{mg}$ intravenosa y aproximación de los bordes de la herida.

A las 24 horas se procede a la intervención quirúrgica por parte de el equipo de especialistas en cirugía de mano: en decúbito supino, utilizando manguito de isquemia a raíz del miembro y anestesia general se realiza ampliación de la herida sobre el tendón del músculo flexor carpo ulnaris, se diseca el plano graso y localizamos el paquete vásculonervioso cubital que seguimos hasta el canal de Guyon. Se secciona el canal de Guyon y observamos la sección completa, a $5 \mathrm{~mm}$ de su origen, de la rama profunda motora del nervio cubital y la integridad de la rama superficial sensitiva y vasos sanguíneos cubitales. Se preparan los cabos nerviosos, se limpian sus bordes y se realiza neurorrafia terminoterminal epineural con monofilamento nylon $8 / 0$ mediante puntos simples sin tensión y adhesivo de fibrina [Imagen 3]. Se sutura la piel con monofilamento de nylon $4 / 0$ y se coloca una férula braquial con ligera flexión de muñeca.

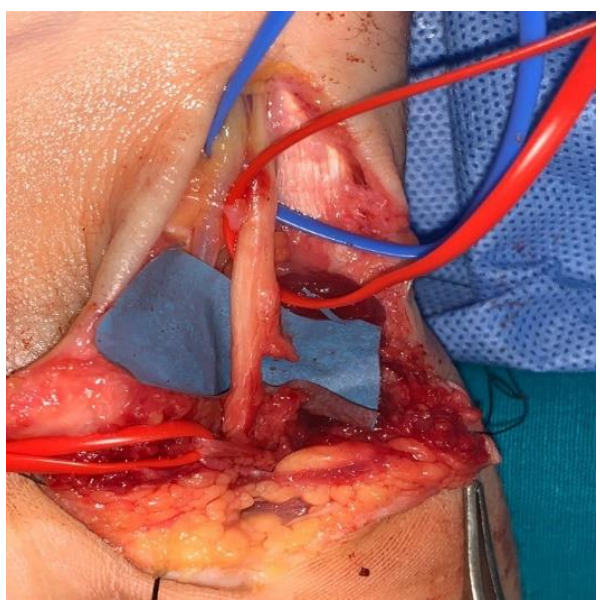

(a)

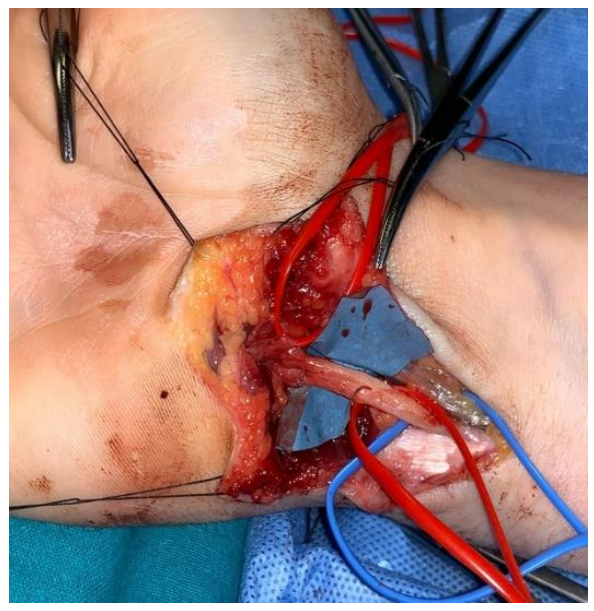

(b)

Imagen 3. (a) Herida ampliada con presencia de sección de la rama profunda motora del nervio cubital a nivel de su bifurcación. (b) Nervio una vez reparada la lesión.

El paciente presenta una buena evolución clínica durante el ingreso y al no presentar complicaciones, es dado de alta a las $24 \mathrm{~h}$ de la cirugía. Se cita al paciente en consultas externas a las 3 semanas de la cirugía. Tras retirar la férula, se observa que la 
herida no presenta signos de complicaciones por lo que se retiran los puntos de sutura y se pauta una ortesis de muñeca para limitar la extensión.

Pasado un mes desde la última valoración, la herida se encuentra totalmente cerrada sin signos de dehiscencia y con buena cicatrización. El paciente continúa con ligera actitud en flexión de cuarto y quinto dedo, pero presenta una fuerza 2/5 en la escala MRC para la abducción y aducción de los dedos, signo de Tinnel centrífugo a la percusión del canal de Guyon y fuerza 1/5 en la escala MRC para la aducción del pulgar. A partir de este momento, inicia rehabilitación y férula noctura y en control clínico al año de evolución, se objetiva mejoría clínica con movilidad completa y fuerza 3/5 en la escala MRC para la abducción, aducción de los dedos y el pulgar.

\section{Discusión}

El interés de este caso radica en la importancia de una exploración correcta en el diagnóstico de las lesiones nerviosas periféricas. De esta manera, podemos sospechar la afectación de una estructura nerviosa y su localización basándonos en una exploración reglada y los conocimientos de la anatomía sin necesidad de pruebas de imagen, para posteriormente, realizar una exploración quirúrgica más orientada.

El nervio cubital se origina principalmente de las raíces espinales C8 y T1 formando el tronco secundario anterointerno del plexo braquial o fascículo medial. Después se dirige hacia el surco bicipital medial para atravesar el tabique intermuscular medial en la mitad del brazo y pasar al lado extensor. Entre el tabique y la cabeza medial del tríceps llega al codo atravesándolo por el surco olecraniano. El nervio se extiende entre las dos cabezas del músculo flexor carpo ulnaris hacia el lado flexor del antebrazo y trascurre por debajo de este músculo hasta la muñeca. Continúa su trayecto por el retináculo flexor radialmente al hueso pisiforme pasando a través del canal de Guyon [2][3][4]. Dentro del canal, discurre medial y más profundo que la arteria cubital.

El límite proximal del canal de Guyon esta formado por el hueso pisiforme y, el límite distal, por el gancho del ganchoso. El techo del canal está formado por el músculo palmaris brevis y el suelo por la combinación del ligamento trasverso del carpo, el ganchoso y el piramidal [3][4].

EL canal de Guyon se divide en 3 zonas: la zona I, que empieza en el borde proximal del ligamento palmar del carpo y acaba distal a la bifurcación del nervio cubital en su rama profunda y superficial; la zona II, que empieza distal a la bifurcación del nervio cubital al arco fibroso de los músculos hipotenares y contiene la rama profunda motora del nervio cubital; y la zona 3, que comienza distal a la bifurcación del nervio y contiene la rama superficial del nervio cubital [5]. En la zona II, la rama profunda motora da una rama para la inervación del abductor digiti minimi, rodea al ganchoso por su cara medial y pasa por debajo del arco fibroso de los músculos hipotenares para dar ramas para inervar a: el 
flexor digiti minimi brevis, el opponens digiti minimi, el aductor pollicis, el fascículo profundo del flexor pollicis brevis, los músculos lumbricales del 4o y 5 o dedo y a los músculos interóseos dorsales y palmares [3]. En la zona III, la rama superficial inerva la sensibilidad de la cara palmar de la mitad del cuarto dedo y todo el quinto dedo y da ramas motoras para el músculo palmaris brevis.

El diagnóstico de esta lesión se basa en la exploración clínica de la función motora y sensitiva de la mano. Dada la inervación de la rama profunda del nervio cubital a nivel de la muñeca, el paciente presentará: déficit en la abducción del quinto dedo, la abducción y aducción de los dedos menores, la flexión de la metacarpofalángica del quinto dedo, la pinza pulgar-meñique, la aproximación del pulgar y debilidad para la flexión metacarpofalángica del primer dedo. Es característico de esta lesión, la aparición del signo de Watemberg (permanencia del quinto dedo en abducción) y el signo de Froment (incapacidad para realizarla pinza digital sin realizar la flexión de la interfalángica del pulgar). También, es típica la aparición de la mano en garra cubital y con el tiempo, la aparición de atrofia de la eminencia hipotenar y atrofia interdigital [1][4].

El diagnóstico mediante pruebas de imagen (resonancia magnética o ecografía) resulta complicado dados los cambios inflamatorios que se producen en la zona. El uso de otras pruebas como la electromiografía, no será de utilidad hasta pasadas 3 semanas de la lesión por permanecer estímulos nerviosos durante este tiempo. Por tanto, nos basaremos para el diagnóstico en la exploración física y quirúrgica [7].

La técnica más indicada dentro de los primeros 5 días de una lesión traumática del nervio cubital es la sutura primaria. Es recomendable realizar la resección de los extremos contundidos del nervio y, posteriormente, realizar una sutura termino-terminal o mediante un injerto en el caso de no poder suturar ambos extremos sin tensión. Se debe utilizar puntos simples epineurales con monofilamento de nylon 8/0-9/0 y el uso de pegamento de fibrina. Se debe inmovilizar mediante una férula para mantener el codo a 90 grados de flexión y la muñeca entre 30 y 40 grados de flexión durante 3 semanas y, posteriormente, retirar la inmovilización del codo y progresivamente aumentar la movilización de la muñeca durante al menos 6 semanas [5][6][7].

El pronóstico dependerá de: la edad del paciente; el tipo, localización y longitud de la lesión; la demora en la reparación; la calidad de los extremos nerviosos y; la correcta sutura quirúrgica. La velocidad de regeneración se estima en $1 \mathrm{~mm}$ al día en adultos, siendo signo de buen pronóstico la presencia de Tinnel positivo centrífugo. A pesar de realizar una buena técnica quirúrgica, se estima que los resultados en las secciones nerviosas periféricas en adultos son buenos solamente en un $46.4 \%$ de los casos [6][7]. 


\section{Conclusiones}

La lesión traumática de la rama motora profunda del nervio cubital es muy rara, pero puede producirse en el contexto de heridas aparentemente simples a nivel de la región cubital de la base de la mano. Es fundamental realizar una exploración física completa en toda herida de la mano para diagnosticar estas lesiones y orientar su localización, que conociendo la anatomía del canal de Guyon nos permitirá su reparación.

Contribución autores: Todos los autores han leído y aceptado la publicación de este manuscrito.

Fondos: Esta investigación no ha recibido fondos externos.

Declaración de consentimiento informado: El consentimiento informado fue aceptado por todos los pacientes que aparecen en el estudio.

Conflicto de interés: Los autores no declaran conflicto de interés.

\section{Referencias}

1. Ozaksar K. Toros T. Kayalar M. et al. Isolated severance of the intrinsic motor branch of the ulnar nerve caused by stab in- juries to the hand: A report of three cases. Acta Orthop Trau- matol Turc, 2007; 41: 249-52.

2. Gross MS. Gelberman RH. The anatomy of the distal ulnar tunnel. Clin Orthop Relat Res. Jun. 1985 (196):238-247.

3. Polatsch DB. Melone CP. Beldner S. Incorvaia A. Ulnar nerve anatomy. Hand Clin. 2007 Aug; 23(3): 283-9.

4. Macías, S. Castellano, J. Vélez, M. \& García, R. Lesiones del nervio cubital en el canal de Guyon: a propósito de 6 casos. Revista Iberoamericana de Cirugía de la Mano. 2017. 37. 042-047.

5. Maroukis BL. Ogawa T. Rehim SA. Chung KC. Guyon canal: the evolution of clinical anatomy. J Hand Surg Am. 2015;40(3):560-565.

6. Lan, Ching-Yu. Tien, Huey-Yuan. Lin, Yu-Te, Hsu. Chun-Cheng, Lin. Cheng-Hung, Chen ShihHeng. Prognosis of Traumatic Ulnar Nerve Injuries: A Systematic Review. Ann Plast Surg. 2019;82(1S):S45-S52.

7. Birch Rolfe Quick, Tom. Nerve injury and repair. En: Green's Hand surgery. Vol II. 7th Ed.: Scott W. Wolfe, Robert N. Hotchkiss, William C. Pederson, Scott H. Kozin. 2017. Ed. Elsevier. p9791023. 